\title{
IntechOpen
}

\section{Sustainable Management Practices}

Edited by Muddassar Sarfraz, Muhammad Ibrahim Adbullah, Abdul Rauf and Syed Ghulam Meran Shah
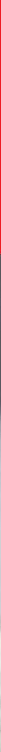



\title{
Sustainable Management Practices
}

\author{
Edited by Muddassar Sarfraz, \\ Muhammad Ibrahim Adbullah, \\ Abdul Rauf and Syed Ghulam Meran Shah
}



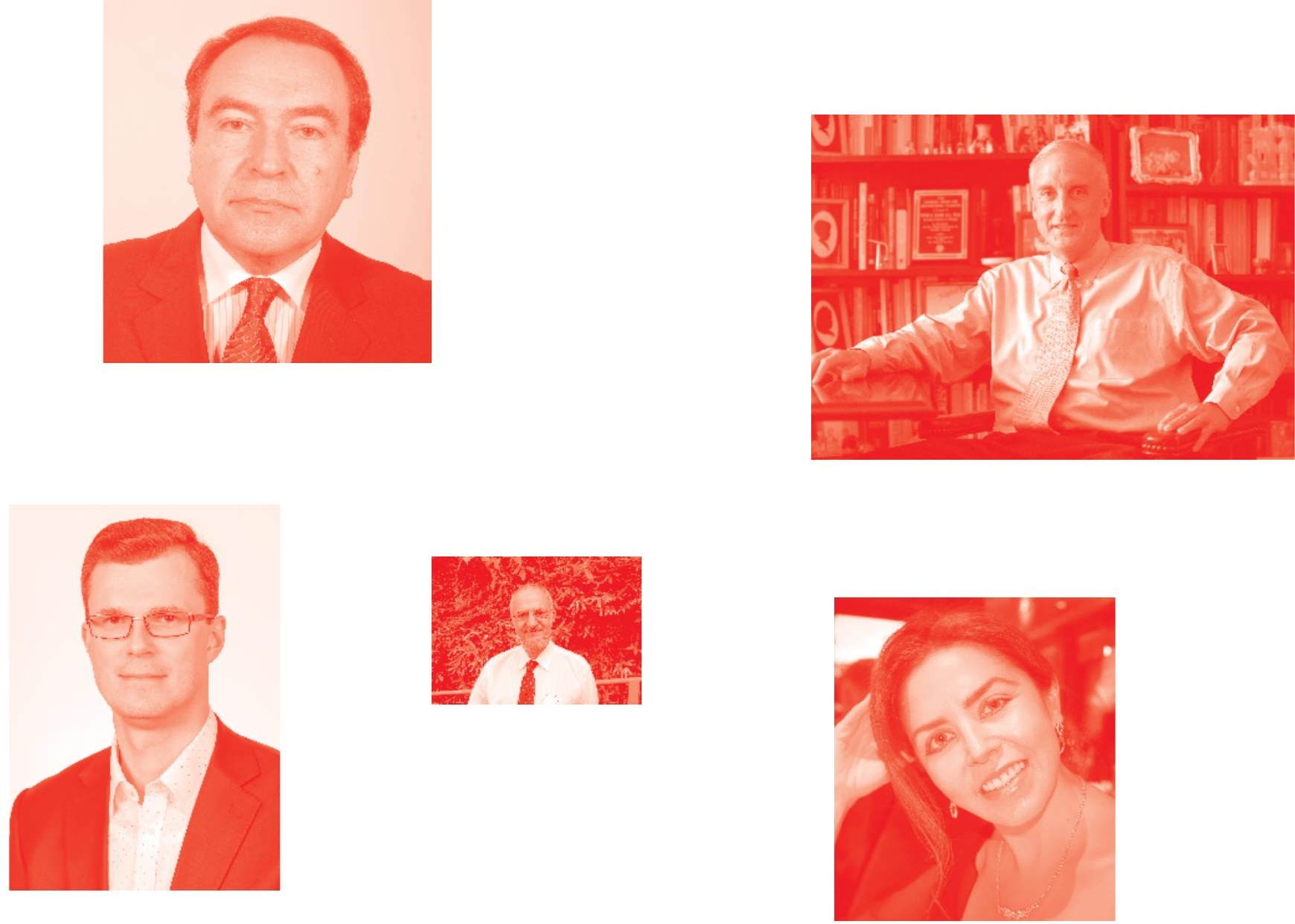

Supporting open minds since 2005
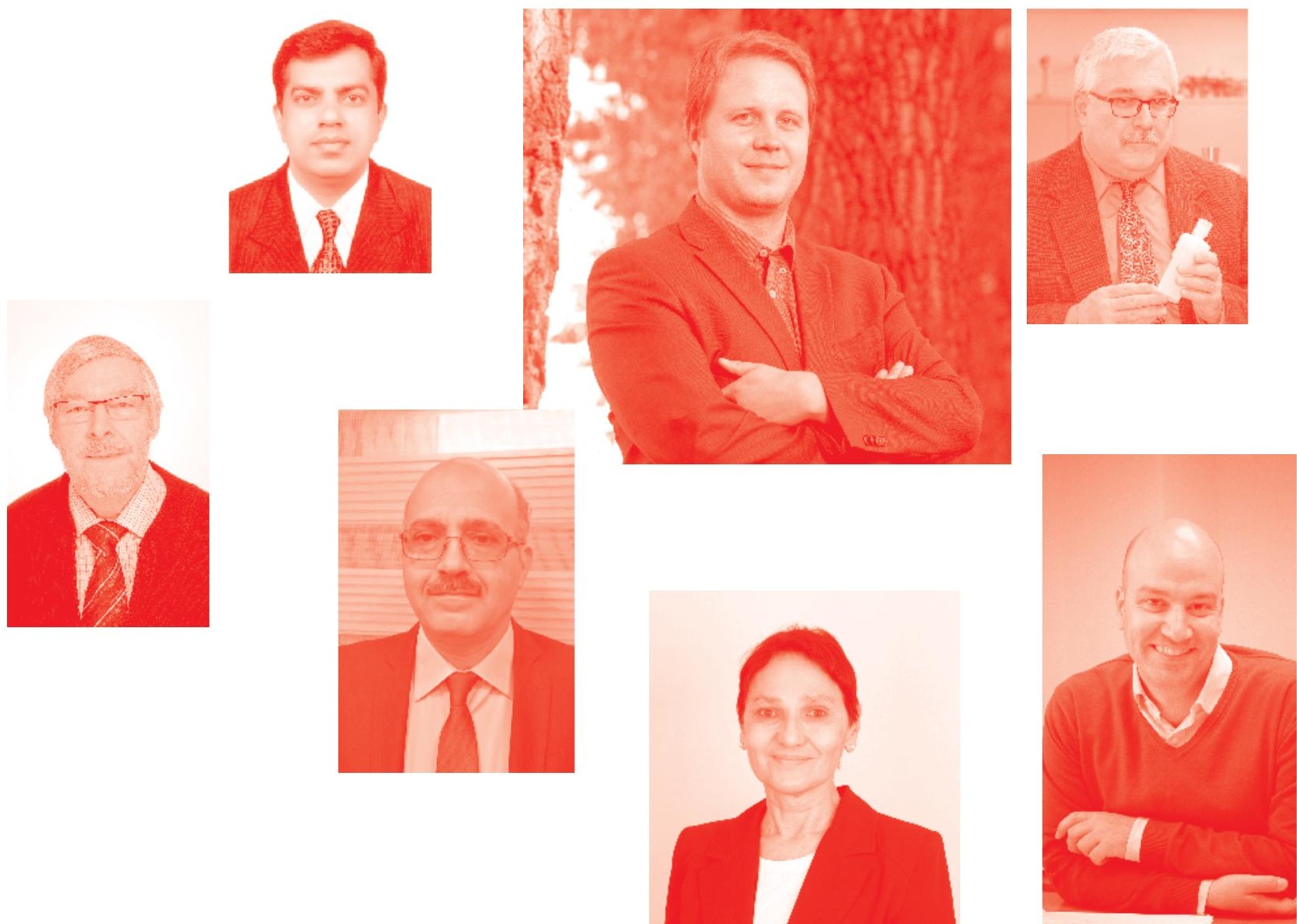
Sustainable Management Practices

http: //dx. doi . org/10.5772/intechopen . 83441

Edited by Muddassar Sarfraz, Muhammad Ibrahim Adbullah, Abdul Rauf and Syed Ghulam Meran Shah

\section{Contributors}

Paola Ochoa, Josep M Blanch, Maria Fernanda Caballero, Catalin Popescu, S. M. Fakhrul Islam, Zahurul Karim, Marek Rozycki, Tugce Ercan, Nidzara Osmanagic Bedenik, Petra Barisic, Robin N.A. Attfield, Kate Attfield

() The Editor(s) and the Author(s) 2019

The rights of the editor(s) and the author(s) have been asserted in accordance with the Copyright, Designs and Patents Act 1988. All rights to the book as a whole are reserved by INTECHOPEN LIMITED . The book as a whole (compilation) cannot be reproduced, distributed or used for commercial or non-commercial purposes without INTECHOPEN LIMITED's written permission. Enquiries concerning the use of the book should be directed to INTECHOPEN LIMITED rights and permissions department (permissions@intechopen.com).

Violations are liable to prosecution under the governing Copyright Law .

\section{(cc) BY}

Individual chapters of this publication are distributed under the terms of the Creative Commons Attribution 3.0 Unported License which permits commercial use, distribution and reproduction of the individual chapters, provided the original author(s) and source publication are appropriately acknowledged. If so indicated, certain images may not be included under the Creative Commons license. In such cases users will need to obtain permission from the license holder to reproduce the material. More details and guidelines concerning content reuse and adaptation can be found at http : //www . intechopen . com/copyright-policy . html.

\section{Notice}

Statements and opinions expressed in the chapters are these of the individual contributors and not necessarily those of the editors or publisher. No responsibility is accepted for the accuracy of information contained in the published chapters. The publisher assumes no responsibility for any damage or injury to persons or property arising out of the use of any materials, instructions, methods or ideas contained in the book.

First published in London, United Kingdom, 2019 by IntechOpen

IntechOpen is the global imprint of INTECHOPEN LIMITED, registered in England and Wales,

registration number: 11086078 , The Shard, 25th floor, 32 London Bridge Street

London, SE19SG - United Kingdom

Printed in Croatia

British Library Cataloguing-in-Publication Data

A catalogue record for this book is available from the British Library

Additional hard and PDF copies can be obtained from orders@intechopen.com

Sustainable Management Practices

Edited by Muddassar Sarfraz, Muhammad Ibrahim Adbullah, Abdul Rauf and Syed Ghulam Meran Shah

p. cm.

Print ISBN 978-1-78985-153-3

Online ISBN 978-1-78985-154-0

eBook (PDF) ISBN 978-1-83962-248-9 


\section{We are IntechOpen, \\ the world's leading publisher of Open Access books}

\section{Built by scientists, for scientists}

\section{$4,300+$}

Open access books available

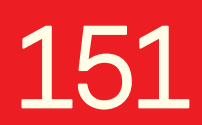

Countries delivered to

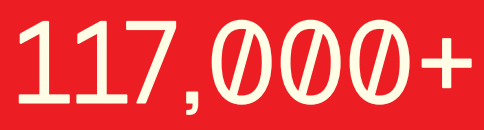

International authors and editors
$130 \mathrm{M}+$

Downloads

Our authors are among the

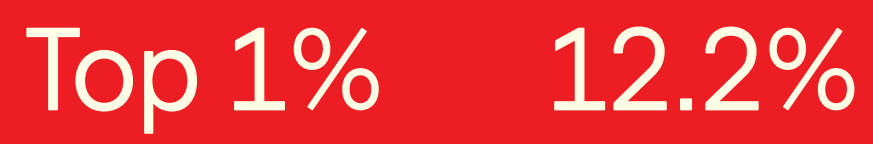

most cited scientists

Contributors from top 500 universities

\section{Interested in publishing with us? \\ Contact book.department@intechopen.com}

Numbers displayed above are based on latest data collected.

For more information visit www.intechopen.com 



\section{Meet the editors}

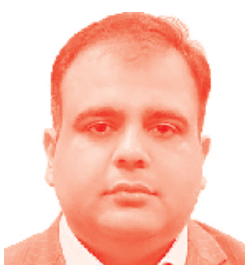

Muddassar Sarfraz is a postdoctoral fellow at the Business School of Hohai University, Nanjing, PR China. He is research fellow at the Human Resource Institute of the Business School, Hohai University. He obtained his PhD in Management Sciences and Engineering from the Business School of Hohai University, Nanjing, PR China. He holds International Master of Business Administration from Chongqing University (China). He has been dedicating himself to the teaching and research of strategic management, human resources, and organizational management. He has published many papers in foreign authoritative journals and academic conferences at home and abroad. He is a member of the British Academy of Management (UK), Chinese Economists Society (USA), World Economic Association (UK), and American Economic Association (USA).

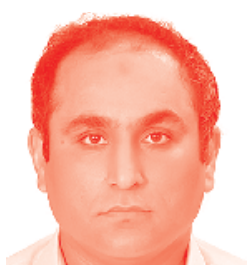

Dr. Muhammad Ibrahim Abdullah is working as an assistant professor at the Department of Management Sciences, Comsats University Islamabad, Lahore Campus, Pakistan. He obtained his PhD degree from Chongqing University in Enterprise Management. His area of interest is business strategy, sustainable management, and strategic marketing. Dr. Ibrahim's work has been published extensively in various journals.

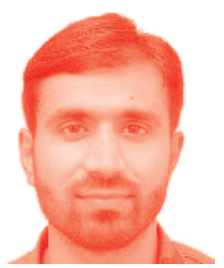

Abdul Rauf obtained his PhD in Finance (Applied Economics) from Southeast University, Nanjing, China. He is currently associated with research projects at the same university. He has published more than 20 research papers in various SSCI/SCI, EI, and ESCI journals such as Environment Science and Pollution Research, Structure Changes and Economic Dynamics, Journal of Cleaner Production, Tourism Economics, Sustainability, Energies, IEEE

Explore, Public Finance Quarterly, etc. His research concentration comprises tourism management in Belt and Road Initiative countries, sustainable and eco-friendly economies, clean and renewable energy, sustainable management science, $\mathrm{CO}_{2}$ emissions, and socioeconomic development.

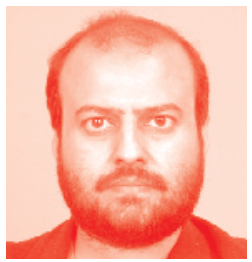

Dr. Syed Ghulam Meran Shah completed his doctorate degree in Business Management in June 2019 from Southwestern University of Finance and Economics (SWUFE), PR China. He obtained a CSC scholarship for the completion of his $\mathrm{PhD}$. During his $\mathrm{PhD}$ study he achieved a two times performance scholarship (2017 and 2018) awarded by the College of International Education, SWUFE, PR China. He was awarded an outstanding foreign graduate certificate in 2019 by the College of International Education, SWUFE, PR China. During completion of his $\mathrm{PhD}$ he published research papers in impact factor journals. He was awarded an MSc degree in Finance from the University of ULM, Germany, in 2009. During his master's study he obtained a DAAD scholarship from Program Matching Funds for finalizing the master's thesis in the Master Program of Finance. He has more than six years of university teaching experience and has taught many courses in applied calculus, financial mathematics, business mathematics, corporate governance, and corporate finance. 



\section{Contents}

Preface

Chapter 1

Over Engagement, Protective or Risk Factor of Burnout?

by Josep M. Blanch, Paola Ochoa and Maria Fernanda Caballero

Chapter 2

Adaptive Sustainable Academic Management Practices

by Cătălin Popescu

Chapter 3

Sustainable Agricultural Management Practices and Enterprise Development for Coping with Global Climate Change

by S.M. Fakhrul Islam and Zahurul Karim

Chapter 4

Inertia in Assessing the Possibilities of Economic Development: Limits in Modelling Economies

by Marek Różycki

Chapter 5

Building the Link between Technological Capacity Strategies and Innovation in Construction Companies

by Tugce Ercan

Chapter 6

Nonfinancial Reporting: Theoretical and Empirical Evidence

by Nidžara Osmanagić Bedenik and Petra Barišić

Chapter 7

Principles of Equality: Managing Equality and Diversity in a Steiner School by Robin Attfield and Kate Attfield 



\section{Preface}

Sustainability is the vehicle that confronts the current dynamic environment of business. Good sustainable business practices are a vehicle to attain competitive advantage, which ultimately makes organizational sustainability undeterred. Conclusively, the significance of corporate governance is inevitable for maintaining sustainability. Organizations have obtained their growth sustainability though competitive advantage but still certain factors can decelerate their performance.

In this regard, sustainable management can augment the efficiency of decision making while ameliorating the corporate governance mechanism. Meanwhile, sustainable management also orientates corporate governance towards corporate social responsibility, which not only attracts the consumer but also suggests that emerging markets should adhere to corporate social responsibility measures. Another contribution of sustainable management is to acclimatize organizations to be accountable before consumers and regulators. Meanwhile, it also recommends specific rules for social, economic, and environmental factors, which influence the business vehemently. Remarkably, sustainable management endorses adherence to particular rules, which can mitigate the unnecessary costs of business while satisfying customers by obeying business ethics strictly.

In the current international environment, it is intensively complicated to prosper in any business without comprehending the pros and cons of catastrophic changes of business, its consequences, and its demands. Sustainable Management Practices will unveil with deep insight the current issues related to corporate governance, sustainable business management, and corporate social responsibility. Further, the reader will assimilate the practical concepts while comprehending the theoretical concepts.

The editors would like to acknowledge the help of all those involved in this project. Without their support, this book would not have become a reality. First, the editors would like to thank each of the authors, who contributed their time and expertise to this book. Second, the editors wish to acknowledge the valuable contributions of the reviewers regarding the improvement of quality, coherence, and content of each of the chapters.

Dr. Muddassar Sarfraz Business School, Hohai University, PR China

Dr. Muhammad Ibrahim Adbullah Comsats University Islamabad, 
Dr. Abdul Rauf

Southeast University,

PR China

Dr. Syed Ghulam Meran Shah

Southwestern University of Finance and Economics,

PR China 


\title{
Over Engagement, Protective or Risk Factor of Burnout?
}

\author{
Josep M. Blanch, Paola Ochoa and Maria Fernanda Caballero
}

\begin{abstract}
Megatrends in the organization and management of work promote intensification and acceleration processes in the form of overload and overtime. These processes, in a framework of deregulation and individualization of labor relations, constitute burnout risk factors. To tackle this contemporary pandemic, the positive occupational psychology proposes engagement as a strategic resource for preventing that syndrome, delaying its appearance, or cushioning its effects. The present study is based on the suspicion that engagement, in addition to functioning as a means of protection against burnout, may also constitute a risk factor for this pathology. The purpose of its exposition is to contextualize, situate, and argue the logic of this approach, and to advance a response proposal to the question about in which circumstances the engagement constitutes a risk factor of burnout: in moderate doses, it works as a protective factor of burnout, while in excessive doses, it acts as a risk factor by hiding the warning signs of the syndrome.
\end{abstract}

Keywords: burnout, engagement, protective factor, risk factor, occupational health

\section{Introduction}

During the first decade of the century, a powerful line of empirical research and an equally influential dissemination device in the scientific and managerial fields, together with the positive psychology of organization and work, placed work engagement in the center of the disciplinary and professional scenario, playing the role of vaccine against the work burnout pandemic.

At the same time, a wide debate has been developing on the nature and specificity of the new construct, on its articulation with that of burnout, and on the metatheoretical background of its construction and application. Most of the discussion focuses not so much on the theoretical and practical utility of the construct, but on the criteria and precautions that should guide the theoretical explanation of the research results and the practical application of the intervention devices.

In general, the literature attributes to the engagement only positive functions of avoidance or minimization of the effects of burnout, reserving for other phenomena of high labor implication, such as workaholism, the role of risk factors of burnout. But this distinction does not seem sufficient to completely eliminate the doubt about whether engagement itself works like a risk factor for burnout. In this study, we will look for the circumstances in which the engagement may facilitate or mask the appearance of this pathology. 
First, some macro trends in the world of work that constitute the emergency context of the burnout pandemic will be analyzed, with special emphasis on the naturalization of working conditions and the psychologization of the sources of the burnout. Then will be described some singular developments of positive psychology, travel companion of work engagement theory. Next, some relevant developments on work engagement and engaged workers in positive organizations will be presented, to end with a balance of the lights and shadows that appear in the current panorama of research and theory on the complex engagement-burnout articulation. On this basis, a re-reading of this relationship will be proposed: engagement works as a protective factor for burnout, when applied in moderate doses, and as a risk factor, if it is present in such excessive doses that they mask anticipatory warning signals from the irruption of the syndrome.

\section{Labor macro trends and new work management}

Recent studies have detected the emergence, on a global scale, of an epidemiological catastrophe of burnout driven by the combined effect of multiple vectors: first, the general dynamics of the labor market toward a scenario characterized by a constant increase in the quantitative and qualitative job demands, in a regime of temporary pressure to execute tasks quickly, and in the framework of an increasing uncertainty and insecurity in employment. This context determines the growing cognitive, emotional, social, and digital work overload in numerous professions, the generalized intensification and acceleration of working time and the corresponding decrease in the time devoted to rest, the dilution of boundaries between work spaces and times, and of nonlabor life, the labor colonization of nonlabor spaces and times, the progressive temporary and social precarization of employment contracts and the flexibilization, deregulation, and individualization of labor relations. In addition, the fulfillment of managerial objectives often demands an over commitment of the workers to the organization, which in the long run can lead to fatigue and exhaustion. This set of transformations constitutes a breeding ground for chronic work stress, considered the main psychosocial risk factor of burnout [1-5].

The last of the five-year reports on Living and Working Conditions in Europe [6] confirms the tendency already pointed out in previous surveys [51] to the significant and sustained increase in the declining European work paradise of the multiple perception of "working at great speed," "with tight deadlines," and with "feeling of general fatigue at work." In the same line, the recent Work and Well-Being Survey, published by the American Psychological Association's (APA's) Center for Organizational Excellence of the American Psychological Association, detects in the United States a fatal combination of overwork, lack of rest time, and almost absence of a managerial culture sensitive to the perverse effects of such excesses and deficiencies for the health of both workers and companies [7]. In the same vein, the second ESENER report highlights the economic, social, and organizational relevance of psychosocial risks and their prevention, while at the same time reflecting a moderate attention given by European businessmen and managers toward occupational safety issues and a remarkably lower interest that they dedicate to the issues concerning the occupational health, as it is the case of the psychosocial risks [8]. For this reason, the International Labor Organization has proposed to change these mentalities, guiding labor policies at a global, regional, and state level not only regarding workers' labor rights, but also regarding the prevention of occupational risks and the promotion of healthy and sustainable work environments $[3,9]$. The World Health Organization itself has joined this task $[10,11]$. 
The panorama described poses the challenge of balancing the functional imperatives of an organizational culture based on values and norms of the market company, such as efficiency and effectiveness, productivity and competitiveness, profitability and quality, cost-benefit analysis or evaluation by results, with human values, such as health and safety at work, occupational well-being and quality of working life. This difficult balance requires a double task: the effective prevention of the psychosocial risks of burnout and the promotion of healthy employees committed to their work.

The concern to prevent the general increase in work stress does not develop in a vacuum, but in the context of the metamorphosis of working conditions driven by the new neoliberal management. This hegemonic current generates a double effect, of objectification and subjectivation. On the one hand, it establishes working conditions under a management by stress regime that usually entails overload of work and temporary pressure, circumstances of risk of burnout. On the other, it transfers responsibility for the management of psychosocial risks from the employing organization to the employed person.

In this context, the psychology of work and its organization shows some lines of internal tension that express its theoretical and practical ambivalence when it comes to the evaluation and prevention of burnout: on the one hand, the orientation more sensitive to social factors explains the phenomenon as an effect of the psychological exhaustion experienced by the worker in given working conditions $[12,13]$, which the International Labour Office declares "indecent" [9]. Focused in this way, the promotion of engagement contributes to the prevention of burnout to the extent that it is combined with the performance of working conditions that determine chronic work stress. On the other, the most markedly clinical orientation of the discipline and the profession, which adopts the individual as an object of analysis and intervention, focuses on burnout above all as a matter of the same affected person, the agent and victim of the problem. In this sense, psychological wear is visualized as the expression of personal failure in coping with the labor demands that an organization imposes on its employees. The equivalent of this clinical approach to burnout presents engagement as an antagonist of burnout, placing it in the category of "personal resources" to effectively face those organizational demands. This clinical accent is more evident in the field of professional intervention in human talent management than in that of scientific research, which usually manages various combinations of resources located in the person and in the job [2, 13-21].

This identification of different "psychologies" of burnout (and engagement) justifies considering previously the links of engagement theories with the current of positive psychology and with its branch of positive organizational psychology.

\section{Positive occupational psychology, background of the work engagement research and intervention}

The traditional way of knowing production in psychology as a discipline and as a profession over the last century focused its object on mental illnesses, weaknesses, and dysfunctions. Placed in this context, the theory and the clinic of the burnout appear like manifestations of the negative psychology which conceives that upheaval like the pathological state to which a person arrived after to have remained a long time exposed to an excessive demand of work that could not or did not know how to face successfully. In contrast, the one related to engagement is inscribed in the line of positive psychology [22-24], based on a new approach of the human being that 
does not focus on the pathology or the "ideology of the disease" [25] but in health and in the study of the phenomena and psychological processes that contribute to the well-being and happiness of people, orienting themselves toward the development of their strengths and the promotion of their optimal functioning [26]. According to Seligman [22], the main driver of the new approach, happy people get sick less, live longer, and function better in everyday life, in their social interactions, and at work. Within the framework of this new trend, promoted by the American Psychological Association (APA), positive occupational psychology studies that optimal functioning in the workplace to discover and promote the factors that allow and facilitate the prosperity of both employees and employers' organizations $[15,17$, 20, 27-31].

The psychology of burnout considers both the environmental and personal factors that affect the phenomenon, although with a certain emphasis on the latter. On the other hand, the psychology of engagement, without disregarding the weight of external variables, including both job demands and job resources and their interaction, emphasizes subjective and intrapersonal factors, presenting the same engagement as "state of mind" that is part of the "personal resources" to coping with the "organizational demands" [14-18, 20, 21].

The psychology of engagement is sensitive to the contagion of certain biases of positive psychology, its traveling companion, as its emphasis on adopting the intraindividual and merely subjective as the basic unit of analysis and intervention. One of the models that contributed to reinforce that radically psychological point of view was the one proposed by Boehm and Lyubomirsky [32] in their Promise of Sustainable Happiness published in the Oxford Handbook of Positive Psychology. In this influential text, the authors start from the observation that traditionally philosophers, writers, gurus of all kinds, and scientists of the most diverse disciplines have considered well-being and happiness as dependent variables of objective external factors (such as, for example, living and working conditions). However, according to them, there is accumulated scientific evidence that what determines that some people are happier than others are not objective circumstances such as salary or marital status or even life events; that together "explain relatively little variation in people's levels of well-being." The key, according to them, is that "happy people are inclined to perceive and interpret their environment differently from their less happy peers." For that reason, they explore "how an individual's thoughts, behaviors, and motivations can explain their happiness over and above the mere objective circumstances of their life." Their research leads them to conclude that happy individuals tend "to view the world relatively more positively and in a happiness-promoting way," to "describe their previous life experiences (...) as more pleasant," and "to use a positive perspective when evaluating themselves and others."

According to its model of primary determinants of sustainable happiness, "three factors contribute to an individual's chronic happiness level: (a) the set point, (b) life circumstances, and (c) intentional activities, or effortful acts that are naturally variable and episodic." The authors dare to specify the coefficient of determination of each of these three influential factors: to the biophysiological base (set point) corresponds $50 \%$ of the causality on chronic happiness, to the life circumstances an insignificant $10 \%$, and to the intentional activities $40 \%$. On the set point, psychology has very little to do. Nor can much be done about external circumstances. Therefore, it is on this important $40 \%$ that research and intervention on well-being and happiness should focus. According to the authors, such intentional activities that include, for example, "committing acts of kindness, expressing gratitude or optimism, and savoring joyful life events," represent "the most promising route to sustaining enhanced happiness." In the text, they also describe half a dozen 
"randomized controlled interventions testing the efficacy of each of these activities in raising and maintaining well-being, as well as the mediators and moderators underlying their effects." His conclusion is that "less happy people can strive to be happier by learning a variety of effective strategies and practicing them with determination and commitment." From this, it implicitly follows that there are no reasons for the unhappy, for objective labor causes to waste their time or spend their energies in trying to change working conditions that entail a high risk of burnout. The path to wellness goes through the development of those subjective strategies. In the nineteenth century, German idealist philosophy was criticized for having limited itself to "interpreting the world" when it was urgent to "transform" it. Here and now the opposite is proposed: There is no need to transform the world; it is enough to reinterpret it, subjectively and individually. In case there is any doubt of the metatheoretical positioning of this "promise of sustainable happiness," in the frontispiece of the concluding remarks of the work is inscribed the well-known phrase of one of the philosophers of individualism, Henry David Thoreau: "Man is the artificer of his own happiness."

This type of model provides the psychology of burnout with a "scientific" pretext to stop worrying about working conditions as psychosocial risk factors. It would be enough to change the subjective conditions from which each employee faces the objective demands of their organization. Binkley $[33,34]$ criticizes the radical "psychologism" of positive psychology of happiness for its connections with the program of the "government of neo-liberal interiority." His study on "happiness as enterprise" is presented as "an essay on neoliberal life" [35]. In the same vein, Fabián and Stecher [36] consider this type of positive psychology as a "construction technology of the new neoliberal subject" and relate their new discourses on happiness with the "neoliberal governmentality" and its maxim slogan: "Dedicate yourself to being happy and everything else will follow." For the historian Horowitz [37], the happiness studies promoted by positive psychology seem destined to persuade people that they can be happy even though the conditions of life, work, health, education, and wages are getting worse. Although not all the tendencies of the complex current of positive psychology assume with the same enthusiasm positions as individualistic as the one described, globally they progress in the same direction, questioning the traditional conception of well-being and happiness as effects derived from the conditions of life and moving precisely in the opposite direction: well-being and happiness lead to good results in life and work.

Understanding the conceptual articulation of the engagement model with that of burnout requires considering not only the theoretical implications of the important epistemic turn driven by positive psychology, but also those of that metatheoretical background of individualism underlying happiness studies. And this applies specially to models of work happiness based on the alleged "scientific evidence" that working conditions, as part of life circumstances, only determine $10 \%$ of job happiness. It seems unrealistic to claim that a person who goes to work every day to a company managed by stress, with a workday marked by task overload and temporary pressure, under a regime of contractually precarious employment, with low salary and minimum social protection, being object of racial discrimination, sexual harassment, mobbing, and third-party violence, can compensate those small inconveniences through a repertoire of magical rituals based on intentional activities as powerful as friendly faces, smiles of gratitude, refills of intrinsic motivation, or expressions on a role of experiences of happiness or good memories preserved. A conception of engagement as a mere personal resource for the individual management of burnout without touching the working conditions could appear as an expression of a psychology made to the measure of new management. 


\section{Work engagement and engaged workers in positive organizations}

Kahn [38] used the term engagement to refer to the energy mobilized by certain employees who strive to achieve organizational goals and conceived this state as opposed to burnout. The psychology of engagement burst onto the scene in the period of transition to the new century as a new turn in research and theorization on burnout, and in parallel to the first developments in positive psychology, as a promise of production of healthy and productive workers for healthy, competitive, and sustainable organizations. With a new look of the human being focused less on its limitations and more on its potentialities, positive organizational psychology shifted attention from workers burned by exhaustion to those more vigorous and enthusiastic about their work [2, 39].

The implantation of the concept in occupational psychology went through an initial phase of some reasonable doubts raised about whether the new construct contributed something new and different with respect to others of the same semantic field already implanted in the discipline, such as those of job involvement, work commitment, organizational citizenship behavior, etc. [2]. At the beginning, Maslach and Leiter [12] presented a symmetrically opposed engagement model to that of burnout, explaining this pathological process as the erosion of a healthy state of engagement characterized by energy, involvement, and efficacy. In this process of psychological deterioration, energy is transformed into exhaustion, participation in cynicism, and efficacy into inefficacy. Over time, the engagement adopted the clearly motivational construct format, which includes energy, activation, effort, perseverance, commitment, and intentionality. The extensive literature available allows for a schematic characterization of engagement, of engaged workers and their importance for the optimal functioning of healthy and positive organizations.

Work engagement was defined and operationalized as "a positive, fulfilling, work-related state of mind that is characterized by vigor, dedication, and absorption" [40]. Vigor refers to "high levels of energy and resilience, the willingness to invest effort in one's job, not being easily fatigued, and persistence in the face of difficulties"; dedication refers to "a strong involvement in one's work, accompanied by feelings of enthusiasm and significance, and by a sense of pride and inspiration"; and absorption refers to "a pleasant state of total immersion in one's work which is characterized by time passing quickly and being unable to detaching oneself from the job."

The engagement, as a personal resource, has internal sources of energy such as intrinsic motivation and self-positive feedback; but it is also nourished by environmental factors, such as social support, positive leadership and coaching, performance feedback, task variety, and opportunities to learn and develop. In addition, the engagement is emotionally contagious within the organization and remains at high levels, because the same staff takes care of it, proactively modifying their work environment [14, 15, 19-21].

The literature identifies numerous characteristics of the engaged workers: they are active, autonomous, self-reliant, and self-responsible; have positive self-concept, self-evaluation, and self-esteem; have high levels of physical and mental health, well-being and quality of work life, emotional stability, performance, optimism, flexibility, adaptability, proactivity, prosociality, initiative, creativity, achievement motivation, and social skills and low levels of anxiety, depression, and burnout. They also show good performance, complain little, are rarely conflictive, and have more initiatives to solve problems related to the demands of work. In addition, they are well predisposed to the practice of job crafting, that is, to restructuring job demands and job resources to better meet organizational objectives, by creating 
their own great place to work. They have a strong feeling of loyalty to the organization; so, they complain little, generate few tensions, and show a minimal intention to leave the job, the company, or the profession. By sharing and taking on the values of the organization, they commit themselves to them; so, they also require less supervision. Although they "sometimes feel tired," they are at the same time "satisfied" of working and with their work [13-15, 19-21]. Precisely, the balance of the latest developments in the research reinforce the evidence of the "buffering role of various job resources on the relationship between job demands and burnout." This new approach emphasizes the "role of the individual in modifying the impact of job demands and resources on motivation and energy, in the form of personal resources, job crafting, and self-undermining" [17].

Organizations with engaged workers enjoy multiple advantages, such as positive social climate; low levels of turnover, absenteeism, accidents, and conflicts; and high levels of productivity, innovation, and employee performance, all of which make them more competitive and sustainable $[14,15,19,20]$.

\section{Lights and shadows of the work engagement model}

The initial research on work engagement was developed almost in parallel with the design of the Job Demands-Resources Model-JD-R-which constitutes the most relevant contribution to the theoretical articulation of burnout-engagement. By demands is understood the set of quantitative and qualitative, cognitive, and emotional, physical, and social requirements of work, which involve psychological wear for the employee. The resources are the set of material, technical, organizational, and social devices and personal and professional skills available to cope with the job demands. The traditional version of the model explains and predicts burnout as an effect of the prolonged imbalance between high demands and low resources, characteristic of chronic work overload; situation that derives in disengagement, burnout, and malaise. This vicious combination is contrasted by a virtuous combination of high demands and high resources, generating health, well-being, and engagement effects (see Table 1).

The review of the extensive existing literature on the subject provides evidence that there is "distinctive pattern of antecedents and consequences of burnout and work engagement": job demands appear as the main cause of burnout, poor health, and negative organizational outcomes. On the opposite pole, job resources appear as antecedents of work engagement, work well-being, and positive organizational outcomes. With the JD-R model, we can understand, explain, and make predictions about employee burnout, work engagement, and outcomes [14-17, 39].

The positive side of the robustness of the JD-R model is contrasted by a dark side in which, according to various critical views, converge deficiencies, ambiguities, contradictions, and unresolved issues in the engagement model, concerning identity and distinctiveness of engagement, limitations in terms of the levels of analysis applied in research on the subject and potential negative effects of engagement.

In general terms, with regard to the first aspect, it is debated whether the engagement refers to a substantive, specific, distinct, univocal, and nonredundant phenomenon with respect to burnout; on whether both constructs constitute two poles of a continuous or two sides of the same coin; about whether their relationship is one of complementarity, compensation, antipodality, antagonism, independence, interdependence, or dialectic and about how much each of them is stable and variable [41-43]. 


\begin{tabular}{|c|c|c|c|c|}
\hline & $\begin{array}{l}\text { Working } \\
\text { conditions }\end{array}$ & Enabling factors & Personal outcomes & $\begin{array}{l}\text { Organizational } \\
\text { outcomes }\end{array}$ \\
\hline $\begin{array}{l}\text { Virtuous } \\
\text { combination }\end{array}$ & $\begin{array}{l}\text { High job } \\
\text { demands } \\
\text { combined } \\
\text { with } \\
\text { high } \\
\text { (job and } \\
\text { personal) } \\
\text { resources }\end{array}$ & $\begin{array}{l}\text { Job crafting } \\
\text { Proactive physical } \\
\text { and cognitive } \\
\text { changes employees } \\
\text { make in their task } \\
\text { and job demands } \\
\text { for a better } \\
\text { achievement of } \\
\text { organizational } \\
\text { goals }\end{array}$ & $\begin{array}{l}\text { Motivation } \\
\text { Work engagement } \\
\text { Job satisfaction } \\
\text { Well-being } \\
\text { Vigor } \\
\text { Health } \\
\text { Proactivity } \\
\text { Flexibility } \\
\text { Creativity } \\
\text {... }\end{array}$ & $\begin{array}{l}\text { High job } \\
\text { performance } \\
\text { Achievement } \\
\text { Productivity } \\
\text { Competitiveness } \\
\text { Efficiency } \\
\text { Innovation } \\
\text { Success } \\
\text { Progress } \\
\text {... }\end{array}$ \\
\hline $\begin{array}{l}\text { Vicious } \\
\text { combination }\end{array}$ & $\begin{array}{l}\text { High job } \\
\text { demands } \\
\text { combined } \\
\text { with } \\
\text { low } \\
\text { (job and } \\
\text { personal) } \\
\text { resources }\end{array}$ & $\begin{array}{l}\text { Self-undermining } \\
\text { Negative: } \\
\text { self-evaluation } \\
\text { self-esteem } \\
\text { self-efficacy } \\
\text { expectations } \\
\text {... }\end{array}$ & $\begin{array}{l}\text { Strain } \\
\text { Work } \\
\text { disengagement } \\
\text { Job dissatisfaction } \\
\text { Malaise } \\
\text { Exhaustion } \\
\text { Burnout } \\
\text { Anxiety } \\
\text { Depression } \\
\text { Insecurity } \\
\text {... }\end{array}$ & $\begin{array}{l}\text { Low job } \\
\text { performance } \\
\text { Failure } \\
\text { Errors } \\
\text { Absenteeism } \\
\text { Turnover } \\
\text { Conflicts } \\
\text { Accidents } \\
\text { Injuries } \\
\text {... }\end{array}$ \\
\hline
\end{tabular}

Table 1.

Aspects of the JD-R model.

Regarding the second, conventional research on work engagement usually moves through the sphere of the individual and rarely exceeds the organizational level. This reduction in the analysis and explanation of complex and multidimensional phenomena to its more intraindividual facet is criticized for its effects of "psychologization," which lead to minimize the role of working conditions as a set of ecological, material, technical, economic, social, political, legal, and organizational circumstances within the framework of which activity and labor relations are developed. Such circumstances are not limited to "job demands." They constitute the context in which these demands are produced and dealt with. On a more general level, the literature on the subject rarely considers variables and factors corresponding to the sociocultural, political-legal, economic, and ideological macro-context, which is the matrix of the organizational culture, management models and values, norms, attitudes, and individual motivations that inspire and nourish work engagement [33-37].

The third point connects especially with the focus of interest of this chapter: With all the accumulated information, has any kind of evidence been built about eventual negative, perverse, or collateral psychosocial effects of work engagement? Have people been detected who, being strongly committed to their work and involved with the values and norms of their organization, have gone through processes of depression or burnout for work reasons? According to the mainstream literature, this type of phenomenon must be attributed not to work engagement, but to "workaholics," a form of addictive behavior motivated by the compulsion to work excessively and incessantly that involves a high level of commitment to the work that it seems, but it is not confused with work engagement. Workaholic's behavior is associated with low levels of health, job satisfaction and quality of social relations; the opposite as in work engagement [44-50]. 


\section{Over engagement, protective or risk factor of burnout?}

The conceptual and operational differentiation between work engagement and workaholics serves to put on the positive plate of the balance all the effects of the work engagement and on the negative those of the workaholics, as well as to obtain consistent empirical results from the application of standardized evaluation instruments of both constructs. The panorama seems so simple, clear, and perfect that it almost leaves no room for doubt.

But the results of empirical research that we have been carrying out with public attention services personnel, mainly from the worlds of the academy and the health and justice services [51-54], lead us to suspect that, in the empirical level, things are less clear than in the constructs: (a) In the context of interview and focus group, we have more difficulty distinguishing the indicators of engagement from workaholics than when we read texts on the subject. (b) The survey shows satisfied professionals above all for the material, technical, and social resources available to them and, at the same time, discomfort due to their job conditions regarding work overload and temporary pressure. In the survey, we apply standardized instruments for assessing working conditions, work well-being, burnout, and engagement. The results allow us to identify an irreducible sector of around $20 \%$ of the surveyed personnel that gives high scores in both burnout and engagement (not workaholics). A staff often so work engaged that, in natural contexts of returning results to people and groups that had requested it, they have difficulty to recognize how exhausted they really are. Which leads us to an interpretation not in accordance with the mainstream: in many of these cases, work engagement, rather than protecting from burnout, masks it, postponing the moment of becoming aware of it and confronting it proactively. In this circumstance, work engagement could work as a psychosocial risk factor for burnout with a delayed effect.

How to reconcile this interpretation with the consensus generated among most researchers on the role of engagement as a protector of burnout? A possible

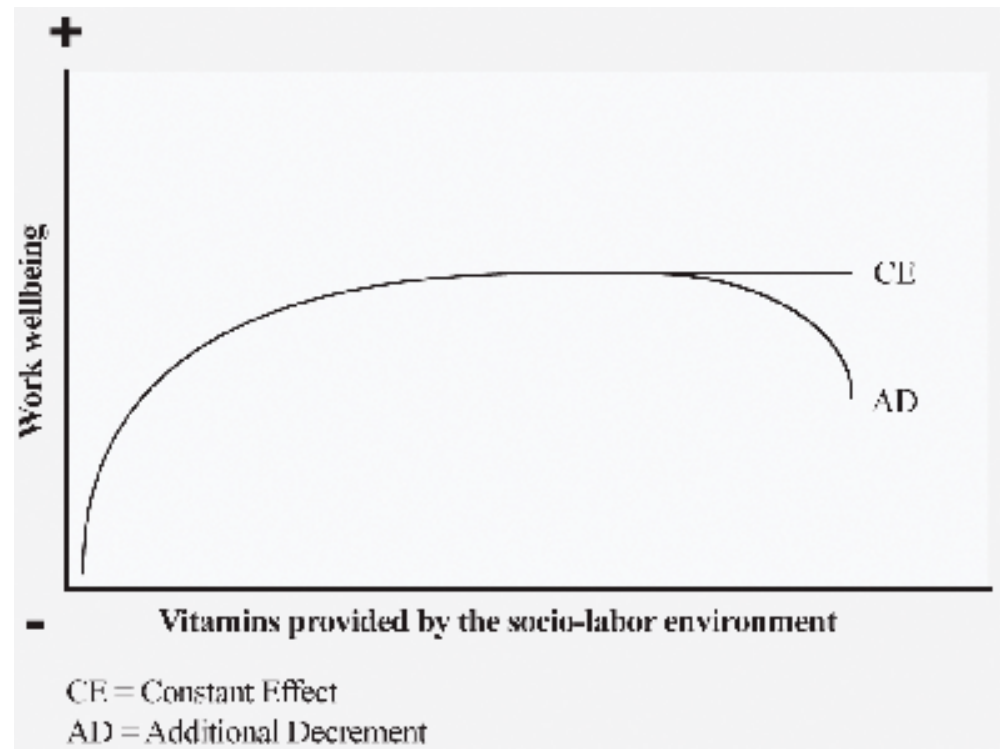

Figure 1.

Socio-labor environment and work well-being. Source: $[55,56]$. 
answer to this question is provided by Warr's vitamin model $[55,56]$ on the sociooccupational determinants of psychological well-being, inspired by the role played by vitamins in the physical health of organisms (See Figure 1).

The application of this model allows to conceive the stress in the employment in terms of toxic effects attributable to hypervitaminosis due to over-demand of work and the one that occurs in unemployment because of psychosocial hypovitaminosis due to deficit of environmental features. Applying the same logic to the field of the relationship between work engagement and burnout, a vitamin deficit of engagement makes the person more vulnerable to burnout. An optimal level of such vitamin effectively prevents burnout, and an excessive level of engagement (not workaholics) could work as a risk factor for burnout by blocking alert signals and allowing the person to continue accumulating fatigue. This interpretation, still in the initial phase of formulation, has relevance in the double plane of theory and practice, which opens the way for future studies and developments in this field.

\section{Author details}

Josep M. Blanch ${ }^{1,2 *}$, Paola Ochoa ${ }^{3}$ and María Fernanda Caballero ${ }^{4}$

1 Universidad San Buenaventura (USB-Cali), Cali, Colombia

2 Autonomous University of Barcelona, Barcelona, Spain

3 Escuela Superior Politécnica del Litoral, ESPOL, ESPAE Graduate School of Management, ESPOL Polytechnic University, Guayaquil, Ecuador

4 National Open and Distance University, Palmira, Colombia

*Address all correspondence to: jmbr.blanch@gmail.com

\section{IntechOpen}

(C) 2018 The Author(s). Licensee IntechOpen. This chapter is distributed under the terms of the Creative Commons Attribution License (http://creativecommons.org/licenses/ by/3.0), which permits unrestricted use, distribution, and reproduction in any medium, provided the original work is properly cited. (cc) BY 


\section{References}

[1] Ulferts H, Korunka C, Kubicek B. Acceleration in working life: An empirical test of a sociological framework. Time \& Society. 2013;22(2):161-185

[2] Schaufeli WB, Leiter WP, Maslach C. Burnout: 35 years of research and practice. Career Development International. 2009;14(3):204-220

[3] ILO. La prevención de las enfermedades profesionales. Geneva: International Labour Office; 2013

[4] EU-OSHA. Psychosocial risks in Europe: Prevalence and strategies for Prevention. Bilbao: European Agency for Safety and Health at Work; 2014

[5] Winston TR, editor. Handbook on Burnout and Sleep Deprivation: Risk Factors, Management Strategies and Impact on Performance and Behavior. New York: Nova Science Publishers; 2015

[6] Eurofound. Sixth European Working Conditions Survey-Overview report. Luxembourg: Publications Office of the European Union; 2016

[7] APA. Work and Well-Being Survey. Washington, DC: APA's Center for Organizational Excellence; 2018

[8] EU-OSHA. Second European survey of enterprises on new and emerging risks (ESENER-2). Bilbao: European Agency for Safety and Health at Work; 2016

[9] ILO. Decent Work Indicators. Concepts and Definitions. ILO Manual. Geneva: International Labour Office; 2012

[10] WHO. Healthy workplaces: A WHO Global Model for Action. Geneva: WHO; 2010

[11] WHO. Benefits of Workforce Health Promotion. Geneva: WHO; 2017
[12] Maslach C, Leiter MP. The Truth about Burnout: How Organizations Cause Personal Stress and What to Do About It. San Francisco, CA: JosseyBass; 1997

[13] Leiter MP, Maslach C. Burnout and engagement: contributions to a new vision. Burnout Research. 2017;5:55-57

[14] Albrecht SL, editor. Handbook of Employee Engagement: Perspectives, Issues, Research and Practice. Glos, United Kingdom: Edward Elgar; 2010

[15] Bakker AB, Albrecht S. Work engagement: Current trends.

Career Development International. 2018;23:4-11

[16] Bakker AB, Demerouti E. The job demands-resources model: State of the art. Journal of Managerial Psychology. 2007;22:309-328

[17] Bakker AB, Demerouti E. Job demands-resources theory: Taking stock and looking forward. Journal of Occupational Health Psychology. 2017;22:273-285

[18] Bakker AB, Demerouti E, Sanz-Vergel AI. Burnout and work engagement: The JD-R Approach. The Annual Review of Organizational Psychology and Organizational Behavior. 2014;1:389-411

[19] Bakker AB, Leiter MP, editors. Work Engagement: A Handbook of Essential Theory and Research. New York:

Psychology Press; 2010

[20] Bakker AB. Job crafting among health care professionals: The role of work engagement. Journal of Nursing Management. 2018;26:321-331

[21] Schaufeli WB. What is Engagement? Employee Engagement in Theory and Practice. London: Routledge; 2013 
[22] Seligman ME. Authentic Happiness: Using the New Positive Psychology to Realize Your Potential for Lasting Fulfillment. New York: Free Press; 2002

[23] Seligman M, Csikszentmihalyi M. Positive psychology. An Introduction. American Psychological Association. 2000;55(1):5-14

[24] Seligman ME, Steen TA, Park N, Peterson C. Positive psychology progress: Empirical validation of interventions. American Psychologist. 2005;60:410-421

[25] Maddux JE. Positive psychology and the illness ideology: Toward a positive clinical psychology. Applied Psychology. 2008;57:54-70

[26] Lyubomirsky S. The How of Happiness: A Scientific Approach to Getting the Life You Want. New York: Penguin Press; 2008

[27] Bakker AB, Rodríguez-Muñoz A, Derks D. The emergence of positive occupational health psychology. Psicothema. 2012;24:66-72

[28] Bakker AB, Schaufeli WB. Positive organizational behavior: Engaged employees in flourishing organizations. Journal of Organizational Behavior. 2008;29:147-154

[29] Cameron KS, Spreitzer GM, editors. The Oxford Handbook of Positive Organizational Scholarship. New York: Oxford University Press; 2011

[30] Leka S, Houdmont J, editors. Occupational Health Psychology: A Key Text. Oxford: Wiley-Blackwell; 2010

[31] Linley PA, Harrington S, Garcea N, editors. Oxford Handbook of Positive Psychology and Work. Oxford, United Kingdom: Oxford University Press; 2010

[32] Boehm J, Lyubomirsky S. The promise of sustainable happiness.
In: Shane JL, Snyder CR, editors. The Oxford Handbook of Positive Psychology. New York: Oxford Press; 2009. pp. 1-21

[33] Binkley S. Happiness, positive psychology and the program of neoliberal governmentality. Subjectivity. 2011;4(4):371-394

[34] Binkley S. Psychological life as enterprise: Social practice and the government of neo-liberal interiority. History of the Human Sciences. 2011b;24(3):83-102

[35] Binkley S. Happiness as Enterprise: An Essay on Neoliberal Life. Albany, NY: State University of New York Press; 2014

[36] Fabián R, Stecher A. New discourses on happiness and neoliberal governmentality: "Dedicate yourself to being happy and everything else will follow". Sociedad Hoy. 2013;25:29-46

[37] Horovitz D. Happier? The History of a Cultural Movement That Aspired to Transform America. New York: Oxford University Press; 2018

[38] Kahn WA. Psychological conditions of personal engagement and disengagement at work. Academy of Management Journal. 1990;33:692-724

[39] Schaufeli WB, Bakker AB. Job demands, job resources, and their relationship with burnout and engagement: A multi-sample study. Journal of Organizational Behavior. 2004;25(3):293-315

[40] Schaufeli WB, Salanova M, González-Romá V, Bakker AB. The measurement of burnout and engagement: A confirmatory factor analytic approach. Journal of Happiness Studies. 2002;3:71-92

[41] Demerouti E, Mostert K, Bakker $\mathrm{AB}$. Burnout and work engagement: 
A thorough investigation of the independency of both constructs. Journal of Occupational Health Psychology. 2010;15:209-222

[42] Gonzalez-Roma V, Schaufeli WB, Bakker AB, Lloret S. Burnout and work engagement: Independent factors or opposite poles? Journal of Vocational Behavior. 2006;62:165-174

[43] Hallberg UE, Schaufeli WB. "Same” but different? Can work engagement be discriminated from job involvement and organizational commitment? European Psychologist. 2006;11(2):119-127

[44] Andreassen CS, Bakker AB, Bjorvatn B, Moen BE, Mageroy N, Shimazu A, et al. Working conditions and individual differences are weakly associated with workaholism: A 2-3-year prospective study of shift-working nurses. Frontiers in Psychology. 2017;8:2045

[45] Bakker AB, Demerouti E, Burke R. Workaholism and relationship quality: A spillover-crossover perspective. Journal of Occupational Health Psychology. 2009;14:23-33

[46] Gorgievski MJ, Bakker AB. Passion for work: Work engagement versus workaholism. In: Albrecht SL, editor. Handbook of Employee Engagement: Perspectives, Issues, Research and Practice. Glos, United Kingdom: Edward Elgar; 2010. pp. 264-271

[47] Schaufeli WB, Bakker AB, Van der Heijden FMMA, Prins JT. Workaholism, burnout and wellbeing among junior doctors: The mediating role of role conflict. Work \& Stress. 2009;23:155-172

[48] Schaufeli WB, Bakker AB, Van der Heijden FMMA, Prins JT. Workaholism among medical residents: It is the combination of working excessively and compulsively that counts. International Journal of Stress Management. 2009;16:249-272
[49] Schaufeli WB, Bakker AB, Van Rhenen W. Workaholism, burnout, and work engagement: Three of a kind or three different kinds of employee well-being? Applied Psychology: An International Review. 2008;57(2):173-203

[50] Zeijen ME, Peeters MC, Hakanen JJ. Workaholism versus work engagement and job crafting: What is the role of self-management strategies? Human Resource Management Journal. 2018;28(2):357-373

[51] Blanch JM. Quality of working life in commoditized hospitals and universities. Papeles del Psicólogo. 2014;35(1):40-47

[52] Granero A, Blanch JM, Ochoa P. Labor conditions and the meanings of nursing work in Barcelona. Revista Latino-Americana de Enfermagem. 2018;26:e2947

[53] Ochoa P. Impact of burnout on organizational outcomes, the influence of legal demands: The case of Ecuadorian physicians. Frontiers in Psychology. 2018;9:662

[54] Ochoa P, Blanch JM. Work, malaise, and well-being in Spanish and LatinAmerican doctors. Revista de Saúde Publica. 2016;50:21

[55] Warr P. Work, Unemployment and Mental Health. Oxford, United Kingdom: Oxford University Press; 1987

[56] Warr P. Work, Happiness and Unhappiness. Mahwah, NJ: LEA; 2007 



\title{
Adaptive Sustainable Academic Management Practices
}

\author{
Cătălin Popescu
}

\begin{abstract}
The unpredictable evolution at global level, in all aspects of society, as a whole, requires close attention from all socio-economic and even political entities, as well as from human decision-makers at various levels, in order to find viable solutions for what a robust and harmonious development of the whole society means. From this perspective, an essential role must be taken by academics and universities. Universities can be considered the true engines of society in terms of promoting, spreading and acquiring the elements that are defining sustainable development. University decision-makers have an obligation to resort to practices adapted to the evolution of the concept of sustainable development in relation to what is happening in the economic, social, political, demographic, ecological or technological spheres. A state of acceptance and awareness has to be created by all of what the society needs to prepare for future generations.
\end{abstract}

Keywords: sustainable university, strategic sustainability, entrepreneurial university, academic decision-makers, adaptive change

\section{Introduction}

Each generation has the same goals, which aim at growth and technological, economic and social development, which means a better life. The perseverance for achieving these goals has enabled mankind to reach its current state of development. Undesirable and avoidable side effects are added to those that are favorable. More and more resources are becoming insufficient as the climate is changing in a negative way and the deterioration of the environment is increasing. Society is increasingly unbalanced, the rich become richer and the poor are getting poorer, many countries have serious difficulties in securing enough food, money and other resources as stated in Ref. [1]. The future and the sustainability of this planet, Terra, are constantly being jeopardized by the lethal actions of mankind, and it is almost exclusively our responsibility to adopt long-term strategies to mitigate the consequences we have been experiencing for a long time. On a planet that currently has 7.7 billion people, each action or lack of action generates a labyrinth of consequences, both in society and the environment both globally and locally. Mankind began to understand, under the effect of several constraints, that if it continues to consume unwarranted, dispel and ignore the signals of this lifestyle, it will self-destruct. The crisis from 2007 to 2008, as well as the forthcoming likely financial crisis, is nothing more than a concrete proof of the negative effects caused by unhealthy habits and over-reliance. 
Prolonged prosperity in the last 30 years has fueled these habits and over-reliance, and they mean that promises of modern economics can create the conditions of their own failure, according to Ref. [2].

Low inflation, high employment rates, rising stock prices and the housing market have led to the conviction that economics and economic growth would be less risky. Trust has become unjustifiably optimistic and the population has taken increasing risks (see [1]). Over the course of time, theories on the causes of the crisis have been proposed, but we can agree with Ref. [3], which declares that the deep explanations of the global crisis are found in the following three hypotheses, which are the hypothesis of government failure, the market failure and rising prosperity. Discussing these hypotheses leads to the conclusion that the crisis is the result of unwanted effects of unsustainable lifestyles and underlines the need for a new development model. In this respect, this new development model is related to the sustainable education approach. According to the UNESCO approach, Education for Sustainable Development aspires to "empower learners to take informed decisions and responsible actions" [4]. Sustainable development in education is increasingly focusing on the role of the formal education sector in partnership with the community as a key player in facilitating the education of society that is needed to meet the growing challenges posed by the environmental and social components of sustainable development.

Therefore, the main objectives of this study are to describe the role and the involvement of the universities in the future society and, also, explain what type of solutions use these universities in terms of sustainable management practices. This concept of sustainable education is related to a full and active academic community involvement that has to use adequate managerial practices, in order to design complex study programs, through the three well known pillars of sustainability, by having as major goals creation of adaptive knowledge abilities and improvement of the quality of life. Universities' role has changed in the last years, from teaching and basic research to the transfer of knowledge and skills in applied research that has to have a commercial and sustainable purpose, so that the universities are now connected to the economic, social and environmental evolution. On the other hand, many educational systems from all over the world have launched programs aiming to increase academic standards and to reconcile concerns for excellence with concerns for equity. Some of these programs have failed to reach their ambitious goals. Meanwhile, the rapid changes taking place in the globalizing world call for major educational reform in which the needs of all students are taken into account, the natural resources of the educational environment are not depleted, and the young generation is optimally prepared to meet the demands of the future world [5]. In order to produce sustainable outputs, there are required important actions starting with adequate curriculum design, teaching methodologies, teacher trainings and equity-enhancing programs. Another requirement in terms of Education for Sustainable Development is to include in the teaching, learning and research processes critical issues such as climate change, biodiversity, sustainable consumption, identifying and replacing conventional energy resources, etc. Since these issues are vital to the entire society, it is necessary to create a number of competencies such as critical thinking or imagining future scenarios that help solve the problems that human society will face in the near or far future. By doing all of these, every human being will get the knowledge, skills and attitudes required for a proper behavior that seeks a sustainable future for next generations. In line with the above mentioned things, an important work contains the top five pedagogical approaches required in the education for sustainable development such as critical reflection, systemic thinking and analysis, participatory learning, thinking creatively for future scenarios and collaborative learning [6]. 
On the other hand, today, from all the sustainable development dimensions, the economic sustainability is probably the most important one for the universities, since the future in academia is linked to entrepreneurial university, university spin-offs and start-up initiatives within universities. But, in order to gain economic sustainability, an ecological economy is needed. This type of economy must create renewable resources if necessary, use non-renewable resources when the renewable ones fall down and supervise the level of emissions with negative impact on the environment, as is stated in [7]. At the same time, according to [8], economic sustainability depends on the ability of natural ecosystems to obtain and store enough energy to sustain human life on Earth.

In the same time, universities set-up "academic programs related to the environmental dimension of sustainability that have grown exponentially across the physical, natural, and social sciences, as well as the humanities and the professions, but the attention to on-campus sustainability has grown even faster" [9].

\section{The concept of "sustainable university"}

Universities are seen as critical entities in the future. In this regard, "higher education institutions have a critical role to play in implementing and driving sustainable development initiatives through their institutional policies and practices" [10].

A sustainable university represents an educational institution that trains properly all the willing and interested persons for sustainable development, provides new insights into urgent social challenges and decreases the environmental and social footprints of its campus operations. One important role of a sustainable university is to empower students to learn about sustainability in an inter-disciplinary and learner-centered way.

The sustainability challenges universities around the world to rethink their mission and to restructure university curricula, research programs and campus life. Graduates are increasingly exposed to concepts of sustainability that are emotionally, politically, ethically and scientifically loaded. They must be able to cope with conflicting norms and values, with uncertain results and ideas, as well as changing general knowledge (e.g. see [11]).

The sustainable university is considering running programs to generate expertise on sustainability issues, in the idea of being an example to society as a whole, through resource conservation programs, waste recycling and waste management and, of course, by focusing on education, research and policy formulation to create a sustainable future. The objectives of sustainable education are to develop students' awareness of their own responsibilities and develop their capacity to contribute to solving sustainability issues. It is also possible to propose the development of trans-disciplinary skills to equip prospective graduates with knowledge, skills and competencies to identify and solve the problems that humanity will face in the near or more distant future.

Universities must devote resources intelligently to become sustainable and to provide students with a living experience in a sustainable environment. At the level of university education, sustainable development refers to the management of specific processes and activities, always taking into account the fundamental and sustainable objective of increasing the quality of services provided by representative institutions. The greatest contribution that higher education can have in sustainable development is to determine students to acquire the skills and knowledge that enable them to make a lasting difference and to make them more responsible in economic, social and environmental terms. What it learns and what is learned is, therefore, critical. The vision is supported by the United Nations, which set the 
period 2005-2014 as the decade of education for sustainable development. The aim is to integrate the principles, values and practices of sustainable development into all aspects of education and learning.

Sustainable development requires to universities around the world to rethink their mission and restructure their university curricula, research programs and campus life.

The curriculum of a higher education institution consists of everything that promotes the development of learners, intellectual, personal, social and physical development. A well designed curriculum is set to reach its targets. For sustainable development of the entire society, higher education institutions must place sustainable development at the heart of the curriculum. Current plans are constantly adapting to the need to incorporate knowledge related to sustainable development. In this sense, various disciplines are proposed in the curricula such as developmental studies, ecological economy, energy and environment engineering, environmental change and management, environmental geology, environmental pollution control, environmental studies, ethics and accountability sustainable development, sustainable management of resources, intercultural communication, culture, society and people, lack of equality and opportunity, social diversity in education, sustainable development, sustainable development, governance and sustainable development, international rural development, international education, training for informal education, social change, sociology and ecology of the community, organizational behavior, natural resources economy, chemicals and the environment, global change of environment environmental impact, culture and community, eco-transport or smart cities, aimed at familiarizing students with the complex and extensive problem of sustainable development, as well as improving the level of awareness of the challenges and dangers to which it is and will be subjected to human society.

The sustainable university is defined in many ways. For instance, "is a notion and concept that has been deliberated in specialized literature on Sustainable Development for about a decade, positioning the institution of the University as a vital driver toward a more sustainable society" [12]. Another point of view identified types of responses to sustainability within universities such as accommodative, reformative and transformative [13]. These types are declared as stages of progress, while the last one is seen as a mean of describing practices at the sustainable university.

Inevitably universities need to adapt to the society evolution in relation with sustainable development approach, and in order to have a successful implementation of the changes toward the future is required a holistic vision [14]. So, for this, it should be taken into account the '4C' model [15], which suggests that "Curriculum, Campus, Community and Culture should be seen as mutually enfolded and complementary foci of the sustainable university".

On the other hand, scientific research carried out in universities should focus largely, and themes defining sustainable development such as renewable energy, design sustainable buildings, green economy, population and development, the legal environment, waste management and so on.

In the next 30-50 years, the society needs to adopt new strategies to meet the needs of a growing population in a sustainable and equitable environment. Higher education has played, play and will play a critical role in determining our success or failure as a whole. The fundamental recommendation is to mobilize a critical mass of internal and external exponents to develop the model of the sustainable university in a variety of locations and communities of higher education. The specific recommendations below are proposed to highlight the internal and external changes to be made to ensure a commitment to the sustainable development of higher education. 
Educational institutions operate in an environment characterized by ever more heterogeneous regulations and funding. For each activity, there is a range of interest groups (businesses, public institutions, NGOs, government agencies, local government, media and students), each one with their own responsibilities, interests and influences, as well as their own visions on sustainable development. Any move that universities do in sustainable development needs to be developed through dialog with all stakeholders.

University administrators and decision-makers have a vital role to play in supporting the transition to sustainable development, guiding the strategic planning of these institutions, coordinating major core programs and managing the interactions of institutions with external stakeholders. The leaders of these universities also have a symbolic role in influencing the views of staff and students on sustainable development.

The evolution of society as a whole makes the main change necessary to consider the attempt to become more flexible in thinking and more connected to the present and future reality in economic and social terms, according to [16]. This can be synthesized through some ideas, approaches and solutions:

- Education plans must be tailored to the needs of the moment, to the requirements of the goods and services market;

- Trying to think beyond purely economic constraints and in terms of cost (paradigm shift);

- Introducing and developing sustainability education, including targeting prospective students to prioritize careers or jobs that are in areas that support sustainable development;

- Close links with the business community, local and regional community;

- Voluntary education activities in the spirit of sustainable development;

- The need to promote change, by applying the principle of value, to everything that an academic community defines;

- Treating the subject as a priority in all disciplines in the curriculum;

- Obligation of clear provisions in the procurement process (type of materials, minimum quantities, limited in the case of toxic or dangerous materials, etc.);

- Accepting only investments that comply with the principle of sustainable development (e.g. unconventional, non-polluting, renewable, "green”, ecological, etc.);

- Making partnerships with business organizations for projects in the field of sustainable development;

- Linking study programs to the realities of the labor market, with the needs of the business environment;

- Introduction and awareness of the concept of sustainable development;

- Initiating large-scale projects in the field of resource management and sustainability; 
- Particular partnerships with local, national and international companies on sustainability issues;

- Partnerships with other universities on sustainability issues and

- Collaborating universities with local and regional firms to influence the curriculum so that there are mutual benefits.

Starting from one of the important missions of the university, the academic education, we can design medium- and long-term educational activities oriented toward the knowledge and development of the concept of sustainable development. Formal educational activities refer to specific courses on sustainable development and its incorporation into existing courses and specific subjects. These include a variety of themes and are valid for a range of qualifications from undergraduate studies to doctoral studies. Informal educational activities aim at raising awareness of volunteering that individuals can take to support sustainable development. They are also useful for changing attitudes and behavior on better practices in sustainable household management, energy and water saving, waste reduction and disposal, selective collection, sustainable consumption and environmentally friendly transport options. Examples of activities specific to informal education include sustainable development or environmental pages on institutional sites; sustainable development groups within student associations; guides for students and staff for a sustainable lifestyle; institutional events; competitions; charity activities, etc.

In the last years many approaches and models related to the sustainable university are proposed. Among all of these works, it is worth to mention an interesting point of view [14], which proposed a model of sustainable university. In fact, this model proposed three different approaches of a sustainable university: an academic approach, an internal and an external approach of the university. The model has the vision proposed by Asitha Jayawardena as starting point. Therefore, this model has to be detailed in an adequate mode. The university consumes natural resources, produces waste and, of course, affects the environment. These aspects are related to the campus and campus family and require focusing of critical issues like access for disabled people, waste management, energy efficiency, occupational health and safety, etc. Advanced-thinking universities are acting as agents in promoting sustainability principles. How universities could equip their students with knowledge, skills or values? The response is very simple: through their core functions-education and research. The model does not focus on the pedagogies, but declares that the knowledge, skills or values can be delivered through formal, informal and no-formal education. The external approach refers to the idea that universities operate and have impacts in communities and ecosystems that range from local to regional and global. In fact, the model aims to be a useful tool for exploring strategies in order to transform the university into a sustainable one. As a first finding of this model, it can be stated that the model can be easily adapted by different organizations that want to green their infrastructure and production processes. Secondly, the sustainable university is not easy to be achieved, but all the efforts, energy, resources and time invested in many universities show progress [17]. Thirdly, the model can represents a starting point for defining the model of a sustainable business organization and could be an important tool for the managers of future organizations.

Another useful contribution is related to another point of view, namely that of participatory approaches [18]. So, participatory approaches can be declared as a requirement, but also as an advantage to the overall model change toward sustainable development. In this regards, this way of looking at specific issues regarding the sustainable development would contribute toward the integration 
of sustainability concept into the university culture. This work described some of the failures and successes experienced within participatory approaches in campus sustainability initiatives, and bring a set of critical success factors that can help to incorporate the dimensions of participation into sustainability assessment. The outcomes offer empirical proof to some of the features related to stakeholder engagement, and connect higher education for sustainable development to empowerment and capacity building. A better integration of the dimensions of participation into sustainability assessment practices can help in defining and establishing participatory approaches on institutional level and promoting a culture of participation in the transition to sustainable universities.

Finally, it will be described a comprehensive study which represent a review regarding the sustainable university [19]. This study, internet based, is split in two components: sustainability implementation methods and assessment tools. This research underlines two sustainability management systems. In fact, two models used to implement the environmental management systems (EMS): the ISO 14001 standard and the environmental management accounting system (EMAS) regulation are presented. For these two models, the similarities found are the advantages of having a systematized management system, either by using an EMS or being the sustainability management systems (SMS) itself; the need to address environmental issues and putting special attention on the use of resources, especially energy, on campus buildings; the university's responsibility of teaching and promoting research activities on sustainability. In conclusion, both models are designed to address a sustainability policy within all four university dimensions-education, research, campus operations and community outreach.

\section{Strategic sustainability of the academic environment}

In many articles, scientific papers or books is stated a key general question: What can higher education leaders, faculty and students do to implement sustainable development in their institutional vision, mission and values statements, their strategic plans and their organizational culture? [10].

In many countries, sustainable development strategies are not legally established, officially through a legislative (parliament, government, etc.). However, in some countries, there is a legal mandate for sustainable development strategies at the parliamentary level. In the EU, for example, there is a need to integrate sustainability issues into Union policies (Article 6 of the EU Treaty, the decisions of the EU Cardiff meeting). The institutional framework responsible for developing, approving and implementing the strategy varies from one country to another, but anyway, environmental bodies (ministries, government agencies, training centers on specific issues, etc.) have begun to play a role bigger. Sustainable strategic management implies, as is declared in Ref. [16], additionally to establishing long-term objectives that are compatible with those on short and medium term, the application of a set of effective principles and criteria, validated internationally, such as

- Integrated management is the principle that involves the unitary approach of production, processing, transport, distribution, use and storage processes, taking into account the life cycle of products and technologies, stakeholder engagement, inter-institutional coordination, optimization processes for the best use of resources;

- Inter-generational equity is a "sine qua non" requirement that the present generation has the right to use and benefit from land resources with the obligation 
to take into account the long-term impact of its activity and to support the resource base and the global environment for the benefit of future generations;

- The life-cycle approach of goods, services and technologies assesses the environmental consequences generated by the economic effects related to the different stages of processing and marketing products;

- Prevention involves reducing the damage to human health and natural capital in relation to the phenomena and economic processes that could be prevented by investments and costs of modernization, repair, treatment or compensation;

- Substitution involves the replacement of inefficient products and services that are highly resource-intensive, with more efficient and less environmentally friendly and less harmful environmental impacts;

- Public participation implies unrestricted access to environmental information, with certain justified exceptions (confidential business information), the public's right to take part in environmental decisions and to take account of their consequences, the ability to react to the parties involved stakeholders) from civil society, the right to know potential environmental risks in time;

- The principle of good governance requires state authorities and institutions to carry out their work transparently, efficiently and honestly, under conditions of preventing and penalizing pollution and promoting environmental protection and

- Public-private partnerships are based on direct, inter-institutional and intra-institutional cooperation between stakeholders represented by public authorities and institutions, NGOs, groups and industrial firms, networks and business people who together can obtain, by aggregating their own expertise and efficiency, a higher added value for the sustainability of economic growth at macro and microeconomic levels.

From this perspective, universities can develop a successful sustainable strategy if they conform to the guidelines presented by T. Ellis' $4 \mathrm{C}$ perspective, according to $[1,20]$. Sustainability strategy for universities must have a Clear goal, which means that those who develop the strategy must select the environmental and social activities that correspond to the environmental and social competences of the university, according to their mission and charter, and which reflect culture, values, its challenges and its overall strategy. Then the university has to engage in strategic Changes. This means that changes need to be made in structures, processes, performance and quantification systems to support the effort to win sustainability, and they must be found in improving communication, employee performance and designing leadership development programs in order to encourage the creation of sustainable value, thinking, skills and practices in this direction. The third feature of the sustainability strategy is Creation. Sustainable creation also involves collaborating with outsiders by inviting them to become strategic partners in the innovation process in all aspects. Last but not least, clear Communication, openness and transparency regarding both successes and failures in relation to people inside and outside the university to build trust and mutual understanding can be considered the fourth feature of the sustainability strategy, this is critical for the university's sustainable success. 
The sustainable university needs to be interactive if it wants to collect potential ideas and feedback from people outside it, and make sustainable adjustments to the strategy in line with them and, also, be student-oriented to collect feedback from students which help universities to generate a sustainable strategy for a period as long as possible.

A key strategic component of the continuous process of improving sustainability is represented by innovation. However, this aspect is very well represented in universities because both didactic and research processes are the basis for innovation. The innovation within universities is related to many issues but the challenges of present days are related to innovative tools to quick skills transfers to the students and innovative learning methods to increase and update the knowledge level of the future graduates, because in time, the labor markets are changing the requirements for the jobs and therefore the potential candidates need to demonstrate that they are qualified and prepared to get these jobs.

A pillar of the sustainability strategy in the academic environment is about discovering and promoting entrepreneurship. In the following paragraph, it will be mentioned relevant aspects regarding the promotion of the entrepreneurial concept in universities and the link with the sustainable university.

\section{Entrepreneurial education versus entrepreneurial university}

In November 2012, the European Commission published the Communication entitled "Rethinking education: investing in skills for better socio-economic results". This policy initiative underlines the fact that "twenty-first century competences" requires efforts to develop transversal skills such as entrepreneurship and highlights "the ability to think critically, take initiative, solve problems and collaborate." These "entrepreneurial skills" should be given particular attention as they not only contribute to concrete entrepreneurial activity but also increase the employability of young people.

Entrepreneurial skills presuppose active methods by which students are determined to give free rein to creativity and the spirit of innovation. Entrepreneurship skills and competences can only be acquired or formed through practical and real-life learning experiences, including the concept of "learning by doing". Entrepreneurial skills can be taught in all subjects as well as in separate subjects. In order to ensure the real pull of entrepreneurial education, it is necessary to achieve learning outcomes related to entrepreneurship; it is also necessary to use assessment methods as well as relevant quality assurance procedures at all levels of education. These should be designed to help students make progress in acquiring knowledge, skills and entrepreneurial attitudes.

A useful method in learning entrepreneurial knowledge is the concept of simulated enterprise. Simulated enterprise represents an innovative and interactive teaching method. Simulated enterprises are created in the same manner as the real companies. In fact, process and activities are simulated in a virtual network, by using the real economic, social and legal rules, applied to each country.

Today, the entrepreneurial university integrates economic development as a function of teaching and research. Creating an entrepreneurial culture will encourage creativity and innovation, using intellectual capital, the most important asset in a university. In this respect, universities need to develop their ability to innovate, recognize and create opportunities, teamwork, risk-taking and respond to challenges. In this respect, it is necessary to encourage and support the creation of collaborative relations with other academic institutions as well as with the business and industry and the initiation of joint projects. 
In connection with the academic environment, realities tell us that we are confronted in a competitive arena. Competition is manifested not only to obtain funding sources for the education and research process, but also to attract the best students, create the best faculties, and above all for the best ideas. The direct beneficiaries of the universities are the students. In this respect, their role as well as their involvement in promoting the principles of sustainable development at the level of the whole society has to be emphasized and need to be fully supported by any decision-maker, responsible or manager.

Also, it is important to underline that the model regarding the Entrepreneurial University has been included in many works and all of these described the approach in different terms such as University Technological Transfer, Innovative Universities and Market Universities [21]. On the other hand, some other works include the issues of effectiveness of teaching the entrepreneurship and holding the special trainings in the Entrepreneurial Universities [21, 22].

Another problem concerns a poor connection, in many cases, in terms of cooperation between universities and businesses in the field of education. This confirms the weak final results of the partnership and the issue of an effective mandatory leader in these situations. Thus, the leaders must provide that "both expertise and new perspectives must be available in the work place, both academic and personal diversity must be present in the institution of higher learning, innovative opportunities must be identified and/or put into practice, time must be made available for reflection (incubation period) and creativity must be followed up by convergent thinking through priorities and choice" [21,23].

\section{The role and the involvement of students in a sustainable university}

The students have to manifest and act as agents of change within universities. In order for students to become agents of successful change in the sustainable development of universities and society, they must have:

1. the knowledge of environmental, economic and social issues related to sustainable development-understanding;

2. a system of values and its own conception to support and measure the actions of a change agent-motivation and

3. the skills required by the change agent-skills.

On the other hand, opportunities and student campus commitments reflect a deep commitment to sustainability through these institutional practices such as new student guidelines, scholarships, job counseling related to community services, sustainability and/or aspects of justice. Also, higher education institutions need to prepare students for careers that are environmentally oriented and/or sustainable; to prepare those who direct students to increase their education and information efforts in the campuses of universities; to train them adaptively for the new demands on the labor market and for the professions and crafts of the future.

In addition, the campus, as a laboratory for learning sustainability and developing related skills, offers models and opportunities for practicing change in student behavior. The activities carried out in the Campus by and for students should be geared toward reducing the "environmental footprint" of the institution. There are plenty of examples of water and energy conservation, carbon dioxide reduction practices, sustainable building construction and targeted renovation, promoting 
clean and healthy food, reducing paper consumption, selective waste collection and so on. Last but not least, students must be the first persons to spread the lessons and the content of the concept of sustainable development, with even the civic and social responsibility of promoters of this concept.

\section{Sustainable tools and practices in academic management}

Everything that the deciders in the academic area think and propose must relate to the major themes and challenges of this century and of this beginning of the millennium:

- the analysis of the efficiency of the use of depleting mineral resources and the potential of the Romanian extractive industry, regarding Romania's energy independence;

- analyzing sustainable solutions for environmental protection and conservation, using clean fuels and technologies, as well as promoting innovative management measures in community management;

- analyzing and developing innovative management tools useful for sustainable resource management and

- promoting innovative educational tools needed to improve the qualifications, skills and expertise of graduates, which will contribute directly to increasing the level of absorption in the labor market, in the context of a knowledge-based economy and a new type of society, the information society, which generates new challenges for occupations, professions or craftsmanship of the future.

In treating properly and solving adequately all these major themes and challenges, by using classical tools and practices, those means that are defining the rapid acquiring knowledge processes and generating adaptive skills for future jobs can be listed [24]:

- Enterprises' piloting: a set of activities undertaken by the respective company management to achieve the mission of the enterprise activity by using welldefined strategies and objectives to ensure the provision of activities of different beneficiaries in terms of quantity, quality and certain terms stipulated in the contract, activities that take place in competition with the activities of other companies;

- Management simulation IT tools: creates competitive situations of economic and management (strategic management) and contribute substantially to the development of participants' ability to diagnose the economic and managerial nature competitive, to substantiate and implement strategic and tactical decisions to be taken in conditions of risk or uncertainty, which is required in terms of rolling out a new business in the real world and wants to be a successful alternative to initiate business and to prepare students for future successfully trained managers to deal with increasingly fierce competition;

- Simulated enterprise: a learning method, an innovative and interactive tool with great student demand. The proximity of the business environment can be achieved by integrating this innovative method into the education 
system with the help of companies that can find a "clone company" within these simulated enterprise laboratories. Thus, in a virtual environment, companies that exist in the real economy can operate. They "borrow" to the simulated enterprise their own identification elements, object of activity, organizational structure, suppliers, customers, market, while the real company's officers can get involved directly in guiding the students alongside the teachers involved in the operation of the virtual company. This learning solution develops skills and abilities for prospective graduates through which they can integrate more easily and quickly into work. In addition, collaboration between academia and business can increase the interest of companies in their involvement in improving the practical training of their future employees and

- Business incubators: an entity that aims at creating a favorable and sustainable environment for start-ups and innovative companies with growth potential. The concept of university incubators is still at the beginning and additional steps need to be added, by generating special, efficient and business-friendly entities that could provide prerequisites for the creation and development of these incubators [25].

On the other hand, based on the own expertise and related to the specific projects [26], the main practices in the field of sustainable development at the academic level should focus on:

a. Research on technical and economic optimization in the energy sector.

At this time, each country tries to maximize its chances of accessing energy sources that give them the chance to get as much energy independence as possible. Since, in most cases, no new mineral resources have been found and, in addition, their excessive use has led to a clear deterioration in air, water and soil quality, but has also led to an increase in the greenhouse effect, more and more countries are concerned about minimizing/optimizing energy production costs, energy efficiency, energy intensity reduction, investigation of potential and alternative energy sources. The oil crisis, materialized by a permanent and major drop in crude oil prices in recent years to a historical level of approx. 27USD/barrel of crude oil on January 20, 2016, had influences throughout the world economy. Realities say that the current model of civilization supports energy consumption predominantly from exhausting natural resources. In addition, there are a number of factors that can create or stimulate a crisis in the energy field:

1. there is an unequal distribution of primary energy resources that divides the world into countries rich in natural resources and countries without such resources;

2. the pressure generated by the major transnational corporations operating in the oil and gas industry which, through their financial strength, can have important influences on various resource, commodity and service markets with major effects in the global economy;

3. industrial and economic development strategies of developed countries to access the various primary energy resources of less developed countries and 
4. the environmental impact generated by the significant consumption of fossilbased resources, as the energy sector is the transport industry's main agents of pollution of all kinds that can create climate change as well.

At the same time, we need to be aware that the evolution of human society will increase consumption of any kind, including energy, in particular. This must be complemented by other trends that will be highlighted in the future: technical and technological development involving the automation and robotics of processes of any kind, the increase of urbanization, the shift of the preoccupations in the investigation and the use of alternative energy sources on the background of the dramatic exhaustion of conventional energy resources, the need to research and finance energy-efficiency projects.

b.Innovative tools for increasing the competitiveness of companies and entrepreneurial skills training.

Another direction of concern in the field of scientific research is to analyze and propose tools and measures in the field of innovation to help increase the economic competitiveness of firms and to train professionals to promote an entrepreneurial spirit. The training and assessment of entrepreneurial skills can help to develop the business environment, create more small- and medium-sized enterprises, create jobs and, implicitly, improve macroeconomic performance.

c. Effective use of existing IT applications and design of particular IT solutions useful to sustainable development.

In this respect, it is necessary to know and use the particular IT applications that cover various topics in order to generate solutions in the spirit of the principles of sustainable development such as money savings, low energy consumption, minimum specific consumption of material resources, reduction of pollution levels, efficiency increased economic efficiency, improved energy efficiency, etc. These applications are licensed by universities and are used in laboratories specific to the topics addressed, in order to familiarize students with the issues related to some disciplines that incorporate and approaches in the sphere of sustainable development.

d.Building effective project proposals and national and international grants to obtain funding for applied research.

Topics that can be covered by the projects relate to various themes but with a major impact on society:

- the efficiency of the use of depleting mineral resources;

- developing innovative management tools useful for sustainable resource management;

- easy transition from school to active work and a successful career;

- creating and developing specific competencies in certain areas;

- innovation in the SME area; 
- innovative management measures in community management and

- promoting sustainable solutions for environmental protection.

The experience gained in these projects is the prerequisite for building new proposals for project applications with a higher quality level and with increased relevance, creating the possibility of obtaining the funds necessary for carrying out the activities proposed in these projects.

All these opportunities should be used in the idea of integrating sustainable development into future project proposals on the three defining components: environment (by protecting the environment and the proper use of natural resources), society (focusing on improving living standards, improving health of the population and raising awareness of the new role that man must have in this information society) and economics (in terms of economic competitiveness in general and increased productivity in particular). The idea of sustainability of any project from the perspective of sustainable development is a necessary issue to treat through which findings and outcomes can help to develop new ideas, solutions and even future projects to support future generations to have a better life.

Also, in the last two decades, universities adapt their main mission in order to respond adequately to the challenges arise from the society evolution toward the future. In this regards, there are some fashionable approach that aims to fulfill the objectives and the stakeholders' wishes, which define the principles of sustainable development. First of all, universities are being increasingly considered as a source for creation of high-technology firms. Based on the relation between science, technology and university spinoffs, academic entities are moving from teaching, training and basic research to a much active and advanced role by creating spinoffs and develop academic entrepreneurial skills and abilities [27]. In this light, universities decided to invest in labs equipment and applied research by developing and commercially exploit their technic and technological inventions. University spinoffs transform these technic and technological inventions into a successful business venture. The process of establishing the spin-off as a new corporation involves transferring the intellectual property rights to the new corporation or giving the latter a license on this intellectual property [28]. On the other hand, according to [29], universities do not have a proper set of competencies in order to create and support spin-off. Therefore, universities need to set-up specific structures (technology transfer office and business incubators) and use new organizational practices for facilitate academic entrepreneurship. In this regard, the universities' internal processes are critical for the spin-off efficiency. For instance, internal processes could eliminate poor initiatives and also, support promising initiatives by using different services such as financing, support in the patenting process or specific guidance. Universities, even they have rules and regulations, could use different levels of freedom in design internal processes about spin-offs. Of course, each university has its own approach in terms of how it processes its structure. In the same manner, the management practices used by universities are not all alike. In fact, the study explored the relationship between management practices and the performance of academic spin-offs. A first conclusion, based on this study, underlined the fact that by having the control on the effects of management practices over academic spinoffs is a mean of control for the universities' internal processes. Another conclusion is relevant for the policy implications for universities and policy-makers "universities should be more aware of the management practices they adopt and how these practices fit into their internal organization".

A means of maintaining links between the academic environment and the business environment is provided by academic consulting [30]. Academic consulting 
is aimed to provide guidance, expertise or professional advice directly to start-ups. Academic consulting allows universities to train properly students out of the curriculum in a focused manner on very well-defined topics. The networks thus created can contribute to the implementation of new sustainable management practices related to academic management (e.g. the realization of internships within the counseling entities).

Another option, considered at the moment, a fashionable practice in sustainable academic management refers to the Student Entrepreneurship Society within the universities administration. Student entrepreneurship society (SES) is considered a mechanism for supporting, developing and encouraging entrepreneurship in the university environment, especially among students and graduates. These SES entities carry out different activities and tasks like stimulating and promoting entrepreneurship approach; organizing training courses for the development of the entrepreneurial skills; supporting the start-ups registration; organizing start-up simulations and set-up business ideas; organizing competitions to attract funding for the best projects; incubate start-ups; coordinating the activities of all business incubators, simulated enterprises, and other entrepreneurial entities; and guidance and support in drawing up business plans.

\section{Conclusion}

Universities represent the structures that need to promote and enforce the successful implementation of as many sustainable development principles as possible. Academic decision-makers need to adapt the curriculum to study each program; use innovative means and methods in the didactic and research process; identify effective solutions for using natural resources; protect and preserve the environment; promote and implement the concept of energy saving; create intelligent solutions to prevent and manage natural disasters; and rapidly generate skills tailored to the new jobs. The successful combination for the successful universities is adaptive change to the new forthcoming challenges by using proper sustainable academic management practices.

Universities have to educate future leaders of corporations and their employees to convince them that the adoption of responsible business strategies in terms of sustainability is a "win-win-win proposal for companies, environment and the society" [31].

This chapter has also some limitations, since it describes the author point of view. Since the specialized literature on issues such as sustainable development, education in sustainable development, sustainable university, entrepreneurial university and sustainable management practices, has an impressive volume and is rich in many book titles, articles and scientific papers, empirical studies and complex research, it is almost impossible to make a comprehensive review which includes all the professional views and opinions. Therefore, the chapter includes a review with some of these approaches, by mentioning some of the important works and studies, and not necessarily containing all the authors who wrote in this vast and complex field. Also in the paragraphs related to the current study, professional opinions and ideas, based on the author's experience, in using specific tools of sustainable management practices, used in some activities that are defining the academic environment functionality such as specific training courses, training sessions on the topic of entrepreneurship, design and implementation of complex projects, organizing and supervising the internships, academic consulting, support and guidance for the business incubators, using of innovative methods such as the simulated enterprise in teaching and research, cooperation with the business environment, collaborative research and so on are expressed. 


\section{Conflict of interest}

I declare no 'conflict of interest'.

\section{Author details}

Cătălin Popescu

Petroleum-Gas University, Ploiesti, Romania

*Address all correspondence to: cpopescu@upg-ploiesti.ro

\section{IntechOpen}

(C) 2019 The Author(s). Licensee IntechOpen. This chapter is distributed under the terms of the Creative Commons Attribution License (http://creativecommons.org/licenses/ by/3.0), which permits unrestricted use, distribution, and reproduction in any medium, provided the original work is properly cited. (cc) BY 


\section{References}

[1] Danciu V. The sustainable company: New challenges and strategies for more sustainability. Theoretical and Applied Economics. 2013;9586:p7-p26

[2] Samuelson R. Causes of the crisis. Real Clear Politics. 2012;19

[3] Palley T. From Financial Crisis to Stagnation: The Destruction of Shared Prosperity and the Role of Economics. Cambridge University Press; 2012

[4] What is Education for Sustainable Development. Available from: https:// en.unesco.org/themes/educationsustainable-development/what-is-esd [Accessed: 2019-02-03]

[5] Van den Branden K. Sustainable education: Basic principles and strategic recommendations. School Effectiveness and School Improvement. 2012;23(3):1-20

[6] Tilbury D, Wortman D. Engaging people sustainability. In: Commission on Education and Communication. Switzerland, Gland: IUCN; 2004

[7] von Hauff M, Kleine A.

Methodological approach for the systematization of the areas of action and the indicators of a sustainability strategy-The integrative sustainability triangle. International Journal of Environment and Sustainable Development. 2006;5(4):372-394

[8] Ikerd J. The Essential of Economic Sustainability. Virginia, Sterling: Kumarian Press; 2012

[9] Cortese A. Towards a sustainable university. Review of designing the New American University. In: Crow M, Dabars W, editors. Great Transition Initiative. June 2016. Available from: http://www.greattransition.org/ publication/towards-a-sustainableuniversity [Accessed: 2019-05-14]
[10] Blessinger P, Sengupta E, Makhanya M. Higher education's key role in sustainable development. In: University World News Newspaper, 07. September 2018. Available from: https://www.universityworldnews.com/ post.php?story $=20180905082834986$

[Accessed: 2019-05-18]

[11] Corcoran PB, Wals AEJ. Higher Education and the Challenge of Sustainability. Problematics, Promise, and Practice. Kluwer Academic Publishers; 2004. DOI: 10.1007/0-306-48515-X

[12] Nolim J, Brorstrom B. The University of Boras as a Sustainable University, Science for the Professions Report Series, Report no. 2015:31, Responstryck, Borås; 2015. Available from: https://www.hb.se/Global/ HB\%20-\%20xternt/Forskning/ Sustainable\%20university\%20webb.pdf [Accessed: 2019-05-17]

[13] Sterling S, Maxey L. In: Sterling S, Maxey L, Luna H, editors. The Sustainable University: Progress and Prospects. London: Routledge; 2013

[14] Grecu V, Ipina N. The sustainable university-A model for the sustainable organization. Management of Sustainable Development Sibiu, Romania, 2014;6(2). DOI: 10.1515/ msd-2015-0002. Available from: https:// www.degruyter.com/downloadpdf/j/ msd.2014.6.issue-2/msd-2015-0002/ msd-2015-0002.pdf [Accessed: 2019-05-18]

[15] Jones P, Selby D, Sterling S. More than the sum of their parts? Interdisciplinarity and sustainability. In: Jones P, Selby D, Sterling S, editors. Sustainability EducationPerspectives and Practice Across Higher Education. Earthscan. Chapter 3, 2010. pp. 39-54 
[16] Denes C, Radu S. Resource Management and Sustainability. Centre of Competence, Lucian Blaga University of Sibiu, Imbunatatirea Managementului Universitar; 2011. Project POSDRU/ 2/1.2/S/4

[17] Velazquez L, Munguia N, Platt A, Taddei J. Sustainable university: What can be the matter? Journal of Cleaner Production. 2006;14(9-11):810-819

[18] Disterheft A, Caeiro S, Azeiteiro UM, Filho WL. Sustainable universities-A study of critical success factors for participatory approaches. Journal of Cleaner Production. 2015;106:11-21. DOI: 10.1016/j. jclepro.2014.01.030

[19] Amaral LP, Martins N, Gouveia JB. Quest for a sustainable university: A review. International Journal of Sustainability in Higher Education. 2015;16(2):155-172. DOI: 10.1108/ IJSHE-02-2013-0017

[20] Tania E. The New Pioneers: Sustainable Business Success through Social Innovation and Social Entrepreneurship. John Wiley \& Sons; 2010

[21] Gagnidze I. Entrepreneurial university model-Short literature review. Model-based governance for smart organizational future BSLAB-SYDIC. In: International Workshop-Roma. Book of Abstracts. January 2017. DOI: 10.13140/ RG.2.2.20373.22241

[22] Munir ZA, Idrus S, Shukur SAM, Ithnin R, Mohamad SS. The effectiveness of entrepreneurial motivational training programme among university students. International Journal of Social Science and Humanity. 2015;5(5):487-490

[23] Oyugi JL. Entrepreneurial and innovative leadership: Evolution towards a better higher institution of learning. Journal of Educational Policy and Entrepreneurial Research. 2015;2(8):18-27

[24] Popescu C, Oprea MC. Innovative methods that facilitate the smooth transition from education to labour market-case study Romania. In: Proceedings of 21th IBIMA Conference on Vision 2020: Innovation, Development Sustainability, and Economic Growth, 27-28 June, 2013; Vienna, Austria. 2013. pp. 1039-1045

[25] Udoh Iboro P, Olaoye A, Oloruntoba A, Sunday DK. University incubators: A pathway to entrepreneurial society. Covenant Journal of Entrepreneurship. 2018;2(2):24-33

[26] Popescu C. Research and contribution to the development of managerial tools for the sustainable management of conventional and non-conventional resources of energy and for the innovation in education and research [habilitation thesis]. Technical University of Cluj-Napoca; 2016

[27] Lerner J. The university and the start-up: Lessons from the past two decades. The Journal of Technology Transfer. 2004;30(1-2):49-56. DOI: 10.1007/s10961-004-4357-8

[28] Pattnaik PN, Pandey SC. University spinoffs: What, Why, and How? Technology Innovation Management Review. December 2014. Available from: www.timreview.ca

[29] Bennasi M, Landoni M, Rentocchini F. University Management Practices and Academic Spin-offs. Working paper 11/2017. Universita Degli Studi di Milano, Dipartimento di Economia, Management e Metodi Quantitativi; September 2017

[30] van Stijn N, van Rijnsoever FJ, van Veelen M. Exploring the motives and practices of university-start-up 
Adaptive Sustainable Academic Management Practices DOI: http://dx.doi.org/10.5772/intechopen.87018

interaction: Evidence from Route 128.

The Journal of Technology Transfer.

2018;43(3):674-713. DOI: $10.1007 /$

s10961-017-9625-5

[31] Willard B. Teaching Sustainability

in Business Schools. Why, What and

How. Green Leaf Pub.; 2004. Available

at: www.greenleafpublishing.com/

content/pdfs/tbswilla.pdf [Accessed:

2016-01-18] 



\title{
Sustainable Agricultural
}

Management Practices and Enterprise Development for Coping with Global Climate Change

\author{
S.M. Fakhrul Islam and Zahurul Karim
}

\begin{abstract}
This book chapter provides an insight into the synthesis of climate change vulnerabilities across various regions of the globe, recent trends, issues and prospects of climate smart agribusiness, the skill, efficiency and sustainable management practices of small and medium enterprises (SMEs) of the globe in the context of climate change, addressing the needs of emerging markets, industries and regional trades through a transformation with development in the areas of technology, value chains, management of environmental and social risk in the supply chains, compliance of food quality and safety regulations, market linkages of smallholders, corporate social responsibility and institutional development. There is a growing concern on food safety regulation and certification as part of sustainable management practices that firms and industries should cope. Sustainable management practices in business prove to be more profitable as they tend to adapt and grow with the changing markets, providing a competitive advantage over other firms. This chapter also focused on the challenges in sustainable business practices as well as suggested a number of development options, institutional and policy issues.
\end{abstract}

Keywords: agribusiness, enterprise development, sustainable management practices, value chain development, climate change

\section{Introduction}

There are growing concerns on the impact of climate change on agribusiness. A number of studies assessed such impact at various country levels and food security challenges [1]. An ever increasing amount of evidence suggests that the continual increase in greenhouse gas emissions is affecting the global climate and altering the local precipitation and temperatures [2]. Climate change is expected to produce significant effects on global water resources and freshwater ecosystems [3, 4]. The effects and intensity of climate change will vary from region to region [5]. Impact of climate on global water storage capabilities and hydrologic functions will have significant implications on agricultural production and food processing sector. 
The impacts of climate-related extremes include alteration of ecosystems, disruption of food production and water supply, damage to infrastructure and settlements and consequences human well-being. For countries at all levels of development, these impacts are consistent with a significant lack of preparedness for current climate variability in some sectors [6].

Adaptation experience is accumulating across regions in the public and private sector and within communities. Climate variability and extremes have long been important in many decision-making contexts. Monitoring and learning are important components of effective adaptation.

This study was carried out with the objectives to examine and assess climate change vulnerabilities across various regions, climate smart agribusiness, development of small and medium enterprises (SMEs), efficiency of SMEs, sustainable management practices, value chain development, and compliance of food safety regulations of World Trade Organization (WTO). It also identified challenges and development options. The study is completed based on extensive review and analysis of relevant information and literature available across various regions of the globe.

\section{Synthesis of climate change vulnerabilities across various regions}

Continuous increase in greenhouse gas emissions is affecting the global climate that altering the local precipitation, temperatures and atmospheric composition $[7,8]$. According to IPCC World temperature, humidity and precipitation will change significantly by 2030 and 3050 due to climate change [9]. There is already an increase in the frequency and intensity of extreme events, such as drought, heavy rainfall and subsequent flooding and high maximum temperatures. The effects and intensity of climate change will vary from region to region [10].

Climate change vulnerability refers to the state of susceptibility to harm from exposure to climate hazards, and the ability of the sub-national territory or region to cope with, and recover from, such exposure as well as manage incremental and long-term change in climate. Climate change vulnerability encompasses how much the sub-national territory (the environment, society, and economy) will be affected or how sensitive it is to the change. Information on climate change vulnerabilities can be used for investment decisions and prioritization of actions and adoption of sustainable agribusiness management practices. Table 1 presents information on regional vulnerability and impact of climate change and Figure 1 illustrates potential impacts associated on the degree of climate change.

Evidence showed that global climate changes found to have considerable impacts on natural resources and livelihoods across different regions of the globe. The observed changes in hydrological systems include changing pattern of precipitation and melting snow. As a result quality and quantity of water resources are changing. The size of the glaciers is reducing due to global warming climate change. It is affecting downstream water resources. The high latitude regions and in high-elevation regions are suffering due to global warming change Productivity and growth of many fresh water and marine species have been affected as a result of climate [6].

A large number of studies covering a wide range of regions and crops identified negative impacts of climate change on crop yields. Climate change has negatively affected wheat and maize yields for many regions. Compared to wheat, the effects of climate change on yield of rice and soybean is less across regions. It is also observed that during occurrence of severe climatic events like flood and drought in major producing regions prices of food grain rises up and thus market also become much sensitive to climate extremes [6]. 


\begin{tabular}{|c|c|}
\hline Regions & Vulnerability and impact of climate change \\
\hline \multirow[t]{5}{*}{ Africa } & $\begin{array}{l}\text { Most vulnerable continents to climate variability and change because of } \\
\text { multiple existing stresses like poverty, political conflicts, and ecosystem } \\
\text { degradation and low adaptive capacity }\end{array}$ \\
\hline & $\begin{array}{l}\text { - By 2050, } 350 \text { to } 601 \text { million people are projected to experience increased } \\
\text { water stress }\end{array}$ \\
\hline & $\begin{array}{l}\text { - Climate variability and change is projected to severely affect agricultural } \\
\text { production and access to food }\end{array}$ \\
\hline & $\begin{array}{l}\text { - Toward the end of the twenty-first century, projected sea level rise will } \\
\text { likely affect low-lying coastal areas with large populations }\end{array}$ \\
\hline & - Climate variability and change can negatively impact human health \\
\hline \multirow[t]{5}{*}{ Asia } & $\begin{array}{l}\text { - Glaciers in Asia are melting at a faster rate and increasing the risks of } \\
\text { flooding and rock avalanches from destabilized slopes }\end{array}$ \\
\hline & $\begin{array}{l}\text { - Climate change is projected to decrease freshwater availability in central, } \\
\text { south, east and southeast Asia, particularly in large river basins. This } \\
\text { decrease could adversely affect more than a billion people by the } 2050 \text { s }\end{array}$ \\
\hline & $\begin{array}{l}\text { - Increased flooding from the sea and, in some cases, from rivers, threatens } \\
\text { coastal areas, especially heavily populated delta regions in south, east, } \\
\text { and southeast Asia }\end{array}$ \\
\hline & $\begin{array}{l}\text { By the mid-twenty-first century, crop yields could increase up to } 20 \% \text { in } \\
\text { east and southeast Asia. In the same period, yields could decrease up to } \\
30 \% \text { in central and south Asia }\end{array}$ \\
\hline & $\begin{array}{l}\text { - Sickness and death due to diarrheal disease are projected to increase in } \\
\text { east, south, and southeast Asia due to projected changes in the hydrological } \\
\text { cycle associated with climate change }\end{array}$ \\
\hline \multirow[t]{5}{*}{ Europe } & $\begin{array}{l}\text { - Future impacts of climate change are projected to negatively affect nearly } \\
\text { all European regions. Many economic sectors, such as agriculture and } \\
\text { energy, could face challenges }\end{array}$ \\
\hline & $\begin{array}{l}\text { In southern Europe, higher temperatures and drought may reduce } \\
\text { water availability, hydropower potential, summer tourism, and crop } \\
\text { productivity }\end{array}$ \\
\hline & $\begin{array}{l}\text { - In central and eastern Europe, summer precipitation is projected to } \\
\text { decrease, causing higher water stress. Forest productivity is projected to } \\
\text { decline. The frequency of peat land fires is projected to increase }\end{array}$ \\
\hline & $\begin{array}{l}\text { - In northern Europe, climate change is initially projected to bring mixed } \\
\text { effects, including some benefits such as reduced demand for heating, } \\
\text { increased crop yields, and increased forest growth. However, as climate } \\
\text { change continues, negative impacts are likely to outweigh benefits. }\end{array}$ \\
\hline & $\begin{array}{l}\text { These include more frequent winter floods, endangered ecosystems, and } \\
\text { increasing ground instability }\end{array}$ \\
\hline \multirow[t]{4}{*}{ Latin America } & $\begin{array}{l}\text { By mid-century, increases in temperature and decreases in soil moisture } \\
\text { are projected to cause savanna to gradually replace tropical forest in the } \\
\text { eastern Amazon basin }\end{array}$ \\
\hline & $\begin{array}{l}\text { In drier areas, climate change will likely worsen drought, leading to } \\
\text { salinization and desertification (land degradation) of agricultural land. } \\
\text { The productivity of livestock and some important crops such as maize } \\
\text { and coffee is projected to decrease, with adverse consequences for food } \\
\text { security. In temperate zones, soybean yields are projected to increase }\end{array}$ \\
\hline & $\begin{array}{l}\text { - Sea level rise is projected to increase risk of flooding, displacement of } \\
\text { people, salinization of drinking water resources and coastal erosion in } \\
\text { low-lying areas }\end{array}$ \\
\hline & $\begin{array}{l}\text { - Changes in precipitation patterns and the melting of glaciers are pro- } \\
\text { jected to significantly affect water availability for human consumption, } \\
\text { agriculture, and energy generation }\end{array}$ \\
\hline
\end{tabular}




\begin{tabular}{ll}
\hline Regions & Vulnerability and impact of climate change \\
\hline North America & Warming in western mountains is projected to decrease snowpack, \\
increase winter flooding, and reduce summer flows, exacerbating & competition for over-allocated water resources \\
- & Disturbances from pests, diseases, and fire are projected to increasingly \\
affect forests, with extended periods of high fire risk and large increases \\
in area burned \\
- Crops that are near the warm end of their suitable range or that depend \\
on highly utilized water resources will likely face major challenges \\
- Increases in the number, intensity, and duration of heat waves during the \\
course of the century are projected to further challenge cities that cur- \\
rently experience heat waves, with potential for adverse health impacts. \\
Older populations are most at risk \\
- Climate change will likely increasingly stress coastal communities and \\
habitats, worsening the existing stresses of development and pollution \\
\hline Source: Synthesis from [11].
\end{tabular}

Table 1.

Regional vulnerability and impact of climate change.

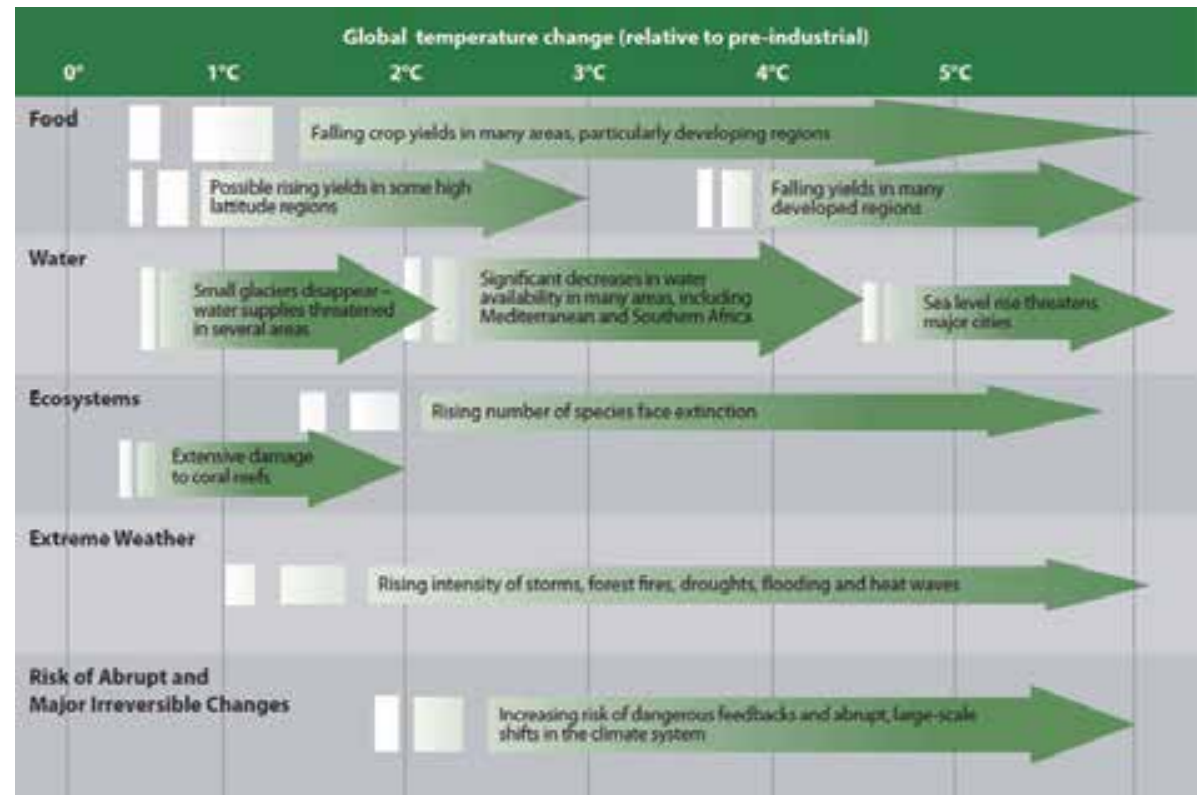

Figure 1.

Potential impacts associated on the degree of climate change. Source: [12].

\section{Climate smart agribusiness}

There is growing concern on sustainable development of a climate smart agriculture in order to increase its productivity and farmers' resilience to climate change as well as reduce its negative contribution through minimizing greenhouse gas emissions and increasing carbon storage on crop land [13].

An agribusiness could be climate-smart which follows an approach to help guide actions to transform and reorient agricultural systems to effectively and sustainably support development under a changing climate. Agribusiness has a wider field of operations such as production and marketing of crops, livestock, fisheries, 
agro-forest, processing of agricultural produces, value chain development, supplies of inputs and machineries. Climate smart agribusiness (CSA) evolves from a process of identifying which production systems and enabling organizations are better suited to respond to the challenges of climate change for specific locations to maintain and enhance the capacity of business in a sustainable way. Three main objectives of CSA are discussed below:

\subsection{Developing opportunities to reduce greenhouse gases emissions compared to expected trends}

Agribusiness is a major source of greenhouse gas emissions (GHG) in the world. On a global scale, all of the world's agriculture accounts for about one quarter of total anthropogenic GHG emissions of the annual human-caused increase in greenhouse gas emissions, in the form of carbon dioxide, methane and nitrous oxide (Figure 2). It contributes to emissions mainly through production of crops, livestock and fisheries, food processing and manufacturing as well as degradation of natural resources.

There is a link with the global climate change with the broad agricultural and energy sectors. Farmers use different forms and amounts of energy to grow food and fibers: transportation fuels, electricity, and industrial chemicals and materials. All of these have some kind of impact on the production of greenhouse gases. Food manufacturing industries also generate carbon dioxide which is around two-third of that generated by agriculture (Figure 3). The trend in emission of carbon dioxide from food manufacturing sector is increasing over the past decades (Figure 4). Non- $\mathrm{CO}_{2}$ emissions from agriculture are projected to increase due to expected agricultural growth.

Agriculture's greenhouse gas emissions can be reduced in several ways. Reducing emission intensity (e.g. the $\mathrm{CO}_{2}$ eq/unit product) through sustainable intensification is one key strategy for agricultural mitigation. The process involves implementation of new practices that enhance the efficiency of input use so that the increase in agricultural output is greater than the increase in emissions [15]. Evidence shows that emission in agriculture can be reduced significantly through adoption of technology of carbon-sequestration. Plants and soils together play a beneficial role for purification air by removing $\mathrm{CO}_{2}$ from the atmosphere and store it in their biomass.

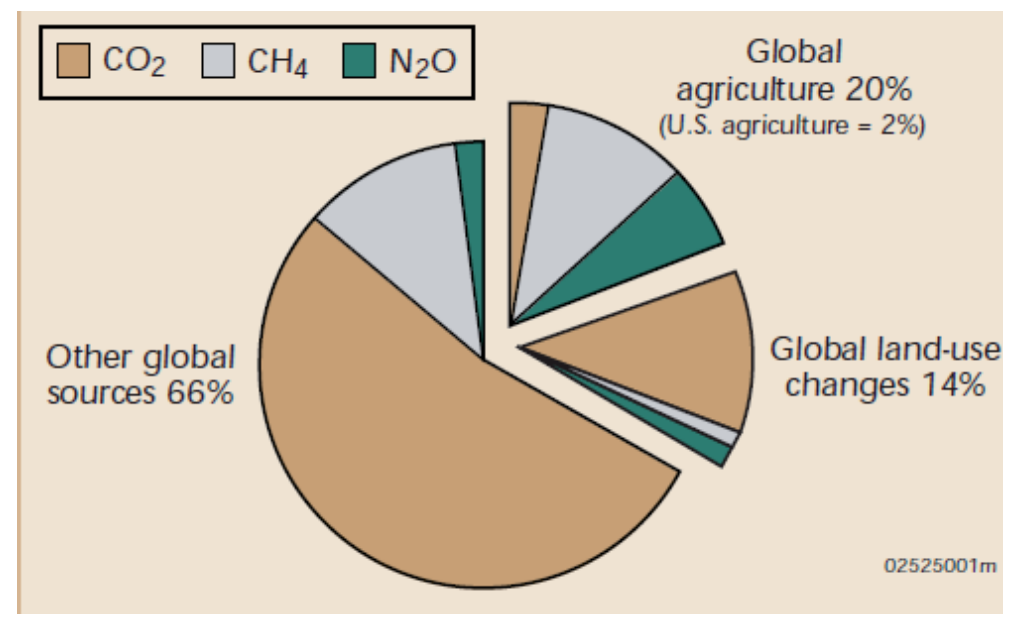

Figure 2.

Source of GHG emissions. Source: [14]. 


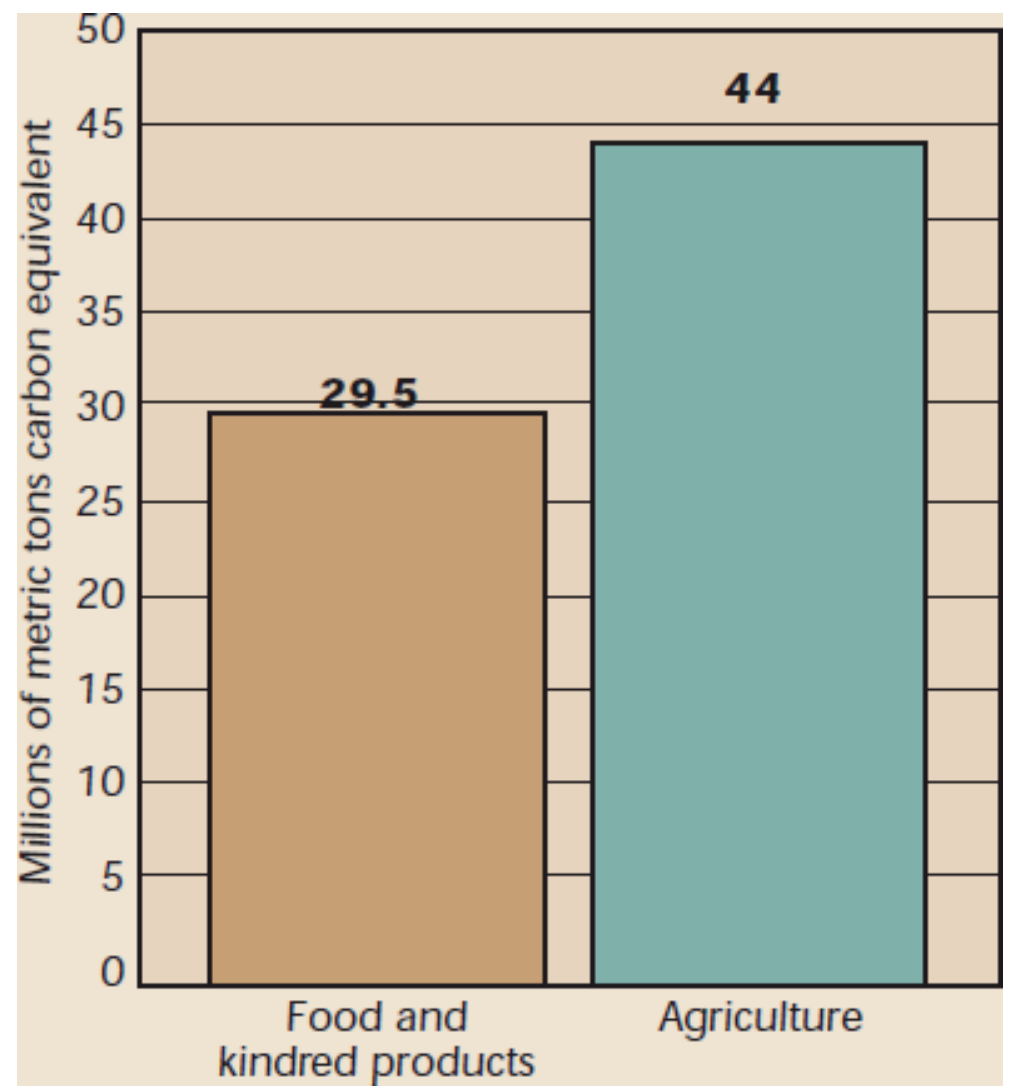

Figure 3.

Emission of GHG from food manufacturing sector. Source: [14].

This is known as the process of carbon sequestration. Integrating agro-forestry with crops and livestock farming and reducing soil disturbances by adopting reduced tillage can help sequestering carbon in agribusiness.

Food processing industries in the globe requires a large amount of fossil energy. There is a high energy demand for thermal processes such as heating, cooking freezing, sterilization, etc. This significantly contributes to the cost of the finished product and to the carbon footprint of the industry. Food processing industries need to adopt technology to improve their systems and processes in order to reduce costs, increase productivity and reduce emission of GHG to mitigate negative

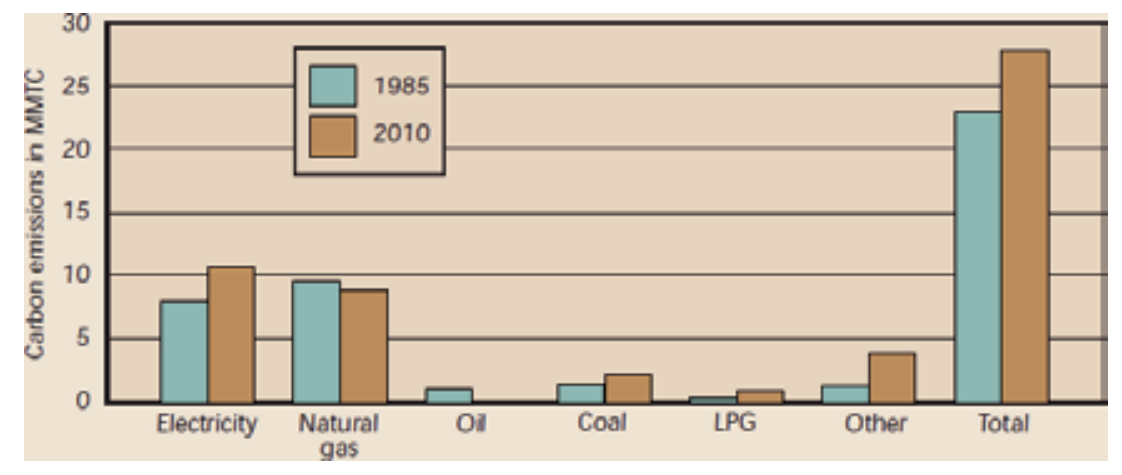

Figure 4.

The trend in emission of carbon dioxide from food manufacturing sector. Source: [14]. 
impact of climate change. Thus climate resilient technologies are thrust areas of interest for the sector for reducing energy consumption and switching to cleaner, alternative renewable energy sources.

\subsection{Building resilience to climate change}

Evidence showed that climate change already had negative impact on agricultural productivity and it is projected to further reduce its productivity by 2030 . Rising temperature, occurrence of flood and drought due to variability in rainfall will reduce crop yield, as well as productivity of livestock and fisheries [16]. It is possible to reduce or avoid the negative impacts of climate change through formulating and implementing effective adaptation strategies. Given the site-specific effects of climate change, together with the wide variation in agro-ecologies and farming system, the effective adaption strategies will vary within countries and regions. The potential adaptation strategy is enhancing the resilience of agroecosystems by increasing ecosystem services through the use of agro-ecology principles and sustainable land management practices, conservation of natural resources and biodiversity. Reducing risk exposure through diversification of production or incomes, and building input supply systems and extension services that support efficient and timely use of inputs and adopting climate resilient stress tolerant crop varieties, livestock breeds and fish and forestry species.

\begin{tabular}{|c|c|c|}
\hline $\begin{array}{l}\text { Elements of climate- } \\
\text { smart agribusiness }\end{array}$ & Sub-system & Mitigation options \\
\hline \multirow{3}{*}{$\begin{array}{l}\text { 1. Management } \\
\text { of farms, crops, } \\
\text { livestock, } \\
\text { aquaculture and } \\
\text { capture fisheries }\end{array}$} & Crops & $\begin{array}{l}\text { Switching varieties or species, changing cropping } \\
\text { calendars, and nutrient management such as micro-dosing, } \\
\text { mulching or organic fertilizers application }\end{array}$ \\
\hline & Livestock & $\begin{array}{l}\text { Improving the quality of pastures and feed, changing herd } \\
\text { management, and specific responses to heat stress }\end{array}$ \\
\hline & Fisheries & $\begin{array}{l}\text { Changes in locations, species and managing temperature } \\
\text { are climate-smart options }\end{array}$ \\
\hline $\begin{array}{l}\text { 2. Landscape } \\
\text { or ecosystem } \\
\text { management }\end{array}$ & $\begin{array}{l}\text { Ecosystem } \\
\text { services }\end{array}$ & $\begin{array}{l}\text { Regulating ecosystem services such as hydrology or } \\
\text { biodiversity, including in the soil, can generate production, } \\
\text { adaptation and mitigation co-benefits. Multiple objective } \\
\text { forest management can generate benefits for food } \\
\text { security, development, adaptation to climate change } \\
\text { (microclimate), water management, soil protection, } \\
\text { agrobiodiversity protection (pollinators) and assist with } \\
\text { carbon storage and greenhouse gas emission reduction. }\end{array}$ \\
\hline $\begin{array}{l}\text { 3. Services } \\
\text { for farmers, } \\
\text { entrepreneurs and } \\
\text { managers }\end{array}$ & $\begin{array}{l}\text { Agriculture } \\
\text { and food } \\
\text { manufacturing }\end{array}$ & $\begin{array}{l}\text { Increasing adaptive capacity of farmers, entrepreneurs } \\
\text { and managers requires increasing climate information } \\
\text { services, such as seasonal forecasts or early-warning } \\
\text { systems, advisory services that link climate information to } \\
\text { agribusiness decisions, and financial services such as credit } \\
\text { and insurance can increase the ability of smallholders to } \\
\text { invest in agribusiness despite increasing climate variability. }\end{array}$ \\
\hline $\begin{array}{l}\text { 4. Changes in the } \\
\text { wider food system }\end{array}$ & $\begin{array}{l}\text { Agriculture } \\
\text { and food } \\
\text { manufacturing }\end{array}$ & $\begin{array}{l}\text { Develop value chain through innovations in harvesting, } \\
\text { storage, transport, processing, retail and consumer } \\
\text { activities }\end{array}$ \\
\hline urce: Authors' synthesis. & & \\
\hline
\end{tabular}

Table 2.

Elements of climate-smart agribusiness and mitigation options. 


\subsection{Increasing agricultural productivity and incomes}

Adopting climate resilient technologies and enhancing the productivity of agro-ecosystems and increasing the efficiency of soil, water, fertilizer, livestock feed and other agricultural inputs could offer higher returns to agricultural producers. These measures can often result in lower greenhouse gas emissions compared with past trends. Table 2 presents the elements of climate-smart agribusiness and mitigation options.

\section{Development of SMEs}

All over the world, there is growing evidence that SMEs play an important role in the national economic development of a country. SMEs are becoming a subject of high attention in the developing, transition and developed countries. SMEs are considered as the engines of growth and drivers of innovation worldwide due to their private ownership, entrepreneurial spirit, their flexibility and adaptability as well as their potential to accommodate to the challenges of changing environments.

The role of SMEs in global economic and social development has been recognized in a number of studies [17-19]. In fact, SMEs play a key role in the socio-economic development of both developed and developing countries, in terms of not only contribution to GDP but also employment generation and growth [20,21]. Currently SMEs are dominating the business sector covering $95 \%$ of firm worldwide and creating $60 \%$ employment of private sector. The important advantage of SMEs is that it can adapt better in response to changing consumers need and markets due to the fact that their organizational structure allows for quicker decision making. Moreover, they are highly flexible to adopt new technology and supporting innovation and promoting competition in the market and better income distribution than the large companies.

SMEs are playing important role toward industrialization and economic development of country due to serving as a starting point. Historically most of the global larger companies originated from SMEs. The industrialized countries could achieve high growth only due to growth of SMEs. It is a growing concern that the market economy started with the born of SMEs and then it progressed with the progress of SMEs. The activities of SMEs are the driving force of an economy and foster employment, economic growth, and poverty alleviation (Figure 5). In some of the global companies emerged in USA, Japan, Germany and China, some of the global companies emerged which were established initially as small and medium sized and later they developed into global big companies.

The numbers of SMEs found to have increasing trend over the decades across the globe. The presence of SMEs is more visible in the industrialized countries and developing countries. In Japan, US, Germany, China more than $99 \%$ companies are SMEs and proportion of employment generated are 66, 53, 68, and 67\% respectively. In the case of Spain, SMEs represent $99 \%$ of all companies and generate approximately $66 \%$ of jobs [23]. These data show the importance of SMEs to accelerating growth and creating the employment necessary to relaunch the economy in Spain. The food industry ${ }^{1}$ is the main manufacturing industry in the European Union, where $95.4 \%$ of companies are SMEs with fewer than 50 employees [24]. In Spain, the food industry has been consolidated as the main economic driver, representing $21.7 \%$ of the entire industrial sector, $18.3 \%$ of employed persons and $15.5 \%$ of added value [25].

\footnotetext{
${ }^{1}$ Europe's food industry means: 4.57 million people employed throughout the EU, a turnover of $€ 1.1$ trillion and $€ 230$ billion in value added, which make it the largest manufacturing industry in the EU. In half of the EU's 28 Member States, the food industry is the biggest employer within manufacturing.
} 


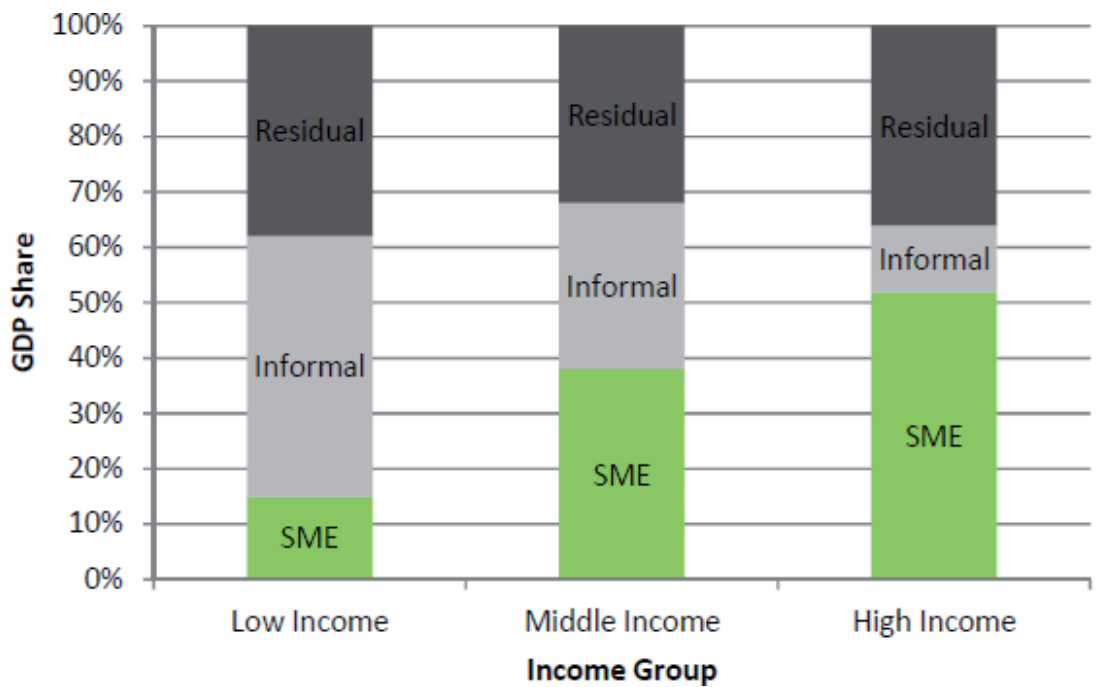

Figure 5.

SME contribution to GDP by countries' income level. Source: [22].

In a developing country like Bangladesh, SMEs are playing an important role toward industrialization and economic development covering $45 \%$ of manufacturing value addition, about $80 \%$ of industrial employment, about $90 \%$ of total industrial units and engaging about $25 \%$ of the labor force and contributing to $75-80 \%$ export earnings. The industrial sector makes up 31\% of the country's gross domestic product (GDP), most of which is coming from SMEs. The total number of SMEs in Bangladesh is estimated to be 79,754 . Of them, $93.6 \%$ are small and $6.4 \%$ are medium. The country's SME sector has created 1.5 million jobs between 2009 and June 2014. Now, private and foreign banks disburse half of all farm loans and a third of these are going to SMEs.

In Thailand, SMEs account for a large proportion of the total establishments in the various sectors. In the manufacturing sector, SMEs comprise $93.8 \%$ of all establishments, employing some 868,000 workers or $38.9 \%$ of the total. Thai SMEs are increasingly seen as creator of new jobs. Vietnamese SMEs employ $64 \%$ of industrial workforce. SMEs in Thailand play an important role in the country's economic development which covered $76.1 \%$ of the manufacturing sector in 2007 . The largest concentration of Thai SMEs is found in the food sector, textiles, apparels and wood products [26].

Compared to large companies, the SMES are more affected due to change of the environment. They face more risk and uncertainty due to environmental changes and shocks due to having limited resources. As a result their responses to environmental change differ with the large companies. They have usually limited options and opportunities to cope with the adverse situation arising from climate change extremes.

\subsection{Efficiency of SMEs}

An efficiency estimate allows a company to know its effectiveness in achieving objectives and managing resources. There is growing body of literature on measuring firm specific efficiency of SMEs [27-38]. The main concern of these studies are estimating cost efficiency which is a relative measure of how close is the cost of a company to the costs of a best-practiced one that produces the same output under similar conditions. The cost efficiency approach has two limitations: Firstly, cost efficiency evaluates the efficiency for a given output level only which does not correspond to the optimal level of production. Hence, a firm can be efficient in terms of its cost of production of given level but not for its optimal output level. Secondly, 
cost efficiency does not consider the output quality of companies. If differences in output quality between companies are not considered, then the costs of higher quality are incorrectly measured as inefficiency [39].

In order to overcome these limitations profit efficiency is used combining two important economic objectives of cost minimization and revenue maximization. Profit efficiency measures the relative distance of the current profit of a company to its optimal frontier profit. The profit efficiency approach is considered to be better than cost efficiency approach for assessing overall company performance because it considers level of outputs and inputs and as well as prices inputs and outputs [39]. Moreover, profit efficiency can be considered as overall efficiency, such that if a company is efficient in terms of its profits, then it will also be efficient in terms of its costs and its scale of production [40]. Therefore, estimating profit efficiency is far more important for SME managers than the partial view provided by an analysis of cost efficiency [41].

SMEs are strongly influenced by the region in which they operate and therefore, their efficiency level will be conditioned by the economic, social and demographic situation of the region in which their activity is developed [27, 30, 31].

In order to formulate and implement business strategies to improve competitiveness of SMEs, it is important to identify the factors affecting efficiency of SMEs [42]. A number of studies investigated the factors affecting the inefficiency of SMEs. One study pioneered the research on this topic with an empirical study in which they analyzed how size, age and facilities affect cost efficiency in manufacturing SMEs [43]. Subsequently, other authors also studied how the cost efficiency of SMEs is affected by employee qualifications, owner experience, location, type of company, female participation in the workforce, capital-labor ratio, foreign investment, export activity and government support [27, 28, 30, 31, 34, 44].

A recent study found an average profit efficiency of $58 \%$ for a sample of 556 small livestock producers in Botswana [45]. The factors that influenced the high degree of inefficiency (42\%) were education level of the farmer, distance to the commonly used market, herd size, access to information and income from crop production. The results of another study showed that the mean profit efficiency of smallholder milk producers in Kenya was $60 \%$ and it range from 26 to $73 \%$ and the factors affecting profit efficiency positively are the level of education, experience, and size of the farm [45].

There are two schools of thoughts on the size and efficiency of company. A number of studies provided evidence that larger firms are more efficient than smaller businesses [35, 36, 43, 46]. The main argument behind this idea is that in a competitive market, the most efficient companies survive and grow, whereas inefficient companies stagnate or exit the industry. On the other hand, some studies supported that small firms are efficient. However, smaller firms are more flexible, have nonhierarchical structures and do not suffer from agency problems owing precisely to their smaller size. These differences could more than offset their size disadvantage and make them more technically efficient than larger companies [31, 47, 48].

The age and efficiency of a company are expected to be positively correlated. First, the oldest organizations in competitive markets will be the most efficient because market inertia will expel inefficient companies [35]. Second, older companies will also be the most experienced in terms of their production and commercial processes and therefore more efficient $[33,46]$. Finally, age can also be a significant factor because younger companies have more problems of accessing credit [49]. Alternatively, a negative relationship between age and efficiency is also possible because young companies have more modern infrastructure and the most advanced technologies [43].

We used a panel data set of 10,000 smallholder firms from 64 districts of all over Bangladesh collected for the year 2004 and 2014 for estimating efficiency of rice production using stochastic frontier function model. The results mean 
technical efficiency of the sample firms in 2004 and 2014 are presented in Figure 6. The mean efficiency of the smallholder firms was $68 \%$ in 2004 and it increased to $80 \%$ in 2014 . It shows that there is a considerable improvement of the mean technical efficiency of the sample firms over the period of 10 years. The main driver of reducing inefficiency in rice production was improvement of the human capital of the firm, i.e., education and experience of the firm operator.

There is positive relationship between labor productivity and efficiency of SMEs because many companies' competitive advantages derive directly or indirectly from human resources [50-52]. There seems to be widespread agreement in the economic literature regarding the positive effect from worker training and skills on the efficiency of companies [30,31]. The factors positively resource use efficiency are greater employee skills and knowledge. These support adoption of new technologies and stimulate innovation and promote the efficient use of resources. The qualifications and skills of employees found have a positive effect on the supply of goods and services of a company and as well as on its good will $[53,54]$.

The development of efficient and competitive SMEs is constrained by SMEs' difficulty in accessing financial resources $[55,56]$. Study indicated that the structure and costs of financing affect the competitiveness of companies, and difficulties in accessing finance restrict the potential of SMEs to execute projects related to technological innovation and internationalization to improve their efficiency. Gaining greater access to credit could have a positive impact on efficiency among SMEs $[19,28,57,58]$.

Governments of various countries are supporting funding for SMEs in order to promote their competitiveness, innovation and socio-economic development. These strategic actions seems justified on the ground that the difficulties which SMEs are experience in accessing funding besides their importance to economic development and generation of employment. Government assistance could come in the form of credit, reduction/exemption of income tax and import duties on raw materials [30].

Exports found to have a positive impact on efficiency of SMEs because companies that export benefit from access to new information sources and knowledge that are sometimes not available in the local market and they can utilize this acquired knowledge to be more efficient [59].

Profit efficiency of SMEs in the food manufacturing industry found to be an important indicator of assessing the overall performance results of SMEs. The results also identified that there is a positive relationship between labor productivity and profit efficiency. This result reveals the importance of training for employees. Profit efficiency found to improve with increasing SME size. The export activity of SMEs is found to positively relate to profit efficiency [27, 30, 38, 60].

A cross countries study of World Bank found that the efficient SME firms found to have better access to new technology through joint-ventures agreement with

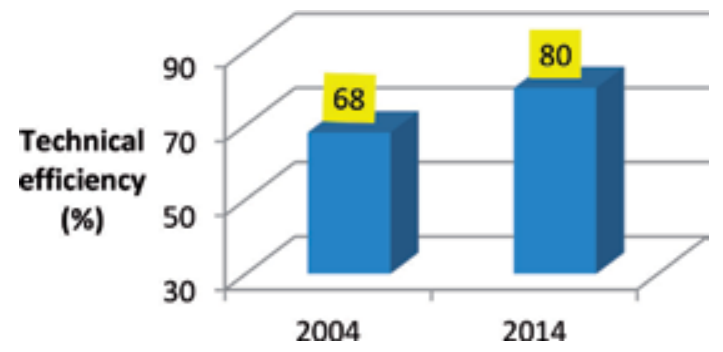

Figure 6.

Firm specific mean technical efficiency of 10,000 smallholder sample firms of 64 districts of Bangladesh in 2004 and 2014. Source: authors estimates. 
foreign partners such as buyers and input suppliers [61]. Their efficiency resulted from possessing more educated and well trained work force, adopting greater automation, practicing quality control in production, adopting compensation practices for the employee that supported job stability and skill acquisition.

Products and services, the way of doing business, management know-how and, external environment are most significant factors in determining the business success of SMEs in Bangladesh [62].

A number of studies found that business success of SMEs dependent on characteristic of entrepreneur and SMEs, management and know-how, products and services, the way of doing business and cooperation, resources and finance, and external environment [63-66]. Innovative product, quality, cost, reliability, and services are the key strategic dimension in business success. External environment factor play a very important role as well for firm success. Social network, government support, and legality, are the key strategic dimension in external environment in business success.

\subsection{Sustainable management practices}

The main concerns about sustainability in agricultural systems and agribusiness are the need to develop technologies and practices that do not have adverse effects on environmental goods and services that are easily accessible and more productive. The global agriculture experienced green revolution with great increase in agricultural productivity through intensive use of HYV seeds, fertilizers, irrigation, pesticides, machinery and improved management practices in the past half-century. Similarly it also experienced a livestock revolution through adoption of improved breed, feed, artificial insemination services, mechanization and improved management practices, etc. Much improvement was found in world food production during the last half century when in aggregate it grew by $145 \%$ with some regional variations in its growth. In Africa, Latin America and Asia it increased by 140, 200, and 280\%, respectively. The highest fivefold increase was in China during the 1980s-1990s.

Similar results also found in industrialized countries, output doubled in the USA over 40 years while it grew by 68\% in Western Europe [67]. Over the same period, world population doubled from 3 billion to more than 6 billion creating more pressure on the demand for food and natural resources $[68,69]$. By 2030 and 2050 global population will be 8 billion and 9 billion respectively and will increase demand food at least by $50-60 \%$ compared to present situation. The issue is how to sustainably transform global agriculture and agribusiness to meet its future food demand keeping balance with the population growth.

An important change in the world food system will come from the increased consumption of livestock products [70,71]. Meat demand is expected to rise rapidly with economic growth and this will change many farming systems.

The inefficient use of some of agricultural inputs already led to considerable environmental harm in various regions. Intensive land use contributes substantially to the loss of habitats, associated biodiversity and their valuable environmental services [72]. Irrigation water is often used inefficiently and causes water logging and salinization, as well as diverts water from other domestic and industrial users; and agricultural machinery has increased the consumption of fossil fuels in food production.

Climate change poses an especially serious challenge to many countries and regions of the globe. In the South Asia, Bangladesh would be worst victim of climate change. Bangladesh's agricultural output and its food security will be at high risk. As a low-lying country situated on a delta, Bangladesh experiences salt water intrusion, land erosion, and drought and can expect increased flooding, and more intense natural disasters. In order to mitigate negative impact of climate change the 
farmers need to adopt climate-smart technologies such as salt tolerant rice variety, drought-tolerant crops and flood tolerant rice varieties. Similarly, agribusinesses firm will need to resolve increased supply chain problems, decreased productivity, and workforce instability resulting from migration.

Globally some sustainability management practices could be adopted. These are: (i) integration of biological and ecological processes into food production processes such as nutrient cycling, nitrogen fixation, soil conservation, etc., (ii) minimizing the use of those non-renewable resources that cause harm to the environment (iii) utilize indigenous knowledge and skills of farmers for substituting human capital for costly external inputs, and (iv) utilize collective efforts or community based approach to solve common agricultural and natural resource problems like pest infestation, water logging, irrigation, etc. (v) adopt intensification using natural, social and human capital assets, combined with the use of best available technologies and inputs (best genotypes and best ecological management) that minimize or eliminate harm to the environment, can be termed 'sustainable intensification'.

As a more sustainable agriculture seeks to make the best use of nature's goods and services, technologies and practices must be locally adapted and fitted to place. Sustainability has three dimensions. These are (i) protecting the environment, (ii) the needs of present and future generations, and (iii) the economy. Integrating these threes could support economic viability of a system with fulfilling the needs of the present and future generations through minimizing depletion of natural resources.

The sustainable management focuses on a firm's impact on the people, planet, and profit so that these could flourish in the future. It can take many forms including investing in sustainable land management, good agricultural practices, improving food quality and safety, using bio safe packaging materials and improving humane working conditions in the factories, etc.

The boundaries of social accountability are changing over the years. The sustainable management implies that firms should adopt a systems wide approach that links various parts of the business with the greater environment at large. Managers need to apply traditional business principles to environmental problems and corporate social responsibility issues.

\section{Value chain development}

The global agrifood system is changing rapidly due to structural changes are occurring throughout the system in response to the modernization of agriculture because of globalization, coordination and shifting consumer and societal demands for safer, better-quality and processed food produced in a socially and environmentally responsible sustainable manner.

Markets are growing rapidly across globe due to urbanization and rising income and creating vast opportunities as incomes rise and diets change. It opens new market opportunities for private sector actors all along the value chain. By 2030, the number of people living in urban areas is projected to increase by $68 \%$ in low income countries and by $31 \%$ in middle income countries. At the same time, rising incomes are driving a dietary change with reduced cereals and increased consumption of animal products, fruits and vegetables and processed foods.

Such consumption changes bring significant new opportunities for farmers, processors and distributors in various regions of the globe. For example, urban food and beverage consumption is projected to grow by about $\$ 400$ billion by 2030 in Sub-Saharan Africa alone. Africa's food market, valued at about US $\$ 313$ billion per year in 2013 could be tripled by 2030, with investments in infrastructure, smart business and trade policies and a dynamic agribusiness sector linking farmers with 
consumers in growing urban areas [73]. In South Asia, the size of food processing sector of Bangladesh is worth US $\$ 2.2$ billion and grew on an average at $7.7 \%$ per annum between FY2004/05 and FY2014/15 [74]. The beverage industry more than doubled during the same period to US dollar 29 million, with an average growth rate exceeding $8 \%$. The food processing sector is thus growing rapidly with prospects for continued growth as Bangladesh's GDP continues to grow. Bangladesh exports over $\$ 700$ million worth of processed food and beverages, of which over $60 \%$ are shrimp and fish products.

Technology and innovations support entrepreneurship in agricultural value chains creating new opportunities to reduce costs and raise incomes. Emerging technologies driven by the Fourth Industrial Revolution include digital database, automation, robotics, and modern manufacturing, new energy technologies and genomics that all offer significant opportunities for the food system.

Agricultural production is a private sector activity comprised of about 450 million private smallholder farmers and many large-scale producers. In low- and lower-middle-income countries, 95\% of all farms are smaller than 5 ha. These small farms occupy almost three-quarters of land in low-income countries and two-thirds of land in the lower-middle-income countries. While smallholders include subsistence farmers and commercial producers who sell in unstructured local markets and those who sell in more organized markets often under contract with buyers. Many productive off-farm activities in agricultural value chains in developing countries are undertaken by small and medium scale enterprises (SMEs).

Producers and consumers are connected through a value chain, which include many actors (Figure 7) and the performance of one segment is dependent on the performance of other segments. A value chain is the full range of activities that are required to create and add value to a finished product or service. So, a value chain consists of different phases starting from collection of raw material, production, processing, distribution and marketing until the product or service reaches the ultimate consumer. A value chain analysis (VCA) examines the linkages between all actors and their functions. It also considers market demand, quality standards and various influences on the chain [76].

While each segment of the value chain can have unique constraints, there is a set of enabling conditions such as the business climate (including policies, regulations, and market structure) and support services (including finance, information, technology, infrastructure, water, and power) that are common to all segments and all value chains in the sector. Addressing the entire ecosystem is therefore indispensable to creating markets and to improving the performance and transformation of value chains [75].

While some value chains are getting longer with more geographical distance between producers and consumers, some are also getting shorter with fewer

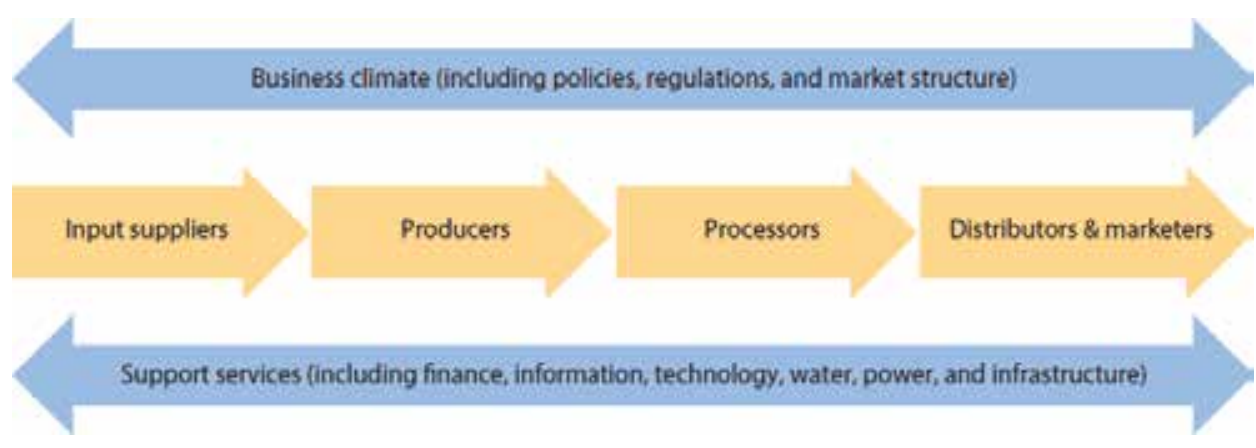

Figure 7.

Agricultural value chain ecosystem. Source: [75]. 
intermediaries via digital e-commerce platforms that link small entrepreneurs in rural areas with national and global markets.

\subsection{Sustainable global value chains (GVC)}

Nowadays, agricultural markets are globalizing rapidly. As a result new consumption patterns and new production and distribution systems are occurring in the regions. In the changing market environment, value chains are controlled by emerging corporate firms and supermarkets and their share of the agrifood systems is increasing in developing regions. Small-scale producers provide over $70 \%$ of the world's food needs while agribusinesses are important generators of employment and income worldwide. Improving the sustainability of food value chains can benefit hundreds of millions of poor households in developing countries, ensuring access to nutritious food to all. For instance, about 100 types of fruits and vegetables are exported from Bangladesh to more than 40 countries in the world. Export of fresh fruits and vegetables from Bangladesh significantly increased in the past decade (Table 3).

Food manufacturing industry being an actor of value chain contributes significantly to a nation's economic development through converting raw agricultural products into finished goods for consumption. Its products are commonly the major exports from a developing country [77]. For instance, frozen foods are the second largest export sector of Bangladesh. The massive natural resources available in Bangladesh make this sector particularly promising for investors looking to supply in international as well as in domestic markets. Bangladesh's export earnings from shrimp and fish export in 2016 were around 348.28 million US\$.

There are potentials to transform Bangladesh's export markets of fresh, frozen horticultural crops and processed food. It is projected that Bangladesh's export value could be increased to around $\$ 1765$ million US \$ per year from the export of fresh and processed foods in the year 2034 from the base year level export value of 380 million US\$ (Figure 8 and Table 4). This would require capacity development of value chain actors, compliance of certification of food quality and safety and improvement of storage and transportation facilities. The export potential of fruit and vegetables is about 160 thousand metric tons and potatoes would be around 200 thousand metric tons a year. During 2015-2034 total export under business as usual scenario will be 14,773 million US\$ and under improved scenario it will be 21,556 million US $\$$ and additional benefit due to improvement will be 6803 million US\$. Table 5 presents information on top 10 vegetables exporters globally.

\begin{tabular}{cccc}
\hline Fiscal year & Quantity exported (MT) & Export value (in million US\$) & Export growth (\%) \\
\hline $2008-2009$ & 24,670 & 50.71 & - \\
\hline $2009-2010$ & 29,370 & 64.21 & $(+) 26.62$ \\
\hline $2010-2011$ & 48,428 & 109.41 & $(+) 70.39$ \\
\hline $2011-2012$ & 59,573 & 134.59 & $(+) 23.01$ \\
\hline $2012-2013$ & 80,660 & 182.23 & $(+) 35.39$ \\
\hline $2013-2014$ & 112,924 & 255.122 & $(+) 40.00$ \\
\hline $2014-2015$ & 160,352 & 362.27 & $(+) 42.00$ \\
\hline Source: Export Promotion Bureau of Bangladesh $(E P B)$ and Hortex Foundation 2013.
\end{tabular}

Source: Export Promotion Bureau of Bangladesh (EPB) and Hortex Foundation 2013.

Table 3.

Export growth of fresh fruits and vegetables. 

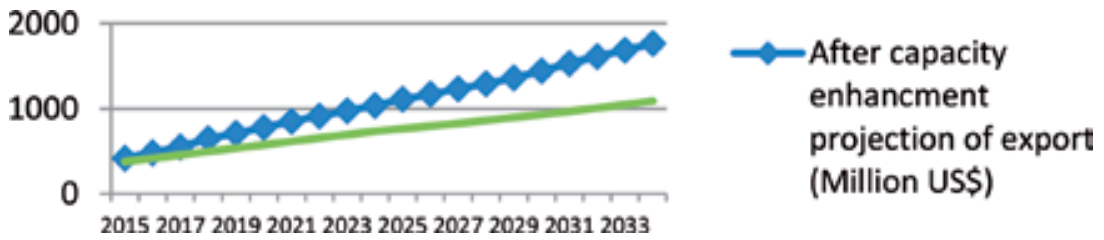

Figure 8.

Projection of export of fresh, frozen horticultural crops and processed food (in million US dollar) under business as usual and enhanced capacity. Source: author's estimation.

It revealed from Table 5 that similar to Bangladesh's export value of horticultural crops in 2015 the export value of vegetables of Thailand was 562 million USD in 2004 and within a 10 year period it increased to 1797 million USD in 2014. Similar trend in growth of export of horticultural crops was observed in Pakistan, India and Afghanistan. Pakistan's major share of exports (i.e. more than $2 / 3$ rd) is from agriculture sector including cotton and cotton based products, rice, fruits, vegetables, etc. During the year 2015, Pakistan exported 1.4 million tons of fruits and vegetables. Export of fresh vegetables of Pakistan increased from 288,200 tons to 751,000 tons and fruits exports increased from 259,900 tons to 682,100 during 2001-2015. During same period export of horticultural crops of India increased from 1092.04 million tons to 2535.57 million tons, it almost doubled during last 15 years. During 2001-2015, the export growth of value of fresh and dried fruits from Afghanistan was around 14\%.

The fresh fruit market is recently more globalized than vegetable. About $9 \%$ of all fruits grown are traded internationally and it is still growing. The fruits traded worldwide are bananas, apples, citrus fruits and grapes ... Recently Latin America appeared as a dominant global export region and China as a giant increasing import market. A large share of fruit is processed as juice and canned fruit. The markets of processed fruits are expanding in US, Europe, and Oceania. The global demand for frozen and fresh fruits is also increasing mainly in the countries other than US and EU. Around $80 \%$ all fruits grown globally are sold as whole fruit. The global demand for frozen fruit has increased by $5 \%$ per year. While, global demand for preserved fruit has remained almost stable but it decreased by over $1 \%$ a year in Europe, Australia, and the US.

Blueberries, avocados, and other popular year-round fruits found to have boosted trend in global fruit trade during 2006-2016, most countries in the world imported these at least four part of the year. As a result, their trade has increased sharply (Figure 9).

\begin{tabular}{cccc}
\hline Year & $\begin{array}{c}\text { Business as usual } \\
\text { projection of export } \\
\text { (million US\$/year) }\end{array}$ & $\begin{array}{c}\text { After capacity enhancement } \\
\text { projection of export (million } \\
\text { US\$/year) }\end{array}$ & $\begin{array}{c}\text { Incremental benefits due } \\
\text { to capacity enhancement } \\
\text { (million US\$) }\end{array}$ \\
\hline 2015 & 380 & & 38 \\
\hline 2020 & 578 & 780 & 202 \\
\hline 2025 & 766 & 1110 & 345 \\
\hline 2030 & 932 & 1444 & 512 \\
\hline 2034 & 1090 & 1765 & 676 \\
\hline Total & 14,773 & 21,576 & 6803 \\
\hline Source: Author's estimation. & & & \\
\hline
\end{tabular}

Table 4.

Projection of export of fresh, frozen horticultural crops and processed food (in million US\$) under business as usual and enhanced capacity scenarios. 


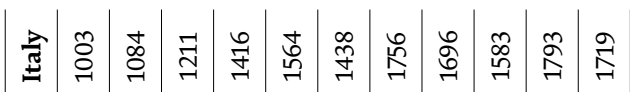

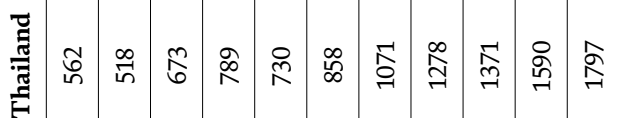

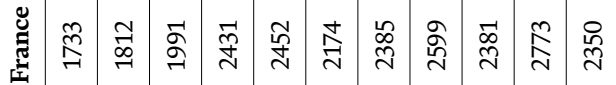

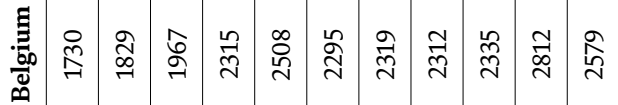

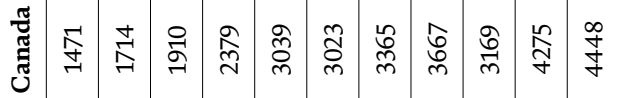

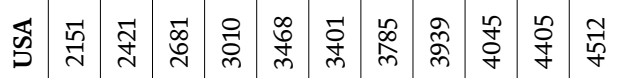

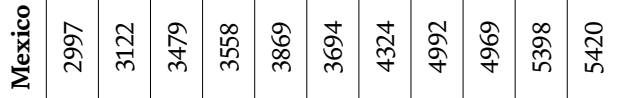

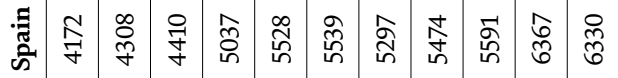

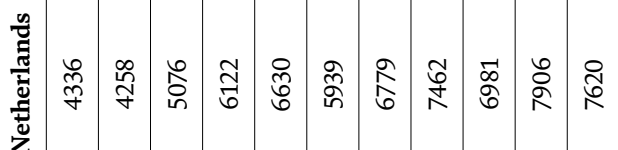

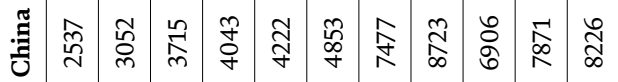

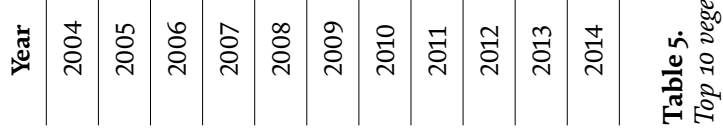




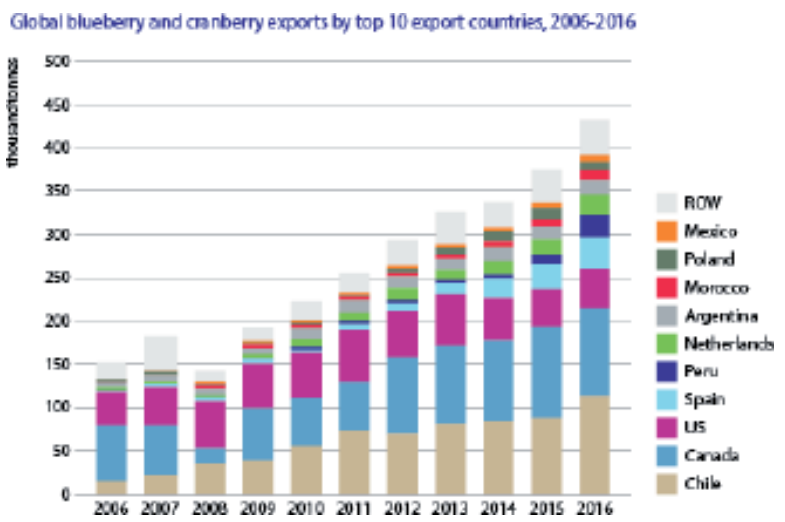

Figure 9.

Rising trade in global export of 'supermarket foods': Export by top 10 countries, 2005-2016. Source: UN Comtrade, 2018.

Over the last decade the international fresh fruit exports is increasing almost by $7 \%$ and most of such increase is consumed by import markets of the US, China, and Germany (Figure 10). The emerging markets like China and India are becoming more important in the global fruit market. The important driving factors of growth in fresh fruit trade are improved market access, changing consumer preferences, increasing purchasing power, improved logistics, and storage and cold-chain facilities. Many fruits can be shipped over long distances by transportation by sea. For Latin American countries like Chile, Peru, Ecuador, and Brazil has opened up a world of opportunities.

The GVC are generated from globalized markets. It motivates firms to operate internationally through outsourcing of activities like design, production, marketing, distribution, etc. [78]. The smallholder farmers form a key part of the GVC and agro-industry, by providing over $80 \%$ of the food consumed in a large section of the developing world [79]. Linking smallholder farmers to global value chain and developing their capacity could transform world agriculture with sustainable growth to feed the future generation. They hold many practical solutions that can help place agriculture on a more sustainable and equitable balance.

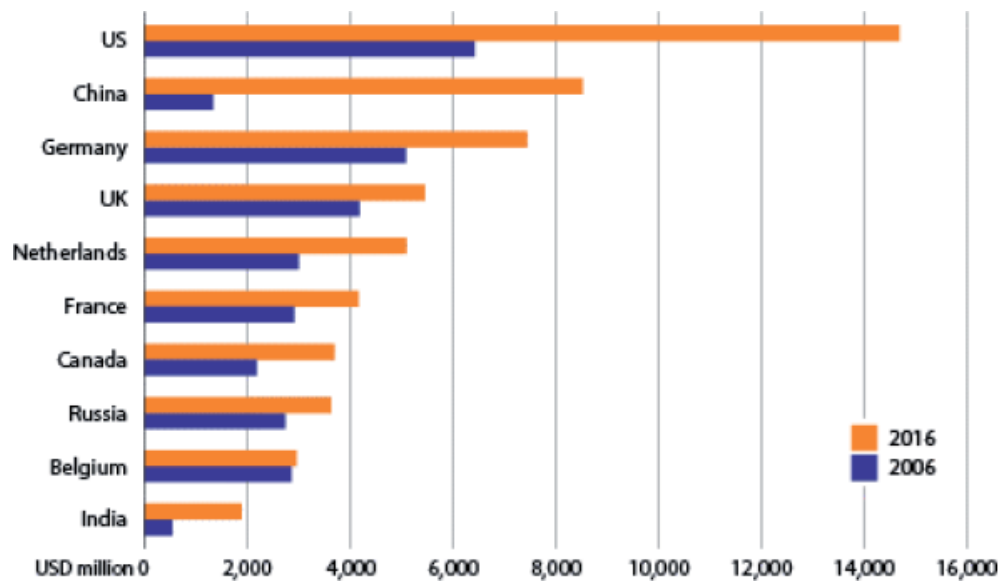

Figure 10.

Top 10 fresh fruit import countries, 2006 vs. 2016. Source: UN Comtrade, 2018. 


\section{Compliance of food safety regulations of WTO}

Export of fresh agricultural produces and food products require compliance of food quality and safety regulation of WTO and meet required standards of importing country. Traceability is an important market requirement for most commodities in high value markets. Often the exportability of food products is limited by noncompliance of the traceability requirement in developing countries. Traceability is an important market requirement for most commodities in high value markets. Often the exportability of food products is limited by non-compliance of the traceability requirement in developing countries. Electronic traceability systems are becoming the norm in developed countries and increasingly in developing countries.

Food safety in developed and developing countries increasingly relies on traceability related information derived from food production history. Furthermore, in order to control diseases, the government need information on sanitary and phyto-sanitary (SPS) condition to ensure safety of imported food. Traceability related information allows compliance with the food quality standards. It thus helps to increase the speed of trading of food companies that comply with it. Consumers of importing country also demand more information on the origin of the food and its traceability information. Traceability related information has experienced a high increase in demand as customs, food safety agencies and consumers increasingly require traceability related information.

Due to emerging markets of quality and safe food across various regions of the globe an investment on improving quality management system could have better payoffs through expanding satisfaction of the consumers and market opportunities. However, there is a challenge for the management of a company to understand the regulatory standards and their adoption in the context of a developing country having imperfect market information.

The globalization of food trade and supply chains requires pre- and post-harvest management to comply with required standard by all participants wishing to supply products to international markets. Current world food trade is valued at $\$ 300-400$ billion according to Food and Agriculture Organization of United Nations. With the demand for food rising to meet the ever growing world population, food safety is becoming more important and growing concern.

The issue of food safety and sustainability of business is interlinked. There are several prominent sustainability challenges that can be tackled in cycle with food safety issues, most of which can be boiled down to the importance of transparency and traceability. More specifically, the most pressing issues are risk reduction and monitoring, brand reputation, food fraud, supply instability and flexibility, meeting consumer demands and addressing climate change impacts.

Traceability challenges exist both within a company's and throughout its supply chain. Having full visibility into the inputs and outputs from each process-from farm to fork, which is not an easy task, nor is it easy to identify risks and opportunities with food safety and sustainability in these areas. The companies need to analyze the risk in the supply chain, prioritize issues that are important to stakeholders and for the environment, and identify technically feasible solutions that are financially viable. The consequences of poorly managing either issue are costly and include damages to a company's reputation, as well as to consumer and investor confidence, Organizations that address these issues together will maximize their returns on investment in joint solutions.

According to FAO the value of global agricultural trade almost tripled during the period 2000-2012 with the result of high food prices and increased demand for high value produces. But the less developing countries (LDCs) could not keep space with 
this high growth as a result their share of global agricultural exports declined during the same period according to WTO. Although tariffs have fallen but non-tariff barriers such as SPS measures have created hurdle to the agricultural exports of LDCs.

The SPS measures are also increasingly addressed in regional and bilateral trade agreements. These agreements focus on the rules and requirements for food safety standards and issues like import licenses, requirements for inspection, testing, certification, labeling, packaging and quarantines. The SPS measures play a critical role in determining a company's ability to access global markets. Table 6 presents food safety standards applicable to African fruit exporters. In order to get access to global markets the exporters require complying with these standards.

Aquaculture provides almost half of the world's supply of seafood, with a value of U.S. $\$ 125$ billion. It employs 24 million people and contributes $13 \%$ of the world's animal-source protein (excluding eggs and dairy) [81]. While capture fisheries

\begin{tabular}{|c|c|c|}
\hline Type of standard & Institution & Standards \\
\hline \multirow{5}{*}{$\begin{array}{l}\text { International } \\
\text { agreements related to } \\
\text { trade and standards }\end{array}$} & World Trade Organization & $\begin{array}{l}\text { Agreement on SPS } \\
\text { Agreement on TBT }\end{array}$ \\
\hline & $\begin{array}{l}\text { Codex Alimentarius Commission } \\
\text { Regional Coordination Committee } \\
\text { for Africa }\end{array}$ & $\begin{array}{l}\text { Codex standards, guidelines and codes } \\
\text { of practice } \\
\text { Maximum residue levels of pesticides }\end{array}$ \\
\hline & $\begin{array}{l}\text { International Plant Protection } \\
\text { Convention }\end{array}$ & $\begin{array}{l}\text { International standards for } \\
\text { phytosanitary measures (ISPM) }\end{array}$ \\
\hline & $\begin{array}{l}\text { International Standardization } \\
\text { Organization (ISO) }\end{array}$ & $\begin{array}{l}\text { ISO Standards on: agriculture } \\
\text { environment, health protection and } \\
\text { safety food technology packaging and } \\
\text { distribution of goods }\end{array}$ \\
\hline & $\begin{array}{l}\text { Southern Africa Development } \\
\text { Community }\end{array}$ & $\begin{array}{l}\text { SADC trade protocol SPS/food safety } \\
\text { annex }\end{array}$ \\
\hline $\begin{array}{l}\text { Importing country } \\
\text { rules }\end{array}$ & European Union & $\begin{array}{l}\text { Legislation on food safety legislation } \\
\text { on crop protection products legislation } \\
\text { on phytosanitary requirements }\end{array}$ \\
\hline Producer protocols & $\begin{array}{l}\text { COLEACP (EU-ACP stakeholders in } \\
\text { the horticultural trade) }\end{array}$ & COLEACP harmonized framework \\
\hline \multirow[t]{2}{*}{$\begin{array}{l}\text { Importing firms' } \\
\text { requirements (key } \\
\text { protocols applied) }\end{array}$} & $\begin{array}{l}\text { EurepGap Euro-Retailer Produce } \\
\text { Working Group British Retail } \\
\text { Consortium (BRC) }\end{array}$ & $\begin{array}{l}\text { EurepGap (European retailers protocol } \\
\text { for good agricultural practice) BRC } \\
\text { protocol }\end{array}$ \\
\hline & Other retailer protocols & $\begin{array}{l}\text { Global foods safety initiative (GFSI), } \\
\text { Assured produce scheme (APS) } \\
\text { Marks \& Spencer Farm to Fork Tesco's } \\
\text { Nature’s Choice Shoprite }\end{array}$ \\
\hline \multirow[t]{2}{*}{$\begin{array}{l}\text { Consumers' } \\
\text { preferences }\end{array}$} & Fair trade labeling & $\begin{array}{l}\text { Fair trade labeling organizations } \\
\text { international (FLO) standards }\end{array}$ \\
\hline & Organic agriculture & $\begin{array}{l}\text { International federation of organic } \\
\text { agricultural movements (IFOAM) - } \\
\text { IFOAM basic standards (IBS) EU } \\
\text { organic standards }\end{array}$ \\
\hline $\begin{array}{l}\text { International } \\
\text { Conventions, "codes of } \\
\text { conduct" or guidelines }\end{array}$ & EU/USA/FAO/Codex & $\begin{array}{l}\text { Hazard analysis and critical control } \\
\text { point (HACCP) }\end{array}$ \\
\hline rce: $[80]$. & & \\
\hline
\end{tabular}

Table 6.

Food safety standards applicable to African fruit exporters. 
production is stagnating, aquaculture could reduce global deficit in fish protein by 2020 [82]. This requires coping with a number of environmental and social problems, such as water pollution and degradation of ecosystems. One response to these problems has been the rise of sustainability certification launched by the Aquaculture Stewardship Council (ASC). This certification requires setting standards for ecological and social interactions, auditing compliance with labeling products and enterprises that meet the standards, and establishing institutions performing these functions.

The greatest demand for certified aquaculture products comes from North America and Europe, where large supermarket and restaurant chains have committed to selling only certified sustainable seafood by 2015 [83]. Global and regional buyers are turning to certified seafood. But only a small proportion of world aquaculture production (4.6\%) is currently certified. Certification is complex and expensive and assumes a level of managerial capability that most aquaculture producers in the Global South do not have. Smallholders are often excluded from markets that require certification [84-86]. Not only producers are excluded, but also up- and downstream supply chain actors also excluded such as collectors, small-scale traders, brokers, and input suppliers.

\section{Challenges}

\subsection{Sustainability of productivity growth}

Demand for food and other agricultural products are projected to increase by $50 \%$ between 2012 and 2050. The main challenge of global agriculture is meeting the rising demand of the growing population which is projected to increase from 7 billion people today to approximately 9 billion in 2050. However, the expansion of productive agricultural land is limited and in addition climate change may pose further constraint. Climate change will pose a serious challenge to the projections of rising global demand for foods and declining per capita arable land. Intensive farming is often degrading world's natural resources. The farmers would have to increase productivity while also positively supporting the provision of various vital ecosystem services otherwise it will cause degradation of natural resources but also exhaust the ability to produce enough food.

Water scarcity will also become a growing constraint, particularly in areas that use a high proportion of their water resources and where production systems will be exposed to high environmental and social stress.

Climate change and natural and human-induced disasters pose multiple concerns, specifically damage and losses to production, degradation of land, forests, water, fish stocks and other natural resources, declining productivity growth and pressures on fragile agricultural livelihoods and ecosystems.

\subsection{Value chains challenge of small-scale operators}

Transformation of agrifood chains in low- and middle-income countries has created serious barriers to the participation of smallholder producers and small scale agro-processors in local, national and global markets. Barriers to smallholder access to supermarket channels, combined with reduced labor requirements, may undermine farmers' livelihoods if they cannot diversify into other rural off-farm activities. The issues of financing, market accessibility and transport, requirement of compliance to standards related to quality, traceability and certification making participation in the global value chains difficult for many small-scale operators. 


\subsection{Postharvest loss}

Around one-third of all food produced globally each year amounting 1.6 billion tons of food worth about $\$ 1.2$ trillion is wasted along the value chain from production to consumption $[85,86]$. Reducing food losses and waste would increase the supply of available food and strengthen global food security. Food losses and waste are also causing negative impact to environmentally sustainable food systems. They are contributing toward considerable waste of land, water, energy and agricultural inputs and cause the emission of millions of tons of greenhouse gases.

\subsection{Compliance of food safety regulations}

We have already discussed in previous section that food and agricultural exports often create SPS compliance challenges. The LDCs have inadequate capacity to comply with SPS requirement for which they struggle to get access to foreign markets. Repeatedly there are happening rejections of shipments due to non-compliance with SPS requirements. As a result the importing countries are putting stricter scrutiny that increases transaction costs, damage reputation and confidence of the exporters.

\section{Development options}

A number of development options can be suggested: (i) promote good agricultural practices and conservation agriculture, (ii) promote mechanization using robotics and ICT, (iii) developing value chains and agro processing, (iv) improving food quality and safety compliance through institutional development and global cooperation for capacity development for addressing compliance of SPS standard and certification, (v) knowledge generation and technology development. Climate smart agro-technology need to be developed with the focus on improvements in productivity and resource-use efficiency.

\section{Policy issues}

A range of technical and institutional solutions might be available to increase food production by at least $50 \%$ by 2050 in order to feed the increased population, reduce poverty and to minimize degradation natural resources and ecosystems of the globe. Policies, institutions and implementation strategies should be adjusted at global, national and local levels to develop capacities of organizations and farmers with the knowledge and financial resources. Knowledge sharing at local, national and global levels focusing on land and water systems development will foster socioeconomic growth across the globes reducing food insecurity and poverty.

The policy and strategies should consider environmental impacts and social consequences of global evolving agrifood systems. Rather considering quantitative increase in production we should also emphasize on better quality.

Policies should be designed to provide SMEs with a package of integrated proactive services such as training, investments in technology and sustainable management practices.

\section{Conclusions}

World's humidity and precipitation will change significantly by 2030 and 3050 due to climate change. Information on climate change vulnerabilities can be used 
for investment decisions and prioritization of actions and adoption of sustainable agribusiness management practices.

A climate-smart agribusiness could achieve three fold objectives: (1) developing opportunities to reduce greenhouse gases emissions compared to expected trends,

(2) building resilience to climate change, and (3) increasing agricultural productivity and incomes.

SMEs are considered as the engines of growth and drivers of innovation worldwide due to their private ownership, flexibility and adaptability as well as their potential to accommodate to the challenges of changing environments. The numbers of SMEs found to have increasing trend over the decades across the globe.

Either cost efficiency or profit efficiency approach could be used for measuring efficiency of SMEs. Profit efficiency can be considered to be overall efficiency, such that if a company is efficient in terms of its profits, it will also be efficient in terms of its costs and its scale of production. Therefore, estimating profit efficiency is more important for SME managers than the partial view provided by an analysis of cost efficiency.

Factors affecting efficiency of SMEs are size, age, employee qualifications, owner experience, location, and type of company, female participation in the workforce, capital-labor ratio, foreign investment, export activity, government support and access to information. Evidence from Bangladesh showed that mean efficiency of the smallholder rice firms increased from 68\% in 2004 to $80 \%$ in 2014 due to improvement of the human capital of the firm, i.e., education and experience of the firm operators. There is widespread evidence in the economic literature regarding the positive effect from worker training and skills on the efficiency of companies.

A number of studies found that business success of SMEs dependent on characteristic of entrepreneur, management and know-how, products and services, the way of doing business, resources and finance and external environment.

The global agrifood system is changing rapidly due to structural changes are occurring throughout the system in response to the modernization of agriculture because of globalization, consumer and societal demands for safer, better-quality and processed food produced in a socially and environmentally responsible sustainable manner. Producers and consumers are connected through a value chain, which include many actors and the performance of one segment is dependent on the performance of other segments.

Small-scale producers form a key part of the global value chain and provide over $70 \%$ of the world's food needs while agribusinesses are important generators of employment and income worldwide. Food manufacturing industry being an actor of value chain contributes significantly to a nation's economic development through converting raw agricultural products into finished goods for consumption. For instance, Bangladesh's export earnings from shrimp and fish export in 2016 was around 348.28 million US\$ in 2015. It is projected that earning of Bangladesh from the export of fresh and processed foods could be raised to more than $\$ 1800$ million USD per year in 2034 from the base year export level of 380 million USD. Linking smallholder farmers to global value chain and developing their capacity could transform world agriculture with sustainable growth to feed the future generation.

Export of fresh agricultural produces and food products require compliance of food quality and safety regulation of WTO and meet required standards of importing country. The globalization of food trade and supply chains requires pre- and post-harvest management to comply with required standard by all participants wishing to supply products to international markets. The exports from LDCs are often constrained by sanitary and phytosanitary (SPS) measures of WTO.

The SPS measures are increasingly addressed in regional and bilateral trade agreements. As a result there are needs to develop capacity of LDCs for requirements of inspection, testing and certification, labeling, packaging and quarantines. 
The challenges identified are (1) sustainability of productivity growth, (2) value chains challenge of small-scale operators, (3) high postharvest loss, and (4) compliance requirement of food safety regulations. A number of development options are also suggested.

\section{Author details}

S.M. Fakhrul Islam* and Zahurul Karim

Modern Food Storage Facilities Project, World Bank, Dhaka, Bangladesh

*Address all correspondence to: smfakhruli@gmail.com

\section{IntechOpen}

(C) 2019 The Author(s). Licensee IntechOpen. This chapter is distributed under the terms of the Creative Commons Attribution License (http://creativecommons.org/licenses/ by/3.0), which permits unrestricted use, distribution, and reproduction in any medium, provided the original work is properly cited. (cc) BY 
Sustainable Agricultural Management Practices and Enterprise Development for Coping... DOI: http://dx.doi.org/10.5772/intechopen.8700o

\section{References}

[1] Climate Change 2014: Impacts, Adaptation, and Vulnerability, Working Group II Contribution, Fifth Assessment Report of the Intergovernmental Panel on Climate Change; Cambridge University Press. 2014

[2] United Nations, Department of Economic and Social Affairs, Population Division. World Population Prospects: The 2015 Revision. New York: United Nations; 2015. Available from: https:// en.wikipedia.org/wiki/Projections_of_ population_growth\#cite_note-UNWPP-2015-4

[3] Godfray HC. Food for thought. Proceedings of the National Academy of Sciences. 2011;108(50):19845-19846

[4] Rask K, Rask N. Economic development and food productionconsumption balance: A growing global challenge. Food Policy. 2011;36(2):186-196

[5] Cirera X, Masset E. Income distribution trends and future food demand. Philosophical Transactions of the Royal Society B. 2010;365:28212834. DOI: $10.1098 /$ rstb.2010.0164

[6] Climate Change 2014: Impact Adaptation and Vulnerabilities, Part A: Global and Sectoral Aspects, Working Group II, Fifth Assessment Report of Intergovernmental Panel on Climate Change (IPCC). 2014

[7] Pall P, Aina T, Stone DA, Stott PA, Nozawa T, Hilberts AG, et al. Anthropogenic greenhouse gas contribution to flood risk in England and Wales in autumn 2000. Nature. 2011;470:382-385

[8] Carter JG, Cavan G, Connelly A, Guy S, Handley J, Kazmierczak A. Climate change and the city: Building capacity for urban adaptation. Progress in Planning. 2015;95:1-66
[9] Climate Change 2013: The Physical Science Basis: Working Group I, Intergovernmental Panel on Climate Change-Business \& Economics. 2014

[10] Vicuna S, Dracup J. The evolution of climate change impact studies on hydrology and water resources in California. Climatic Change. 2007;82:327-350

[11] UNFCCC. Climate Change: Impacts, Vulnerabilities and Adaptation in Developing Countries. 2005. Available from: https://unfccc.int/resource/docs/ publications/impacts.pdf

[12] Stern N. Review on the Economics of Climate Change. United Kingdom: HM Treasury; 2006. Available from: http://www.amazon.com/EconomicsClimate-Change-Stern-Review/ dp/0521700809

[13] World Bank. Policy Brief: Opportunities and Challenges for Climate-Smart Agriculture in Africa. Washington, DC: World Bank; 2013. Available from: https://openknowledge. worldbank.org/handle/10986/26079.

License: CC BY 3.0 IGO

[14] U.S. Department of Energy.

Emission and Reduction of Greenhouse Gases from Agriculture and Food Manufacturing: A Summary White Paper; U.S. Department of Energy Office of Energy Efficiency and Renewable Energy Office of Industrial Technologies. 1996

[15] Smith P. et al. Climate Change 2014: Mitigation of Climate Change. Ch. 11; IPCC, Cambridge Univ. Press. 2014

[16] IPCC Summary for Policymakers. In: Field CB et al., editors. IPCC Climate Change 2014: Impacts, Adaptation, and Vulnerability. Part A: Global and Sectoral Aspects. Cambridge Univ. Press; 2014 
[17] Doern R. Investigating barriers to SME growth and development in transition environments a critique and suggestions for developing the methodology. International Small Business Journal. 2009;27(3):275-305

[18] Harvie C. SME clustering and networking and its contribution to regional development: An overview of the key issues. In: SMEs in Global Economy Conference. 2007. p. 4

[19] Hussain I, Hussain M, Hussain S, Si S. Public private partnership and SMEs development: The case of AJ \& K Pakistan. International Review of Business Research Papers. 2009;5(5):37-46

[20] Assefa A. A comparative analysis of the development of small scale industries in region 14 with other regions. In: Wolday A, editor. Small Scale Enterprise Development in Ethiopia: Proceedings of the Sixth Annual Conference on the Ethiopian Economy; Addis Ababa. 1997. pp. 88-112

[21] Hallberg K. Small and Medium Scale Enterprises: A Framework for Intervention. Small Enterprise Unit, Private Sector Development Department, The World Bank Research Paper; 21 May 1999; Washington, DC. 1999

[22] Ayyagari M, Demirgüç-Kunt A, Beck T. Small and Medium Enterprises Across the Globe: A New Database. WorldBank Policy Research Working Paper 3127. 2003

[23] DGI and PYME. 2015. Available from: http://www.ipyme.org/ publicaciones/retrato pyme 2015.pdf

[24] Food Drink Europe. Annual Report; 2017

[25] INE. Estadística Estructural de Empresas Sector Industrial del INE; 2017
[26] NSO. Data Summary Report of the 2007 Industrial Census: Whole Kingdom. Bangkok: National Statistical Office of Thailand; 2007

[27] Balios D, Eriotis N, Fragoudaki A, Giokas D. Economic efficiency of Greek retail SMEs in a period of high fluctuations in economic activity: A DEA approach. Applied Economics. 2015;47(33):3577-3593

[28] Barchue WJ, Aikaeli J. Efficiency of small and medium-sized enterprises in Liberia: The case of Monrovia. Business and Management Review. 2016;18(2):1-20

[29] Battese GE, Rao DSP, Walujadi D. Technical Efficiency and Productivity Potential of Firms Using a Stochastic Metaproduction Frontier. CEPA Working Paper 7/2001. Armidale: Center for Productivity and Efficiency Analysis, School of Economics, University of New England; 2001

[30] Charoenrat T, Harvie C, Amornkitvikai Y. Thai manufacturing small and medium sized enterprise technical efficiency: Evidence from firm-level industrial census data. Journal of Asian Economics. 2013;27:42-56

[31] Charoenrat T, Harvie C. The efficiency of SMEs in Thai manufacturing: A stochastic frontier analysis. Economic Modelling. 2014;43:372-393

[32] Coll-Serrano V, Blasco-Blasco O. Análisis comparativo de la eficiencia de la PYME textil española: Una aproximación al efecto de la liberalización en el periodo 20042006. Rect@. Revista Electrónica de Comunicación y Trabajos de ASEPUMA. 2011;12(1):33-52

[33] Hill H, Kalirajan KP. Small enterprise and firm-level technical efficiency in the Indonesian garment 
industry. Applied Economics. 1993;25(9):1137-1144

[34] Kotey B, O’Donnell CJ. Data envelopment analysis in small and medium enterprises: A study of the Australian food, bever-ages and tobacco manufacturing industry. Small Enterprise Research. 2002;10(2):3-22

[35] Lundvall K, Battese GE. Firm size, age and efficiency: Evidence from Kenyan manufacturing firms. Journal of Development Studies. 2000;36(3):146-163

[36] Mini F, Rodriguez E. Technical efficiency indicators in a Philippine manufacturing sector. International Review of Applied Economics. 2000;14(4):461-473

[37] Mohamad R, Majid NA, Noh NF, Ahmad MF. Technical efficiency (TE) of small and medium (SME) food enterprise in West Malaysia. Economic and Technology Management Review. 2010;5:51-55

[38] Yang JC. The efficiency of SMEs in the global market: Measuring the Korean performance. Journal of Policy Modeling. 2006;28(8):861-876

[39] Berger AN, Mester LJ. Inside the black box: What explains differences in the efficiencies of financial institutions? Journal of Banking \& Finance. 1997;21(7):895-947

[40] Fitzpatrick T, McQuinn K. Measuring bank profit efficiency. Applied Financial Economics. 2008;18(1):1-8

[41] Maudos J, Pastor JM, Perez F, Quesada J. Cost and profit efficiency in European banks. Journal of International Financial Markets Institutions and Money. 2002;12(1):33-58

[42] Lovell CK. Production frontiers and productive efficiency. In: Fried HO,
Lovell CK, Scmidt SS, editors. The Measurement of Productive Efficiency: Techniques and Applications. New York: Oxford University Press; 1993. pp. 3-67

[43] Pitt MM, Lee LF. The measurement and sources of technical inefficiency in the Indonesian weaving industry. Journal of Development Economics. 1981;9(1):43-64

[44] Álvarez R, Robertson R. Exposure to foreign markets and plant-level innovation: Evidence from Chile and Mexico. The Journal of International Trade and Economic Development. 2004;13(1):57-87

[45] Bahta S, Baker D. Determinants of profit efficiency among smallholder beef producers in Botswana. International Food and Agribusiness Management Review. 2015;18(3):107

[46] Jovanovic B. Selection and the evolution of industry. Econometrica. 1982;50(3):649-670

[47] Álvarez R, Crespi G. Determinants of technical efficiency in small firms. Small Business Economics. 2003;20(3):233-244

[48] Le V, Harvie C. Firm Performance in Vietnam: Evidence from Manufacturing Small and Medium Enterprises, Department of Economics, University of Wollongong, Working Paper 04-10; 2010

[49] Diamond DW. Monitoring and reputation: The choice between bank loans and directly placed debt. Journal of Political Economy. 1991;99(4):689-721

[50] Datta DK, Guthrie JP, Wright PM. Human resource management and labor productivity: Does industry matter? The Academy of Management Journal. 2005;48(1):135-145

[51] Pfeffer J. Competitive advantage through people. California Management Review. 1994;36(2):9-28 
[52] Pfeffer J. The Human Equation: Building Profits by Putting People First. Boston, MA: Harvard Business Press; 1998

[53] Malerba F. Learning by firms and incremental technical change. The Econometrics Journal. 1992;102(413):845-859

[54] Cohen S. Big ideas for trainers in small companies. Training \& Development Journal. 1998;52(4):26-31

[55] Beck T, Demirgüc-Kunt A, Levine R. SMEs, Growth and Poverty. NBER Working Paper W11224; 2005

[56] Hamilton RT, Fox MA. The financing preferences of small firm owners. International Journal of Entrepreneurial Behavior and Research. 1998;4(3):239-248

[57] Peel M, Wilson N. Working capital and financial management practices in the small firm sector. International Small Business Journal. 1996;14(2):52-68

[58] Segura J, Toledo L. Tamaño, estructura y coste de financiación de las empresas manufactureras españolas. Investigacion Economica. 2003;27(1):39-69

[59] Golovko E, Valentini G. Exploring the complementarity between innovation and export for SMEs growth. Journal of International Business Studies. 2011;42:362-380

[60] Porter ME. Ventaja Competitiva, Creación y Sostenimiento de un Desempeño. México, DF: Co. Editorial Continental, SA de CV; 1987

[61] Batra G, Tan H. SME Technical Efficiency And Its Correlates: Cross-National Evidence and Policy Implications. Washington D.C., May 2001: World Bank Institute Working Paper, Paper presented at the World Bank's Economist Forum; 2003
[62] Islam MA, Mian E, Ali MH.

Determinants of business success of small and medium enterprises (SMEs) in Bangladesh. Business Review. 2008;4(2):45-57

[63] Kristiansen S, Furuholt B, Wahid F. Internet cafe entrepreneurs: Pioneers in information dissemination in Indonesia. The International Journal of Entrepreneurship and Innovation. 2003;4(4):251-263.67

[64] Indarti N, Langenberg M. A Study of Factors Affecting Business Success among SMEs: Empirical Evidences from Indonesia; 2005

[65] Swierczek FW, Ha TT.

Entrepreneurial orientation, uncertainty avoidance and firm performance: An analysis of Thai and Vietnamese SMEs. The International Journal of Entrepreneurship and Innovation. 2003;4(1):46-58.69

[66] Hitt M, Ireland D. The intersection of entrepreneurship and strategic management research. In: Sexton D, Landström $\mathrm{H}$, editors. Handbook of Entrepreneurship. Oxford: Blackwell; 2000. pp. 45-63

[67] FAO. FAOSTAT Database. Rome, Italy: FAO; 2005

[68] Kitzes J, Wackernagel M, Loh J, Peller A, Goldfinger S, Cheng D, et al. Shrink and share: Humanity's present and future ecological footprint. Philosophical Transactions of the Royal Society B. 2008;363:467-475. DOI: 10.1098/rstb.2007.2164

[69] Pretty J. The Earth Only Endures. London, UK: Earthscan; 2007

[70] Fitzhugh HA. Competition between livestock and mankind for nutrients. In: Waterlow JC, Armstrong DG, Fowden L, Riley R, editors. Feeding the World Population of More than Eight Billion People. New York, NY/Oxford, UK: Oxford University Press; 1998 
[71] Delgado C, Rosegrant M, Steinfield H, Ehui S, Courbois C. Livestock to 2020: The Next Food Revolution. IFPRI Brief 61. Washington, DC: International Food Policy Research Institute; 1999

[72] Scherr SJ, McNeely JA. Biodiversity conservation and agricultural sustainability: Towards a new paradigm of 'ecoagriculture' landscapes. Philosophical Transactions of the Royal Society B. 2007;363:477-494. DOI: 10.1098/rstb.2007.2165

[73] World Bank. Growing Africa Unlocking the Potential of Agribusiness. 2013. Available from: https://siteresources.worldbank. org/INTAFRICA/Resources/africaagribusiness-report-2013.pdf

[74] USDA. Food Processing Industries in Bangladesh, GAIN Report No. 3013. 2013. Available from: file:///E:/ Sustainable\%20Mnagement $\% 20$ Practices/Food_Processing_Industries_ in_Bangladesh.pdf

[75] World Bank. Future of Food: Maximizing Finance for Development in Agricultural Value Chains. Washington, DC: World Bank; 2018. Available from: https:/openknowledge.worldbank.org/ handle/10986/29686. License: CC BY 3.0 IGO

[76] Kaplinsky R, Morris M. A Handbook for Value Chain Research. 2001. Available from: http:// asiandrivers.open.ac.uk/documents/ Value_chain_Handbook_RKMM_ Nov_2001.pdf

[77] da Silva CA, Baker D, Shepherd AW, Jenane C, Miranda-da-Cruz S. Agroindustries for Development. 1st ed. Wallingford, United Kingdom: CABI Publishing; 2009

[78] Organisation for Economic Co-operation and Development (OECD). Global Value Chains. 2014. Available from: http://www.oecd.org/ sti/ind/global-value-chains.htm
[79] International Fund for Agricultural Development (IFAD). Smallholders, Foodsecurity and the Environment. 2013. Available from: http://www.ifad. org/climate/resources/smallholders_ report.pdf

[80] UNCTAD. Costs of Agri-food Safety and SPS Compliance United Republic of Tanzania, Mozambique and Guinea: Tropical Fruits. UNCTAD—Division on International Trade in Goods and Services, and Commodities; 2005

[81] Food and Agriculture Organization of the United Nations (FAO). The State of World Fisheries and Aquaculture. Rome: FAO Fisheries and Aquaculture Department; 2012

[82] Hall SJ, Delaporte A, Phillips MJ, Beveridge M, O'Keefe M. Blue Frontiers: Managing the Environmental Costs of Aquaculture. Penang, Malaysia: The World Fish Center; 2011

[83] Asche F, Dahl RE, Gordon DV, Trollvik T, Aandahl P. Demand growth for salmon in the European market. Marine Resource Economics. 2011;26:255-265

[84] Lebel L, Lebel P, Garden P, Giap DH, Khrutmuang S, Nakayama S. Globalizations. 2008;5:211-226

[85] Maertens M, Swinnen JFM. World Development. 2009;37:161-178

[86] Food and Agriculture Organization of the United Nations. Global Food Losses and Food Waste, 2011; FAOSTAT Database; BCG FLOW Model. 2015

Findings, in 2015 Dollars; 2015 



\title{
Inertia in Assessing the Possibilities of Economic Development: Limits in Modelling Economies
}

\author{
Marek Różycki
}

\begin{abstract}
We cannot transcend our world, our history and time to see ourselves from a broad enough perspective, and so our reasoning is limited by our being in the world. It is easy to draw conclusions a posteriori, analyse historical events and assume that our ancestors were, or should have been, aware of connections which we observe in hindsight. We also find it easy to interpret current affairs, label them and draw conclusions about their future development in accordance with the current theories and our zeitgeist. We are wrong to do so in both situations. Human perception is subject to the laws of inertia. Without realising inertia's immense influence, we will create models of the world which are distant from reality and short-lived. Players in (what appears to be) the information economy want us to believe that endless progress is possible. States and economic agencies behave as if this were given and no other possibility should be worth serious consideration. Every business and every country present prognoses showing ever-increasing indicators. We want everything to grow: the GDP, our profit margins and sales. Human population continues to grow as well, globally, but is progress the indicator of human population? Is development our destiny?
\end{abstract}

Keywords: economic development, limitations, crisis, risk, results

\section{Introduction: progress as a virus}

In his seminal 1976 book The Selfish Gene, Richard Dawkins famously posited that culture, which is a set of intersubjective rules considered to be true and real by human societies, can be viewed as a human virus [1]. Just as biological parasites strive to multiply their DNA without care for the state of their carrier, so too ideas strive to multiply without care for their carrier, human cultures and societies. Dawkins calls these ideas memes. Memes' only function is to spread from person to person, thus increasing the total number of believers in a particular idea. And by modifying individual consciousnesses, memes also modify the physical reality. The majority of contemporary economists who, like the priests and magi of yore, attempt to foresee future, believe that we can all carry on getting richer: individuals, corporations and states alike can keep on increasing their value and their resources. Humans consider themselves the top of the food 
chain and, admitting no natural enemies, want to be the masters of the world and control its fate. We believe that, at least in theory, human activity has no bounds and we can endlessly create new beings, ideas and myths. It is true so far as ideas go, but in reality economic growth and other forms of "progress" can lead humanity to extinction.

\section{The limits of the progress}

Another unique feature of Homo sapiens is the ability to create unreal and unnatural entities. Only humans can describe reality and, consequently, to diverge from reality in creating ideas which as yet do not exist in reality. We can even imagine illogical beings and convince ourselves that they are real. In this way, we have been able to creatively explain our activities, and when we conceive of our explanations in universal terms-as laws or belief systems-they in turn change our consciousness. Humans have become masters of the world and have come to believe it their responsibility to subdue the earth [2]. This belief informs our repeated attempts to alter the reality. Since the times humans were hunter-gatherers, we have been limited by resource availability. We moved around in search of food, but nature could not have fed as many of us as we are now without human-led adaptation. Development in nature is limited to evolution and changes in resource use. Having reached the limits of what nature had to offer, humans had to adapt. Unlike animals, which evolve to adapt to the changing conditions, we changed the conditions. The subsequent agricultural, industrial and scientific revolutions of human culture and consciousness allowed us to alter our world without altering ourselves: without evolution.

Consequently, our bodies are still those of hunter-gatherers, rather than those of office and industrial workers. When our ancestors discovered that they can grow edible plants and keep edible animals, they changed their habits. They started tilling land, irrigating it and harvesting, storing and processing their produce in order to have a steady supply of food. The food did indeed become steady, but it was also more labour-intensive, and the new diet was less varied than before. Finally, it caused our ancestors to settle in one place. If we accept that evolutionary success is marked by the widest possible spread of specific DNA, we will also have to admit that, by choosing certain plants for cultivation over others, we have caused those plants' expansion. It is these plants, having us convinced by their properties to cultivate them, that are the true evolutionary winners: wheat, potatoes, oats and other plants which now dominate Earth, thanks to humans. Could it be said that, according to the progress-as-virus principle, these plants have domesticated Homo sapiens and, by proliferating so successfully, caused the extinction of other species and thus altered the ecosystem? Humans have done the same, however. We domesticated other species in order to secure more plentiful and more varied nutrition and increase our holdings. In effect, we have caused further changes to the ecosystems and in particular to biodiversity, and, indeed, locally we have caused resource depletion. In this new situation, new forms of life began to thrive: ones which found humans and their stores of food a favourable environment.

Progress, defined as the spreading of DNA and multiplying of the species, has always entailed a focus on short-term gain and cost dispersal to other species, which experience no particular benefits from the dominant species' growth. Earth's real estate is limited. Fresh water, arable land, mineral and fuel deposits are limited. The idea of endless progress may, therefore, be an unrealistic dream which exists only within a world view peculiar to our society: a collective consciousness. To understand the process of creating reality and rules which inform it, we must identify types of realities within which humans operate. There are three: 
- Objective reality, in which individual beings exist independently of humans. Radioactivity, stones and wind exist even if humans deny their existence. We can name objects and states, but this does not alter their essence. At this level, progress is limited by the change in the form of existing resources.

- Subjective reality, or individual experience. Here everything depends on the individual. Their death ends it all. Two people can exchange experiences through speech and writing, but the recipient is entirely responsible for processing and decoding the message, and, in the end, everyone must live through an event in order to gain the experience of it. Subjective reality is also accessible to animals. We can train a dog or tame a horse. This does not, however, mean that all dogs and all horses are trained and tamed. In this context progress means making new associations, learning and experiencing. These functions are all specific to particular individuals.

- Subobjective reality, which exists only where many people share a belief, a mythology, or conviction that others behave according to agreed conventions. This type of socially constructed reality makes it possible to create legal fictions such as money, currency markets, or security. These fictions become real through behaviours which modify the physical reality. By introducing the notion of monetary value, we can assign purchasing power to pieces of paper and accept them in return for goods and services even though in reality it is impossible to attribute to them an absolute, direct usefulness. At this level endless progress is entirely possible.

It is the ability to create subobjective realities that separates us from animals. We can create anything we can imagine. This means that every conceptual system, every culture and every economy will work so long as the majority of its participants believe in it. We currently accept that all people are equal and each person has rights. We have created organisations whose sole aim is to ensure that these rights are protected, even though there is no such thing as rights in nature.

We must recognise that, when we assume the subobjective reality to be real and objective, we are bound to make errors due to our disconnection from the physical world.

Nowhere is our realisation of this disconnection better illustrated than in our recent creation of virtual reality, entirely unreal and yet capable of eliciting the same reactions from people, as the engagement with the real world.

\section{The theory of inertia: limits of the progress}

Humans are limited by their very being in the world and consequently, we will never truly understand ourselves. This is especially true of the entire workings of the human brain, understanding which would be the best basis for creating a perfect android. We do not understand consciousness because if we did, we would be able to transplant it onto non-human entities, and the idea of humanity would be forever transformed. Until this happens, our failure to account for our limitations leads us to create unverifiable myths. One of the chief human errors is the assumption that we can evaluate and predict the future.

When Isaac Newton published, in his 1697 Philosophiae Naturalis Principia Mathematica, the equations which describe natural phenomena in the language of mathematics, the process of altering our understanding of the world began. Since Newton's equations proved verifiable across many fields, people came to believe that 
it is possible to formulate a universal equation descriptive of the workings of the entire world, or a part of it, even if this part is in fact a created subobjective reality.

The nineteenth century was replete with scientific discoveries; more and more exceptions to Newton's laws were recorded, and ever more sophisticated scientific theories were proposed. All of this culminated in the early twentieth century, with the development of quantum physics and mechanics. This intricate model explains the world better than Newton's laws, but it is not widely applied because of its complexity. Quantum theories broadly conclude that every macro-scale process is the result of laws governing the micro-scale. We must therefore realise that human behaviours are also the result of physical processes at the molecular level. Everything is comprised of atoms, and these are governed by micro-scale laws whose effect will be noticed in the macro-scale.

Let us assume that quantum theories are correct and that, accordingly, the only certainty is that any given activity will have an effect, but we cannot establish specific probability of a particular effect.

Alternatively, let us assume that the probability of each effect is $50 \%$ : it will either happen or not. Very frequently, processes progress differently than planned, and, therefore, any prediction potential will be flawed. Humans tend to rely on experience, but this method is never fully verifiable. We can capture the relationships between individual elements of various prediction models in (Figure 1)

In effect, the ability to foresee future precisely is very limited and flawed. The certainty of each event can be calculated as 50\%, which should lead us to seek out not just the possible events but also their consequences. In existing models, probability is not the measure of objective reality but a subjective image of the existing models' ineffectuality.

We may form the following observations [3] based on the above diagram:

1. Possible events are not unlimited, and the number of possible events depends on the correlations between the relevant factors, with varying threshold limit values to each combination. It is also possible to define threshold properties of events, based on their combinations, although it is not always possible to identify individual events. At the same time, every possible event will be congruous with its nature, even if we are not aware of what it is.

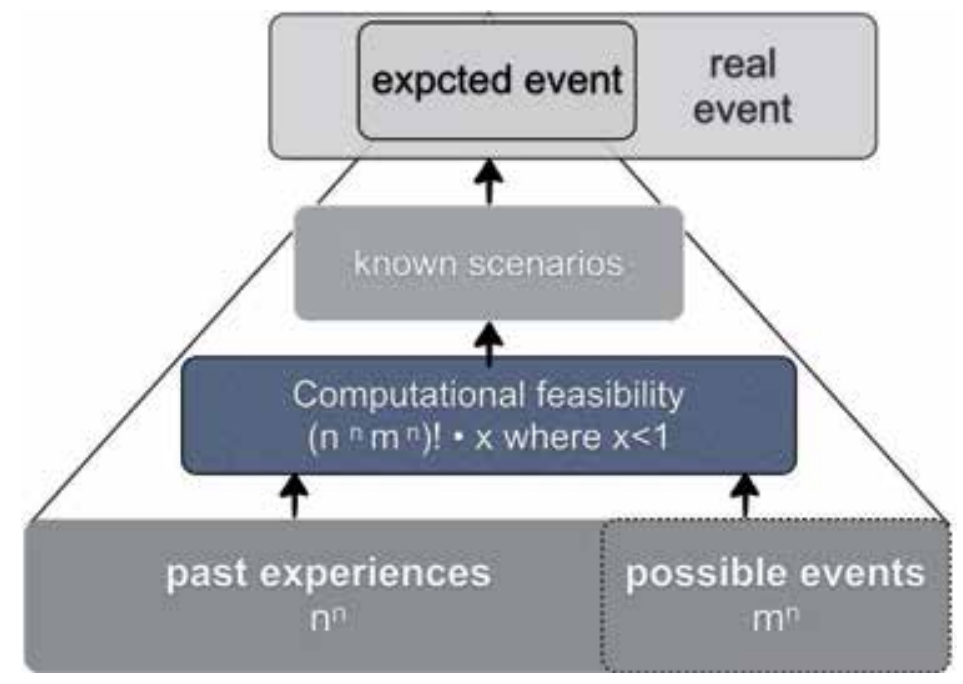

Figure 1.

Determinants of decision verifiability. 
2. Human experience is based on concrete past events, recorded in the individual and the collective memory. Describing history as it does, this data set also informs us about the possible futures: the greater the set, the more possibilities for consideration. However, the set is never complete-giving rise to the black swan phenomenon, as well as sod's/Murphy's law. This appears to be congruous with the wider laws of physics and explains the inadequacy of future event prediction models which rely on computation using arbitrary coefficients.

3. Identification of possible events is based on computational feasibility; however, the focus should be on predicting possible consequences and deciding the course of action based on preparation for all eventualities, rather than on event probability. Stock exchange analyses are a particularly good example: the more complex the model, the better the analyses-which still does not rule out error. This is because human behaviours within markets result from subobjective processes and attempting to assess these processes alters the behaviours. However, if we account for acceptable losses and expected profits for each transaction, to succeed we simply have to ensure that expected profits outweigh acceptable losses. If we make $10 \%$ on a profitable transaction, we can invest five times in a row and lose $1 \%$ : we still make a profit.

4. Known scenarios (as expressions of the applied computational feasibility) will be appropriate to the degree to which past experiences and possible events are considered.

5. If, at the stage of future event assessment (identifying scenarios), we fail to consider possible events not based on experience, our analysis will be flawed.

Without a specific methodology, it is impossible to avoid the limiting influence of experience; therefore, no risk assessment is fully rational. It should, instead, be regarded as ancillary and not the foundation of decision-making.

The above arguments led to the development of the theory of inertia [4]. This model is informed by the following premises and correlations:

Premise 1 . The probability of positive and negative outcome of our actions is always $50 \%$. We have no influence over the outcome of our actions.

Premise 2. Since we cannot influence the actual event which will pass as the result of our actions, any focus on this event will be futile. The outcome for our enterprise will be the result of our preparation for the event, and not of actions taken to achieve the desired outcome.

Premise 3. Preparation for all possible outcomes (negative as well as desired) should be the goal of our actions. Lack of preparation is a decision which will result in negative outcomes.

Further, we note the following correlations:

Correlation 1. Negative outcomes of every action are the result of human errors or mistakes or machine malfunction. The risk of negative outcomes can be minimised through multi-level monitoring and controls which would verify that decisions are taken based on sound assumptions, that actions are followed through, and that machinery is kept in working condition with timely checks, repairs and part replacements.

Correlation 2. If the outcome of our actions does not result from human or machine factor, we have no influence over it. In such cases we must develop contingency procedures for all outcomes beyond our influence.

Two more correlations have been observed in addition to the above:

Correlation 3. When analysing real events and human behaviours, we must be aware that attempting to assess these events and behaviours may alter the 
behaviours, rendering the analysis unverifiable. If an organisation publishes plans to increase sales and the market share, it can help achieve these plans if the potential investors respond positively, or it can have the opposite result if they react by supporting the competition, for example, in order to prevent a monopoly.

Correlation 4. Micro correlations must be reflected in the macro-scale. The family and the state should function according to the same budgetary norms. Neither one, nor the other, can freely spend means which they do not possess.

Failure to consider the above statements leads to a partial understanding of an event. A model which fails to consider alternative outcomes is incomplete, and analyses based on such a model are unverifiable. The idea of GDP growth based on direct investments financed by taxes entails limiting economic activity and degrading the purchasing power of all market participants. If our analysis does not consider this outcome, it will be uncertain and unverifiable. Analyses predicting constant growth and development can be equally unverifiable.

\section{Market growth cycle}

All social sciences-including the sciences of safety and of economics-assume that everything is subject to change. These sciences try to explain correlations and enable better forecasting of changes. Investments and the behaviour of market participants depend on the verifiability of such forecasts. As noted above, during planning we have to account for at least the following characteristics of the system within which we operate, in micro- as well as macro-scale:

- Non-analysability (first-degree system): analyses and their publication do not influence the behaviour of the system.

- Analysability (second-degree system): analyses and their publication can influence the behaviour of the system and the expectations of its development.

The second instance especially requires us to pay attention to avoid the limitations of inertia-led thinking. The benefits available to us are illustrated in Figure 2.

Every product and service, as well as other products of human initiative, such as notions of value or cryptocurrencies, are subject to economic cycles. Every entity begins, develops and then ends. The development of all aspects of human activity can be seen on the diagram.

We can assume that every product, service and state in the introductory phase are characterised by low sales or limited distribution. Next comes the growth phase, characterised by increased external parameters. After that comes maturity: the activity stabilises, and its features become fixed. Both latter phases are characterised by a steady sales growth (or another type of distribution growth). This is usually accompanied by the economies of scale effect: the decrease of cost of production/provision per unit. The activity's market success leads to the appearance of copycats; competition and imitations follow swiftly, except in situations where physical or subobjective barriers exist. This leads to market saturation and, eventually, to the decline of the activity: sales fall for all producers.

Growth parameters do not always mirror cost parameters. Usually the costs are high to start with, and then they fall. The diagram below illustrates it with segment A-B. Usually, this tendency prevails until the moment cost parameters fall below growth parameters (Figure 3 ).

Segment C-D is the state of maturity: costs fall, and profits stabilise. New players enter the market, interested in a share of the profits. Usually, this results in falling 


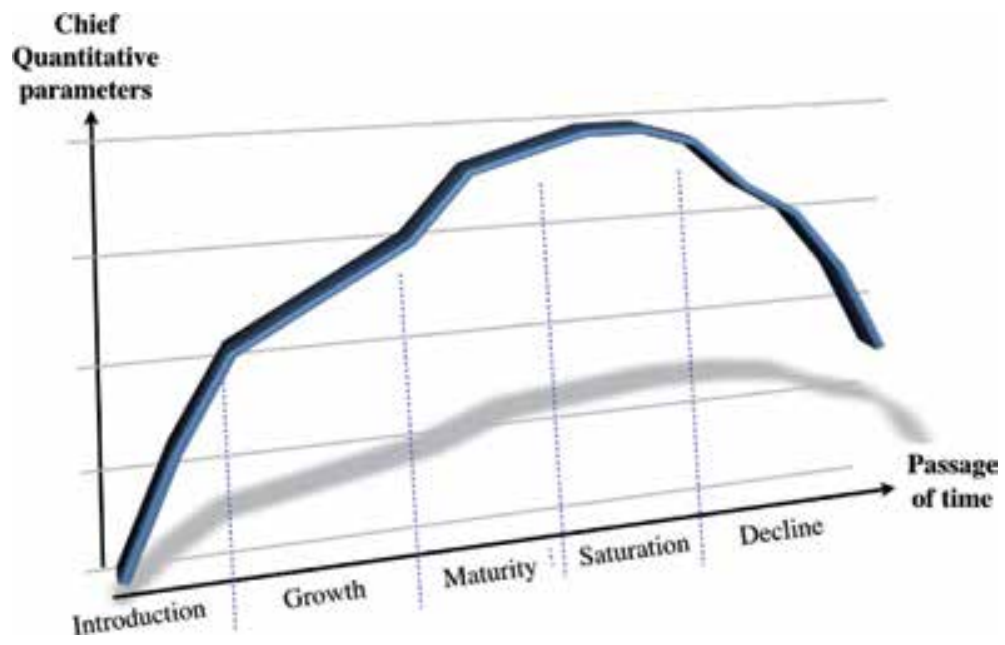

Figure 2.

The development of all aspects of human activity.

consumer prices, but product/service creators can continue to lower their costs, and so their profits continue, despite falling prices. By the time we reach market saturation (segment D-E), it appears that costs have been borne and our continued operation entails only direct costs of production. When the market shrinks and we produce less, our direct costs also fall. However, we may be faced with indirect costs. If prices of land or means of production fall or if the costs of invested capital, which cannot be freed up in a particular situation, grow, our profits will diminish. The current sciences of marketing and management provide a lot of ideas on cost cutting, efficiency maximising and measuring the quantitative parameters of our activities. A lot of time and effort is usually devoted to extending the maturity phase and preventing falling sales. Marketing at the micro-scale and regulation at the macro-scale can extend maturity and saturation, but they cannot change physical and systemic limitations. If our analyses remain only partial, losses become a real risk.

According to the theory of inertia presented above, growth is only possible until the limits are set by the physical and subobjective reality.

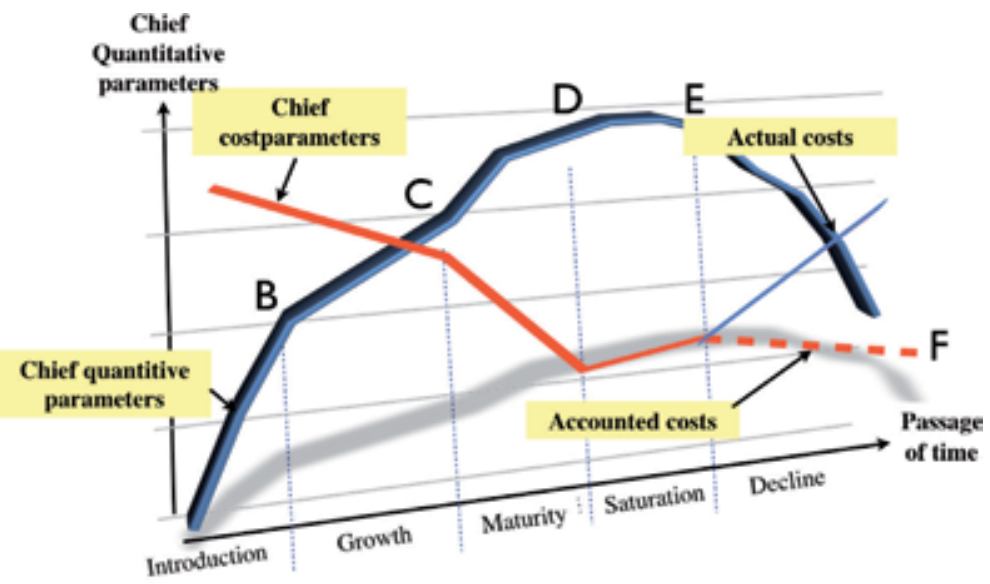

A

Figure 3.

Main trends in activity. 
How does this theory influence our vision of the life cycle?

Broadly speaking, every civilisation develops until the point when its foundational system of subobjective beliefs is exhausted. Political and religious powers are part of this system and are not above it. Political and religious tweaks to the system can alter profoundly the subobjective and physical reality. If the consumption of a particular type of meat becomes a moral norm, it extends the maturity and saturation phases for the meat producers. The curves which illustrate the real economic cycles differ significantly from the relevant theoretical considerations. Particular phases are longer or shorter, and they develop faster or slower. Our desire for domination pushes us towards maximisation. We want forever more and forever new, but a moment comes when we cannot demand greater prices for the goods and services we provide and where there is no greater efficiency to be striven for. When we reach this point, we have three options.

Option 1. Our idea/activity succumbs to stagnation or decline. It will cease to excite or inspire confidence and will attract fewer buyers. Consider black and white television sets or cassette players. After growth and saturation, these products no longer sell, and offering them is not cost-effective. A niche market may continue for connoisseur consumers, but it will be characterised by high prices due to high costs resulting from a lack of economies of scale.

Option 2. Our idea/activity stops developing and becomes irrelevant to the market. Maturity-/saturation-level indicators hold for a long time beyond this point.

Consider the bicycle. More or less 150 years old, it was expected to be superseded by the motorcycle and the motorcar. More recently we have had electric bicycles, but the original idea continues to inspire and attract purchasers. Today nobody tries to unseat the bicycle with a new invention, although within the category new ideas and new technologies supplant old ones. But the basic concept of a human-powered two-wheeled vehicle remains the same.

Option 3. Forced development. After the market saturation phase, it remains possible to maintain high quantitative parameters, however, at disproportionately high costs. We can force development by way of profit concentration and cost dispersal and lower profits per unit. Take steel. The technology dates back to the seventeenth to nineteenth centuries, when it developed rapidly and with revolutionary results. The twentieth century relied mostly on technologies which had already been in place, and in global production terms, we reached peak steel. First steel-related patents appeared during World War One. The task of patents is to limit competition and concentrate profits: such moves aim to maintain or increase quantitative parameters through increasing barriers and costs. The technology itself moves slowly: we have electroslag remelting of stainless steels and continuous casting. We add new elements to create new alloys, but these are incremental changes, nothing revolutionary for the technology or profits it promises. To get more steel, we simply have to increase our ongoing depletion of the natural environment. As a result, other measures are deployed to increase/concentrate profits, such as offshoring production to countries in which the costs of production are lower and environmental regulations less stringent. Steel production profits invariably migrate to regions other than where it has been made and are limited to fewer individuals than the numbers of those affected by the costs of production and environmental destruction.

Let us look at warehousing. First, we had pallets and pallet racks. These became a standard even in small warehouses. Improvements followed: half-pallets, folding pallets, etc. More recently, automated warehouses have appeared, which can be developed until the limits of construction or organisational safety are reached. What is more, it turns out that economic indicators adjust to the majority view. Do we need automated warehouses? It cannot be known, but the majority of vocal economists view them as a necessary development. 
Another example is crash statistics: The larger the vehicle, the greater the damage, and the greater the surface and load capacity, the more damaged goods. Which way do vehicles develop? We make vehicles lighter and yet larger, more capacious. We create gargantuan warehouses and monster vehicles, which are then driven bumper to bumper. The ever-decreasing efficiency and the ever-increasing environmental costs of such a system are clear for all to see. Growth will occur, but at the price of environmental destruction and, what follows, human annihilation. This is where growth is heading, if we ignore correlations stemming from the theory of inertia. Currently, we try to limit the effect of transport on the environment by tweaking fuelling technologies which cause toxic emissions. We imagine that electric vehicles will solve the problem. Indeed, we will reduce the emissions of $\mathrm{CO} 2$ during transport; however, the production, utilisation and disposal of car batteries are an environmental time bomb which we choose to ignore.

What volumes of greenhouse gas will we create in making electricity to power these batteries? As road users, we do not know and we are not interested. We focus on a popular topic and meanwhile we ignore facts. We keep alive a fossilised system, the costs of whose preservation will continue to grow and in which the concentrated profits generated by the transport industry will be neutralised by dispersed losses. Instead, we should modify the economic model to reflect real observations. We can do this by accepting the necessity to account for the inevitability of the end. In teaching economics, we should point to the opportunities for growth but also to the indicators that an activity should be ended. In accordance with the proposed theory of inertia, it is impossible to secure endless growth, but it is possible to identify the criteria for points (or states) at which an existing system ought to be reconfigured into a different system or subsumed by another system. We can illustrate it in (Figure 4).

For the time being, we shall ignore costs and efficiency; instead, we shall focus on the quantitative parameters of a system, such as sales or production quantities.

To start with (segment $\mathrm{A}-\mathrm{B}$ ), growth is slow and requires considerable investment. Initial implementation is the goal at this stage. Ideas are all-important, and sales are in the hands of those who own the product. At this stage of creating a sector, an organisation or a product, intellectual piracy can happen: the general public learns about the

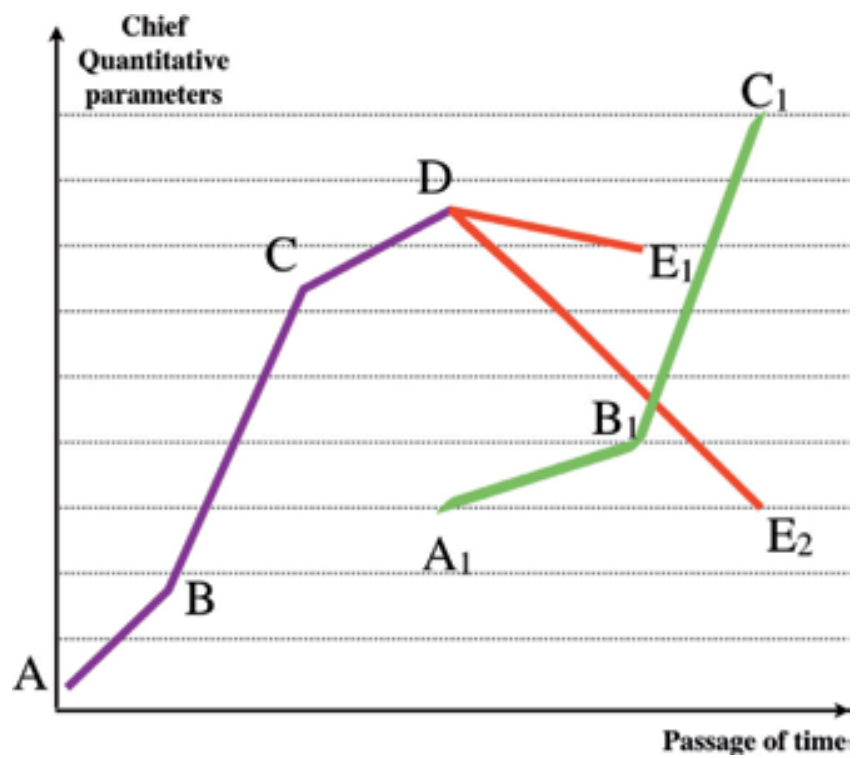

Figure 4.

Activity analysis. 
real creators of revolutionary activities after many years or never. The more time passes since the creative act, the easier it is to foster a creation myth. In this way we can build an intersubjective reality which will help develop the product and its market potential.

By the time we have passed point $\mathrm{B}$, the proposed model is widespread; however, most consumers prove to be happy with a lower-quality product or service than initially expected.

The digital revolution follows the same rules. The idea of storing and processing information as binary code on digital media has become universal, but initially few organisations were able to use computers as their creators intended, to their full capacity. Initially, computers were bought mainly to serve as digital typewriters: the idea and its possibilities were ahead of their time, and the creators had to accept this restricted use-both the consumers and the producers tacitly agreed to self-limit. Technology does not stand still, however, and subsequent product and market innovators made improvements to data processing itself and to the way in which it was presented for consumption. Progress has occurred; we move from theory to practice. Organisations reproduce each other's solutions. Improvements (and patents) increase. The system develops until all possibilities have been exploited and there is no further economic reason to continue further development. We have reached point C. In reality, this point is often reached inconspicuously. Organisational inertia occurs: too many people are interested in saving the status quo, what they know and what they are used to, to accept that an idea or activity has reached the end of its possibilities. From this moment on, any development is forced at a disproportionate cost. As mentioned above, when a new service enters the market, we can observe increased innovation. In the marketplace, this is reflected by an increase in patents, utility models and new solutions. Innovation is especially high at the beginning and at the end of the growth phase (segment $\mathrm{C}-\mathrm{D}$ ).

The second peak of innovativeness results from the above-mentioned inertia and is an attempt to prolong the life cycle of the product/service. The growth phase is characterised by maximum efficiency and productivity. After we have reached point $\mathrm{D}$, we enter stagnation, and our indicators are less advantageous.

At this stage we can choose one of the three options discussed above.

Option 1: stagnation and decline, illustrated by segment D-E1

Option 2: acceptance of lower quality or other parameters, illustrated by segment D-E2

Option 3: forced development, illustrated by segment D-E3

The D-E2 and D-E3 variants are characterised by increased costs. The only way to fulfil the potential would be to make deep changes or introduce new solutions, before point $\mathrm{D}$. This is illustrated by the line A1-B1-C1, which mirrors the earlier line A-B-C and is subject to the same life cycle conditions: it runs inevitably towards D1, at which point its further development will be limited.

The solution is to transform an existing system into a part of another system or reevaluate the assumptions. The economy will grow until one of its resources no longer provides any possibility of growth. If we reformulate our goals and replace the old system with a new system before this happens, the economy will survive. If it does not, natural selection will occur, and only those who are best adapted to the new conditions will survive.

If a country's GDP reaches a level determined by its limitations (e.g. agricultural resources or mineral deposits) and at the same time the country's population continues to increase, a shortage will occur which will encourage people to concentrate profits and disperse losses, that is to say to displace the costs of maintaining assets.

In the past, war was a frequent means of rebalancing this shortage.

Currently, instead of war we are observing increasing segregation: the drive to maintain the assets of the rich West is causing a displacement and dispersal of costs. 
Cheap production in the East is causing environmental destruction and natural resource depletion but also the division of people into those who have and those who do not have the means to participate in concentrated profits.

Developing countries bear the greatest costs of the continued growth of developed economies because they do not have the means to optimise these costs. Climate change-all the violent weather we are already experiencing-is chiefly the result of the developed countries' activity. However, the repercussions affect mainly the poor nations. Additionally, if financing development is achieved through loans, we have a continual vicious circle of dependency. Poor countries must produce more in order to pay off their debts to the rich countries, who create the debts with their lending policies. Ultimately the costs are borne by the whole of humanity.

\section{Conclusion}

Economic theories, like every creation of the human mind, are cyclical: they are created, develop, linger and pass away. The theory of inertia stresses that awareness of the possibility of unplanned events, and being prepared for the effects of any such unplanned events, is crucial to our success and survival in real market situations. If we assume that the probability of every event is $50 \%$ and take measures to prepare for the effects of all possible future events, we increase our chances of survival. According to the theory of evolution, future-proofing is the basis of survival. Close inspection of our environment should convince us to make such changes to our existing system as to best utilise our resources and create new possibilities. Our analyses should consider the possibility of failure. What is important is not whether we reach a level of development indicated by a given value of GDP (Gross domestic product), but whether we are prepared for growth as well as for stagnation or shrinking of the economy.

\section{Author details}

Marek Różycki

M/D/R/K Trusted Adviser Group Sp z o.o. Mikołów, Poland

*Address all correspondence to: m.rozycki@mdrk.eu

IntechOpen

(C) 2019 The Author(s). Licensee IntechOpen. This chapter is distributed under the terms of the Creative Commons Attribution License (http://creativecommons.org/licenses/ by/3.0), which permits unrestricted use, distribution, and reproduction in any medium, provided the original work is properly cited. (cc) BY 


\section{References}

[1] Dawkins R. Extended Selfish Gene. Oxford: Oxford University Press; 2016

[2] This belief is present in many religious texts. In the Bible we are told to subdue the earth, whereas in the Quran we are placed at the centre of the world and given all the world's goods by God

[3] Rozycki M. Paradigms of risk, hazards and danger. In: Hessami A, editor. Perspectives on Risk, Assessment \& Management Paradigms. London: Intechopen Limited; 2018

[4] Rozycki M. Inertia in procurement risk management. In: Jabłoński A, editor. Sustainability and Scalability of Business Theory and Practice.

New York: Nova Science Publishers Inc; 2017 


\title{
Building the Link between Technological Capacity Strategies and Innovation in Construction Companies
}

\author{
Tugce Ercan
}

\begin{abstract}
Interest in construction industry innovation has been growing with the globalization and in parallel with change of the building production processes. However, despite its potential for gaining sustainable company performance, many construction companies have failed by management of innovation. In this context, the main theme of this study is to examine how technology capacity in construction companies changes according to the main innovation areas. The technology capacity and the integration of technology to organization is one of the main determinants of construction innovation. The main purpose of this study is to determine how the existence of different innovation areas in construction companies is related to the technology capacity features. A questioner survey was conducted to collect data from construction professionals, and they were asked assess their company's current position about technology capacity and activity level of predicted innovation areas-product, process, and organization. Independent sample t-test was employed to see the differentiation of technological capacity among different innovation types. The results indicate that the technology capacity of the construction companies, which are active in the fields of product, process, and organizational innovation, is in a varying strength.
\end{abstract}

Keywords: construction company, innovation, technology capacity, product innovation, process innovation

\section{Introduction}

Construction activity in Turkey is undergoing a transformation due to changing lifestyles and evolving needs. In recent years, intelligent building systems, environmental buildings, modern living spaces, home-office systems, and entertainment and activity centers have become indispensable for modern projects in the direction of new tendencies in the sector. The importance of urban transformation in Turkey increased in housing market. In the first three quarters of 2017, the annual real growth by $10.2 \%$ in the domestic construction sector exceeded GDP growth of $7.4 \%$. Turkish construction companies continue to operate actively in domestic as well as abroad. In 2017, the total value of projects undertaken by Turkish contractors increased by USD 1.6 billion compared to the previous year and amounted to 
USD 14.7 billion. The construction sector is highly sensitive to economic activity. Production in the sector is generally in line with economic activity. However, in the recent years, activities in the sector depend on the internal dynamics of the market conditions.

When we compare the Turkish construction sector with other sectors, it is observed that it is slow in terms of innovative trends, and technology-oriented innovation development and adaptation remains to be seen. According to the research results of Genç et al., only $14.8 \%$ of Turkey construction sector professionals are sufficient with innovation level in the construction sector [1]. However, in today's market conditions, innovating and adapting to it is critical for sustainable firm performance. The construction sector, which also triggers the internal dynamics of the markets in the country, is expected to show improvement in innovation areas.

Drucker emphasized that innovation is a major responsibility of management in all industries [2]. With the new dynamics of competitive international markets, the importance of this responsibility has also increased for construction companies. As a result of rapid developments in technology, changes in the number and quality of the connections of the sub-markets in different geographies of the construction sector have been actualized. This change allows firms to participate in international competitive environments, creating different competitive conditions and making innovation an important means of competition. As Carbonara and Pellegrino indicated that market concentration seems to be positively correlated to the innovation in construction industry; however, the internal technology capacity is also a necessity. For example better innovation opportunities are created through new contracting systems, such as BIM-based procurement procedures [3]. Bengtsson emphasized the importance of coordinated construction logistics that might not only be to increase productivity but also to facilitate collaboration, learning, and innovation between interorganizational actors [4].

In this context, the main theme of this study is to examine how technology capacity in construction companies changes according to the main innovation areas. Technology capacity of the construction company is a decisive force for product, process, and organizational innovations. Effective use of technology in products and processes is a decisive factor in ensuring collaboration that ensures the innovation process. It is unrealistic for the construction company to manage the complex processes of construction project without technology support and to be successful in collaboration. In that case, the size of the innovation in the construction company is strongly linked to the technology capacity. However, there is a lack in literature on how technology capacity need is transformed among different innovation types. So the main purpose of this study is to determine how the existence of different innovation areas in the construction companies is related to the technology capacity features. Searching for answers on how the differentiation for technology capacity requirements for innovation types in construction companies can be called as sub-purpose of this study. Product, process, and organizational innovations have diverse technology needs for formation in construction business.

The technology capacity and the integration of technology to organization is one of the main determinants of construction innovation. As Holt insisted that "radical innovations are the result of technological impetus, whereas minor innovations that follow arise in response to market demand" [5]. In that case, innovation in construction is a phenomenon that takes place with technology capacity within the organization and market pressure. Market and customer demands create beginnings and opportunities for innovation, but they are not enough. Findings of the work will provide important practicalities for future theoretical work on innovation in construction. 
Building the Link between Technological Capacity Strategies and Innovation in Construction... DOI: http://dx.doi.org/10.5772/intechopen.88238

\section{Technology capacity and innovation in construction companies: theoretical framework}

Technology capacity is the managerial and organizational skills that an organization needs to efficiently utilize hardware and software technologies and to complement technological change processes [6]. Technology capacity, which we can define as the ability to find and use technology to maintain and achieve competitive advantage, is the use of the company's technical resources and all its technical functions to enhance and modernize the company's productivity and performance [7]. Whereas innovation is the application of new knowledge to the industry, this practice can take place in the forms of product, process, social, and organizational change.

Technology capacity develops in company' processes and is reinforced with the old experience of the company. Jin and Zedtwitz propose three basic steps to describe the technology capacity in organizations: acquisition, analogy, and technology development [8].

- Acquisition: Companies choose technologies from developed countries and acquire mature technology from multinational companies to reduce their entry risks and R\&D investments.

- Analogy: Companies absorb the transferred technology and distribute the technology into the company.

- Technology development: Firms develop and innovate their own new technologies, ultimately enabling domestic technology to compete with top-notch innovations in developed countries [9].

In developing countries such as Turkey, construction firms often develop technology capacity in the forms of acquisition and analogy. "Technology development," which includes pure innovation, is proceeding in the form of purchases from developed countries and other sectors.

Technology capacity is an array of information that includes both practical and theoretical knowledge as well as methods, procedures, experience, and physical devices and equipment. Technology capacity includes the company's superior and heterogeneous technical assets and is closely related to product technologies, design technologies, process technologies, and information technologies [8].

Technology capacity, in this context, can be considered as the core capability that enables firms to develop and sell products and services valued by targeted customers and to manage customer relationships more effectively [10].

Technology capacity also refers to the ability to develop and design new products. It processes and updates the information about the physical world in unique ways and ensures that this information is converted into the desired designs and instructions. Thus, not only the technological capabilities but also the capabilities to expand the basic competencies effectively mobilize the technology flow and technological resources [11]. Moreover, technology capacity requires a deep scientific understanding. Unlike science, technology capacity is often implicit in firms' experiences and skills, as well as the ability to produce new knowledge [7].

For this reason, we can say that the strong tendency toward technology capacity will increase innovation efficiency. Innovation process and the ability to change construction companies are slower than in other manufacturing sectors. Adaptation of new ideas to the process and product is more difficult and slower [12].

Construction companies do not do laboratory work to develop radical new ideas, 
but instead develop innovative solutions to solve everyday management problems. Innovation activity takes place in fractional and gradual stages in the construction companies' process [13].

The innovation in construction often has a particular tendency to be developed specifically at the project level ( $a d$ hoc), whereas in other production sectors, innovations are being developed in line with the ideas of employees, with their experience in production and service provision, and the challenges they face. In present market conditions, innovation and innovation management are admitted as an important tool in determining competitive advantage and organizational performance.

Barret et al. pointed out that there are many differences regarding innovation between the construction sector and other production sectors [14]. For example, in the building life cycle, the construction industry is constantly active and influential as a system; hence, a much larger proportion of the stakeholders must be involved in the innovation process, and innovation can arise in any area. Innovation in construction involves many actors, including governments, building material suppliers, designers, general contractors, specialist contractors, the labor workforce, owners, professional associations, private capital providers, end users of public infrastructure, vendors and distributors, testing service companies, educational institutions, certification bodies, and others. In their study on the role of stakeholder engagement in construction innovation, Widén et al. emphasized the need to develop communication plans as well as the formation of stakeholder engagement plans and strategies for prominent stakeholders as an integral part of construction innovation [15]. Therefore, innovation in construction takes more than the changes in people or ideas; the whole company must be organized in this direction, and the technological capacity of the company is one of the most important sources of innovation.

\subsection{Basic innovation areas in construction companies}

There are different ways to classify innovation in project-based organizations. A common classification originating from manufacturing studies is to separate between product and process innovations [4]. The first is product innovation. Products of construction are mostly durable so that it is usually possible to defer replacement of an existing structure. Another reason is that products of construction are usually costly investments. Product innovation represents innovative product/service development and delivery to the marketplace. The product may be a physical one, or it may be a combination of physical product and service as well as construction. In the context of the construction company, the application of innovative design trends, the application of new materials, and the implementation of technological innovations that will increase productivity are possible activities in this innovation area. From another perspective product innovation in construction is knowledge about design science (knowledge of behavior of the nature and knowledge of strength, stability, cost, esthetics, and function of the combined materials in the nature) and the knowledge about construction materials [16]. Kuznets also pointed out the central role of product innovation in long-term economic growth [17]. Nam and Tatum pointed out that product innovation is perhaps the most important contributor to the technological progress of the construction companies [16]. Some of the product-focused innovations described by managers involved in this study's field work include the development of new construction methods in seismic isolator structures, hard fill applications, the development of new materials in prefabrication and the design of better fasteners, and the development of sustainable building materials. 
Nam and Tatum identified four key factors in product innovation in construction: owner's demands, problems, designer's bank of technology, and contractor's process technology [16]. The owner's demands are the key initiator of the innovation process for a constructed product. In a design company, key employees' technological capability is a reference point for innovative buildings.

The second basic innovation area is process innovation that is related to its capacity to be fast and flexible in construction processes. The knowledge about construction process-the methods for combining the materials, labor, equipment, tools, energy, new procurement systems, and other resources complete the basic elements of process innovation. It is able to provide standardization in building products and express the rapid adaptation of the changes in the project process in the organization. Being able to make different ways of construction methods from others is also considered as an important process innovation. Process innovation implies the development of internal processes and capabilities, including reengineering. Expert participants of this study indicated that enterprise resource planning (ERP) and system analysis and program (SAP) development applications for the organizational innovation in construction work, new hardware/software portfolio management information models, and proactive digital marketing strategies are developing elements for process innovation. Construction management; computer applications in design and construction, notably in computer-aided design and drafting (CADD); and integrating engineering and management data bases are also some examples for process innovation in construction. It is possible to say that lean construction and adaptation to Industry 4.0 area rising trends in the sector.

Finally, in the scope of this study, organizational innovation is discussed for the last basic innovation area. Organizational innovation can be interpreted as bringing the organizational structure into an innovative structure in general. It is important to design a target-oriented project organization structure. The development of collaborative work environments, major changes to the organizational structure, introduction of cross-functional teams, and outsourcing of major business functions are the other areas of activity to improve the technological infrastructure of communication channels and improve organizational structure.

It also deals with the implementation of a new or significantly changed corporate strategy and is about advanced management techniques, for example, knowledge management systems, Investors in People, etc.

\section{Methodology}

This study is a descriptive research. The descriptive research study is typically concerned with determining the frequency with which something occurs or the relationship between variables to make predictions [18]. After conducting an extensive literature review, the problem statement, research framework and measurement parameters for research construct were determined. To predict the differentiation of technological capacity among different innovation types like product, process, and organization in construction companies, a sample survey such as a cross-sectional study was conducted.

To assess the reliability of the research, Cronbach's alpha coefficient was employed. The reliability of the scales was measured by Cronbach's alpha, and these were compared to those in previous studies. The fact that the factor structure of a scale is appropriate for the theoretical underpinnings is a desirable component of studies on validity and reliability. Cronbach's $\alpha$, as a measure of internal consistency, was also used to examine the reliability of the measurement scales. This value 
is expected to be over 0.60 [19]. The reliability test results for the scales used in the research were above 0.60 , which indicates that all factors have internal consistency $(\alpha=0.944)$.

\subsection{Field research: innovation areas and technology capacity link}

The survey asked construction professionals to assess their company's current position about technology capacity. This survey consisted of four sections: (1) demographic data of the respondents (specialization, education background, age, etc.), (2) company information (size, location, market, etc.), (3) assessment the levels of technology capacity of the construction company, and (4) assessment the applied innovation types. Survey questions of technology capacity were asked using a seven-point Likert scale (1, strongly disagree and 7, strongly agree). The presence of different innovation activity types were asked as dichotomous questions (0, Active and 1 , Non-active).

In this study, Wang's technological capability measurement scale (with Cronbach's $\alpha$ value of 0.90) [10] was employed to assess the construction company' technological resources and abilities (Table 1). Wang's technological capacity measurement scale consists of 10 parameters referring to technological capability of the construction company like investment in R\&D activities, on-the-job training opportunities, etc. Figure 1 states the research framework of the study. According to the framework, this study assumed that technology capacity is a strong predictor for being innovation active in three basic innovation activity areas: product, process, and organization.

Statistical analyses were undertaken using the Statistical Package for the Social Sciences (SPSS). Independent sample t-tests were performed to test whether the mean values on each TC parameter for the groups were equal for:

a. Product innovation active and non-active

b. Process innovation active and non-active

c. Organizational innovation active and non-active

Technological capability measurement scale

TC1. We always make relatively heavy investment in R\&D activities

TC2. We have accumulated stronger and various technological skills

TC3. On-the-job training is provided frequently in our firm to improve the technical skills of employees

TC4. We are qualified to attract and motivate talented experts

TC5. We have the ability to accurately predict future technological trends

TC6. We are skillful in applying new technology to problem solving

TC7. We are one of the leaders in construction industry to establish and upgrade technology standards

TC8. We always lead technology innovation of the principal industry

TC9. Compared with our major competitors, we have competitive and powerful technology strategy

TC10. We have strong capability to integrate external technological resources with in-house resources of our firm

Table 1.

Wang et al. [10] technological capability measurement scale. 


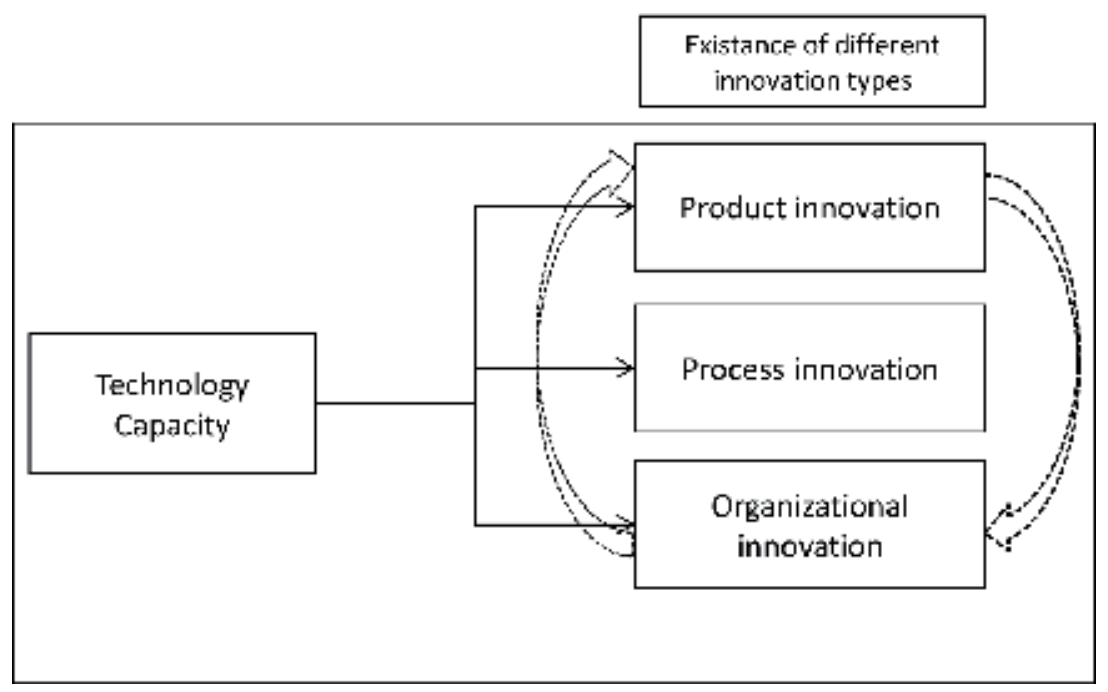

Figure 1.

Research framework.

\subsection{Sampling and data collection}

Regarding the scope of the study, the survey was sent to 150 members of the Turkish Contractors Association (TCA) and 150 members of Association of Turkish Consulting Engineers and Architects (ATCEA) via e-mail in a digital survey format. These associations represent a major portion of the civil engineering professionals in Turkey [20]. The pilot survey also revealed that most of the construction companies in Turkey apply innovation practices in a quantifiable manner. So there is no limitation for company size in this research as Mansfield suggests that the size of firms has little effect on innovation, at least when a firm is above some threshold size [21].

A total of 91 construction professionals actively working at construction companies in Turkey responded. Therefore, the survey's rate of response was $40 \%$. The respondents were senior- and middle-level managers of construction companies listed in TCA and ATCEA.

According to the demographics of the survey, $45.7 \%$ of the respondents were in the age range of $25-35$ years, while $31.9 \%$ were in the age range of $36-45$ years. About $58.6 \%$ of respondents were civil engineers and $13.8 \%$ of them were architects. When the survey participants' characteristics were examined, it was observed that $71.6 \%$ had more than 400 employees and $75.9 \%$ had a parent organization. The fields of activity of the participating firms are several such as housing construction, heavy construction, construction except housing, construction management, and design.

\section{Basic research findings}

\subsection{Link between product innovation and technology capacity}

Product innovation represents the development and introduction of innovative products and services. According to the results of the study, 34 of the 91 production companies reported to be active in the field of product innovation. There were two ways of interpreting the results of the t-test. The first method was to compare the test significance level against the level of significance, which was set at 0.05 . The 
alternative method was to compare the test $t$-statistics against the critical $t$ value. It can be seen from Table 2 that all the technology capacity parameters have significant level $<0.05$. When the technology capacity indicators of the companies that are active and not active in product innovation are examined, it is observed that the technology capacity of firms active in product innovation is high. To realize product innovation in construction companies, the parameters TC6 "the ability of application of new technologies in problem-solving" and TC5 "the ability to determine future technology trends and to determine the technology standards of the sector" become prominent. According to the empirical results, R\&D investments and technology leadership strategies are ineligible in firms where product innovation has not been realized. The technology capacity of construction companies where the product innovation took place differentiates statistically $(p<0.05)$ in all technology capacity criteria from the companies that do not realize product innovation (Table 2).

\subsection{Link between process innovation and technology capacity}

Process innovation involves reengineering function which means the development of internal operations and capabilities. According to the results of the study,

\begin{tabular}{|c|c|c|c|c|c|c|c|}
\hline \multirow[b]{2}{*}{$\begin{array}{l}\text { Technology } \\
\text { capacity } \\
\text { parameters }\end{array}$} & \multirow[b]{2}{*}{$\begin{array}{c}\text { Product } \\
\text { innovation }\end{array}$} & \multirow[b]{2}{*}{ Mean } & \multicolumn{2}{|c|}{$\begin{array}{l}\text { Levene's test } \\
\text { for equality of } \\
\text { variances }\end{array}$} & \multicolumn{3}{|c|}{ t-test for equality of means } \\
\hline & & & F value & Sig. & tvalue & $\begin{array}{c}\text { Sig. } \\
\text { (two- } \\
\text { tailed) }\end{array}$ & $\begin{array}{c}\text { Mean } \\
\text { difference }\end{array}$ \\
\hline \multirow[t]{2}{*}{ TC1 } & Active (34) & 5.50 & 3.277 & 0.074 & 5.582 & 0.000 & 2.06 \\
\hline & $\begin{array}{c}\text { Non-active } \\
\text { (57) }\end{array}$ & 3.43 & & & 5.96 & 0.000 & \\
\hline \multirow[t]{2}{*}{ TC2 } & Active & 5.85 & 19.232 & 0.000 & 4.818 & 0.000 & 1.73 \\
\hline & Non-active & 4.12 & & & 5.324 & 0.000 & \\
\hline \multirow[t]{2}{*}{ TC3 } & Active & 5.26 & 4.465 & 0.037 & 2427 & 0.017 & 0.96 \\
\hline & Non-active & 4.29 & & & 2.545 & 0.013 & \\
\hline \multirow[t]{2}{*}{ TC4 } & Active & 5.79 & 11.510 & 0.001 & 4.290 & 0.000 & 1.44 \\
\hline & Non-active & 4.35 & & & 4.748 & 0.000 & \\
\hline \multirow[t]{2}{*}{ TC5 } & Active & 5.88 & 5.337 & 0.023 & 5.150 & 0.000 & 1.86 \\
\hline & Non-active & 4.01 & & & 5.810 & 0.000 & \\
\hline \multirow[t]{2}{*}{ TC6 } & Active & 6.00 & 14.521 & 0.000 & 4.11 & 0.000 & 1.36 \\
\hline & Non-active & 4.63 & & & 4.72 & 0.000 & \\
\hline \multirow[t]{2}{*}{ TC7 } & Active & 5.67 & 12.830 & 0.001 & 4.91 & 0.000 & 1.85 \\
\hline & Non-active & 3.82 & & & 5.53 & 0.000 & \\
\hline \multirow[t]{2}{*}{ TC8 } & Active & 5.50 & 4.496 & 0.037 & 5.389 & 0.000 & 1.99 \\
\hline & Non-active & 3.50 & & & 5.935 & 0.000 & \\
\hline \multirow[t]{2}{*}{ TC9 } & Active & 5.70 & 5.301 & 0.024 & 4.154 & 0.000 & 1.53 \\
\hline & Non-active & 4.17 & & & 4.588 & 0.000 & \\
\hline
\end{tabular}

Table 2.

Independent sample t-test analysis results for product innovation. 
Building the Link between Technological Capacity Strategies and Innovation in Construction... DOI: http://dx.doi.org/10.5772/intechopen.88238

47 of the 116 construction companies participated in the study reported that they were effective in the field of process innovation. When the technology capacity indicators of the companies that are active and not active in the process innovation are examined, it is observed that the technology capacity of the companies active in process innovation are higher in accordance with the results obtained in the product innovation. In order to realize process innovation in construction companies, the parameters TC5 "the ability to accurately predict future technological trends," TC10 "strong capability to integrate external technological resources with in-house resources of our firm," and TC9 "strong technology strategies" are fundamental. In the companies where process innovation did not take place, there was insufficient development in the field of innovation-oriented R\&D investments and strong/various technical capabilities. In this type of construction companies, the intention of human resources to create initial ideas for innovation is weak. On the other hand, technology capacity of the construction companies where process innovation took place differentiates significantly $(p<0.05)$ in all TC criteria from the companies that did not perform process innovation (Table 3). Some examples

\begin{tabular}{|c|c|c|c|c|c|c|c|}
\hline \multirow[b]{2}{*}{$\begin{array}{l}\text { Technology } \\
\text { capacity } \\
\text { parameters }\end{array}$} & \multirow[b]{2}{*}{$\begin{array}{c}\text { Process } \\
\text { innovation }\end{array}$} & \multirow[b]{2}{*}{ Mean } & \multicolumn{2}{|c|}{$\begin{array}{l}\text { Levene's test } \\
\text { for equality of } \\
\text { variances }\end{array}$} & \multicolumn{3}{|c|}{ t-test for equality of means } \\
\hline & & & Fvalue & Sig. & tvalue & $\begin{array}{l}\text { Sig. } \\
\text { (two- } \\
\text { tailed) }\end{array}$ & $\begin{array}{c}\text { Mean } \\
\text { difference }\end{array}$ \\
\hline \multirow[t]{2}{*}{ TC1 } & Active (47) & 5.19 & 3.27 & $0.074^{*}$ & 5.72 & 0.000 & 2.03 \\
\hline & $\begin{array}{c}\text { Non- } \\
\text { active(44) }\end{array}$ & 3.15 & & & 5.69 & 0.000 & \\
\hline \multirow[t]{2}{*}{ TC2 } & Active & 5.76 & 19.23 & $0.000^{*}$ & 6.37 & 0.000 & 2.06 \\
\hline & Non-active & 3.70 & & & 6.27 & 0.000 & \\
\hline \multirow[t]{2}{*}{ TC3 } & Active & 5.29 & 4.46 & $0.037^{*}$ & 3.54 & 0.001 & 1.32 \\
\hline & Non-active & 3.97 & & & 3.52 & 0.001 & \\
\hline \multirow[t]{2}{*}{ TC4 } & Active & 5.68 & 11.51 & $0.001^{*}$ & 5.22 & 0.000 & 1.63 \\
\hline & Non-active & 4.04 & & & 5.15 & 0.000 & \\
\hline \multirow[t]{2}{*}{ TC5 } & Active & 5.59 & 5.33 & $0.023^{*}$ & 5.21 & 0.000 & 1.82 \\
\hline & Non-active & 3.77 & & & 5.17 & 0.000 & \\
\hline \multirow[t]{2}{*}{ TC6 } & Active & 5.80 & 14.52 & $0.000^{*}$ & 4.31 & 0.000 & 1.37 \\
\hline & Non-active & 4.43 & & & 4.26 & 0.000 & \\
\hline \multirow[t]{2}{*}{ TC7 } & Active & 5.44 & 12.83 & $0.001^{*}$ & 5.38 & 0.000 & 1.92 \\
\hline & Non-active & 3.52 & & & 5.32 & 0.000 & \\
\hline \multirow[t]{2}{*}{ TC8 } & Active & 5.27 & 4.49 & $0.037^{*}$ & 6.13 & 0.000 & 2.11 \\
\hline & Non-active & 3.15 & & & 6.09 & 0.000 & \\
\hline \multirow[t]{2}{*}{ TC9 } & Active & 5.46 & 5.30 & $0.024^{*}$ & 4.18 & 0.000 & 1.49 \\
\hline & Non-active & 3.97 & & & 4.13 & 0.000 & \\
\hline \multirow[t]{2}{*}{ TC10 } & Active & 5.57 & 10.76 & $0.001^{*}$ & 4.71 & 0.000 & 1.50 \\
\hline & Non-active & 4.06 & & & 4.64 & 0.000 & \\
\hline
\end{tabular}

${ }^{*}$ Statistical significant at level of $<0.05$.

Table 3.

Independent sample t-test analysis results for process innovation. 
of technological innovations adapted to management processes include adaptation of software portfolio management modules to integrated management systems, BIM maturity level, design, and development of ERP systems in the management of cash flows.

\subsection{The link between organizational innovation and technology capacity}

The organizational innovation field can be interpreted as bringing the organizational structure into an innovative structure in general. When the link between management innovation and technology capacity is explored, it is understood that the existence of management innovation in the construction firms is directly linked to the technology capacity. The maturity level of the technology capacity of construction companies that make the management innovation is significantly different from the firms that tend to stay traditional in terms of management. Innovation in the field of management is triggered by the use of new technologies to correct problems and activities in the construction process (TC6).

As Hartman stated out that the problems in construction business have a dependency of constructional tasks on clients or a dependency of constructional tasks on locations [22]. The changing demands of clients may lead to problems that may offer opportunities to propose a solution with new technologies that meets the demands best and create innovations. In addition to being influenced by technological capacity, innovation in the organizational field provides a convenient structure in its application. An investment that can be developed and implemented for a single project will not be feasible for both the firm and the investor.

The strong technological capabilities of the company are a prominent parameter for innovation in the field of management (TC4). The technological skills such as programming, project management, analysis of big data, data models, business intelligence, information security applications, etc. that the construction company own are also providers for innovative organizational structures (Table 4).

Ranking of the most differentiated technology parameters among different innovation areas.

A ranking of the working technology capacity parameters was carried out to determine the relative importance of the various TC parameters as perceived by the respondents (Table 5). This ranking is shown in Table 4. This shows that the four most important attributes identified were "TC6. We are skillful in apply new technology to problem-solving," "TC5. We have the ability to accurately predict future technological trends," "TC2. We have accumulated stronger and various technological skills," and "TC4. We are qualified to attract and motivate talented experts."

\subsection{Limitation of the study}

As with many studies of the construction industry, the selected research methods and data used in the studies can inhibit the generalization of the findings beyond the study sample [23]. First limitation effect on the study is the data gathering procedure. The surveys were not distributed to a random sample of the construction industry. And the second limitation of this study is that it was based on the measurement of the research constructs TC and INVACT using the survey respondents' own, perhaps biased, perceptions. Therefore, this research needs to be further examined using proper qualitative and quantitative measures instead of a self-assessment approach. Another significant point is that a larger sample size would provide greater reliability in the results. 
Building the Link between Technological Capacity Strategies and Innovation in Construction... DOI: http://dx.doi.org/10.5772/intechopen.88238

\begin{tabular}{|c|c|c|c|c|c|c|c|}
\hline \multirow[b]{2}{*}{$\begin{array}{l}\text { Technology } \\
\text { capacity } \\
\text { parameters }\end{array}$} & \multirow[b]{2}{*}{$\begin{array}{l}\text { Organization } \\
\text { innovation }\end{array}$} & \multirow[b]{2}{*}{ Mean } & \multicolumn{2}{|c|}{$\begin{array}{l}\text { Levene's test } \\
\text { for equality of } \\
\text { variances }\end{array}$} & \multicolumn{3}{|c|}{ t-test for equality of means } \\
\hline & & & F value & Sig. & tvalue & $\begin{array}{l}\text { Sig. } \\
\text { (two- } \\
\text { tailed) }\end{array}$ & $\begin{array}{c}\text { Mean } \\
\text { difference }\end{array}$ \\
\hline \multirow[t]{2}{*}{ TC1 } & Active (54) & 5.05 & 0.240 & $0.625^{*}$ & 5.779 & 0.000 & 2.08 \\
\hline & Non-active (37) & 2.97 & & & 5.794 & 0.000 & \\
\hline \multirow[t]{2}{*}{ TC2 } & Active & 5.59 & 5.550 & $0.021^{*}$ & 6.061 & 0.000 & 2.02 \\
\hline & Non-active & 3.56 & & & 5.827 & 0.000 & \\
\hline \multirow[t]{2}{*}{ TC3 } & Active & 5.16 & 4.272 & $0.042^{*}$ & 3.260 & 0.002 & 1.24 \\
\hline & Non-active & 3.91 & & & 3.170 & 0.002 & \\
\hline \multirow[t]{2}{*}{ TC4 } & Active & 5.62 & 6.270 & $0.014^{*}$ & 5.891 & 0.000 & 1.81 \\
\hline & Non-active & 3.81 & & & 5.611 & 0.000 & \\
\hline \multirow[t]{2}{*}{ TC5 } & Active & 5.46 & 1.863 & $0.176^{*}$ & 5.167 & 0.000 & 1.84 \\
\hline & Non-active & 3.62 & & & 5.101 & 0.000 & \\
\hline \multirow[t]{2}{*}{ TC6 } & Active & 5.75 & 12.772 & $0.001^{*}$ & 4.754 & 0.000 & 1.51 \\
\hline & Non-active & 4.24 & & & 4.492 & 0.000 & \\
\hline \multirow[t]{2}{*}{ TC7 } & Active & 5.35 & 2.283 & $0.134^{*}$ & 5.744 & 0.000 & 2.05 \\
\hline & Non-active & 3.29 & & & 5.650 & 0.000 & \\
\hline \multirow[t]{2}{*}{ TC8 } & Active & 5.11 & 0.458 & $0.500^{*}$ & 5.958 & 0.000 & 2.11 \\
\hline & Non-active & 3.00 & & & 5.989 & 0.000 & \\
\hline \multirow[t]{2}{*}{ TC9 } & Active & 5.51 & 1.128 & $0.291^{*}$ & 5.551 & 0.000 & 1.89 \\
\hline & Non-active & 3.62 & & & 5.419 & 0.000 & \\
\hline \multirow[t]{2}{*}{ TC10 } & Active & 5.53 & 2.813 & $0.097^{*}$ & 5.387 & 0.000 & 1.69 \\
\hline & Non-active & 3.83 & & & 5.217 & 0.000 & \\
\hline
\end{tabular}

${ }^{*}$ Statistical significant at level of $<0.05$.

Table 4.

Independent sample $t$-test analysis results for management innovation.

\begin{tabular}{cccc}
\hline & $\begin{array}{c}\text { Product innovative active } \\
\text { companies }\end{array}$ & $\begin{array}{c}\text { Process innovative } \\
\text { active companies }\end{array}$ & $\begin{array}{c}\text { Organizational innovative } \\
\text { active companies }\end{array}$ \\
\hline TC6 & 1 & 1 & 1 \\
\hline TC5 & 2 & 3 & 3 \\
\hline TC2 & 3 & 2 & 2 \\
\hline TC4 & & & \\
\hline
\end{tabular}

Table 5.

Importance ranking of technology parameters among innovation areas.

\section{Conclusion}

Innovation plays an important role in successfully responding to changes in the construction company's environment. Innovation is an important competitive edge and a prerequisite for organizational success [24]. Being open to changes and, 
respectively, adapting to new conditions need to be the main component of the innovation strategy in construction industry. Secondly, developing technical aids and using them for problem solving is indispensable component for being innovative in construction business. Industry relationships and client demands have an extremely significant influence on construction innovation $[23,25,26]$.

In order to produce innovation in a successful organization, different factors need to come together, and the knowledge assets of innovation should be managed effectively. The technology capacity covering the majority of the information assets of innovation is an important innovation enabler for construction companies. As a result of this study, it has been determined that the technology capacity of the construction companies, which are effective in the fields of product, process, and organizational innovation, is in a varying strength.

It has been predicted that product innovation activities in construction companies have increased and become active with the application of new technologies in problem solving. The use of innovative material and construction technique indoor or outdoor applications is possible by using the company's technology to solve problems in the emergence of this new product.

Process innovation, which is another innovation area, is developing especially due to integrating external technology resources with internal resources. For example, combining different project management modules with ERP, which is a holistic management system approach, will facilitate the implementation of an innovative system in the company's processes.

Finally, organizational innovation is an essential element for the formation and development of all kinds of innovation. The companies that are in the organizational innovation process have a high capacity to apply new technologies in problem solving, similar to the construction companies that perform product innovation. This means that the organization is open to change and can adapt to change. New project delivery models and organizational models are constantly evolving in the process of complex global construction projects. At this point, the management and perfection of multiple new connections of organizational change necessitate the adaptation of new technologies. As an example, IPD system applications are becoming a rising trend in the sector and necessitate the change and renewal of organizational structures. In this type of dramatic changes, the introduction of new BIM applications in communication and contract management processes becomes important for the project success.

Unlike other sectors, the construction sector is project-based, and the challenges brought by the cooperation and collaboration of stakeholders bring innovative developments to a standstill. The strengthening of both the technological infrastructure and the human resources in the context of the technological capacities of the construction companies is the main source for product, process, and organizational innovation.

Turkey as a developing country is in the process of harmonization with the European Union. In the process, according to the Republic of Turkey Ministry of Development's Tenth Development Plan (2014-2018), placing the concept of innovation in the construction sector, the locomotive of Turkey's economy, was in the main targets.

In this context, by supplying the production and service quality of the construction sector to international standards, supply and demand must be provided with a high-value-added and sustainable structure with an innovative approach. In order to maintain competitiveness abroad, focusing on high-quality and informationintensive projects is of great importance among the targets set by the ministry [27]. In this context, the fact that Turkish construction companies are active in innovation is gaining importance in terms of the economic plans of the sector and the 
Building the Link between Technological Capacity Strategies and Innovation in Construction... DOI: http://dx.doi.org/10.5772/intechopen.88238

country. The development of new technologies for the use of new technologies in the solution of the problems at various stages of the construction project comes to the fore in terms of both company and industry performances.

\section{Author details}

Tugce Ercan

Faculty of Architecture, Yildiz Technical University, Istanbul, Turkey

*Address all correspondence to: tugcesim@yahoo.com

\section{IntechOpen}

(C) 2019 The Author(s). Licensee IntechOpen. This chapter is distributed under the terms of the Creative Commons Attribution License (http://creativecommons.org/licenses/ by/3.0), which permits unrestricted use, distribution, and reproduction in any medium, provided the original work is properly cited. (cc) BY 


\section{References}

[1] Genç O, Bozkurt A, Coşkun H, Erdiş E. Türkiye İnşaat Endüstrisindeki İnovasyon Düzeyinin İnşaat Mühendisliği Penceresinden Görünümü, Çukurova University. Journal of the Faculty of Engineering and Architecture. 2015;30(2):183-189

[2] Drucker P. Innovation and Entrepreneurship. New York: Harper \& Row; 1985

[3] Carbonara N, Pellegrino R. The role of public private partnerships in fostering innovation. Construction Management and Economics. 2019;37(8):1-18. DOI: 10.1080/01446193.2019.1610184

[4] Bengtsson SH. Coordinated construction logistics: An innovation perspective. Construction Management and Economics. 2019;37(5):294-307. DOI: $10.1080 / 01446193.2018 .1528372$

[5] Holt K. Product innovation management. Technical report. Organization for Economic Co-operation and Development; Paris, France. 1983

[6] Morrison A, Pietrobelli C, Rabellotti P. Global value chains and technological capabilities: A framework to study learning and innovation in developing countries. Oxford Development Studies. 2008;36(1):39-58

[7] Afuah A. Mapping technological capabilities into product markets and competitive advantage:

The case of cholesterol drugs. Strategic Management Journal. 2002;23(2):171-179

[8] Jin J, Zedtwitz M. Technological capability development in China's mobile phone industry. Technovation. 2008;28(6):327-334

[9] Linsu K. Stages of development of industrial technology in a developing country: A model. Research Policy. 1980;9(3):254-277

[10] Wang Y, Lo H-P, Zhang Q, Xue Y. How technological capability influences business performance: An integrated framework based on the contingency approach. Journal of Technology Management in China. 2006;1(1):27-52

[11] Kumiko M. Interlinkages between systems, key components and component generic technologies in building competencies. Technology Analysis And Technology Management. 1994;6(1):107-120

[12] Loosemore M. Construction innovation: Fifth generation perspective. Journal of Management in Engineering. 2015;31(6):04015012(1-9). DOI: $10.1061 /($ ASCE) ME.1943-5479.0000368

[13] Pellicer E, Yepes V, Correa CL, Alarcón LF. Model for systematic innovation in construction companies. Journal of Construction Engineering and Management. 2014;24(2):23-36

[14] Barrett P, Sexton M, Lee A. Innovation in Small Construction Firms. 1st ed. London, UK: Spon Press; 2008

[15] Widén K, Olander S, Atkin B. Links between successful innovation diffusion and stakeholder engagement. Journal of Management in Engineering. 2014;30(5):04014018

[16] Nam CH, Tatum CB. Toward understanding of product innovation process in construction. Journal of Construction Engineering and Management. 1989;115(4):517-534

[17] Kuznets S. Economic Growth of Nations: Total Output and Production Structure. Cambridge, Mass: Harvard University Press; 1971 
Building the Link between Technological Capacity Strategies and Innovation in Construction... DOI: http://dx.doi.org/10.5772/intechopen.88238

[18] Churchill GA, Iacobucci D.

Marketing Research: Methodological

Foundation. 9th ed., USA: Chicago

Dryden Press; 2005

[19] Nunally JC. Psychometric Theory. New York: McGraw-Hill; 1978

[20] Ozorhon B, Oral K, Demirkesen S. Investigating the components of innovation in construction projects. Journal of Management in Engineering. 2016;32(3):04015052

[21] Mansfield E. Research and Innovation in the Modern Corporation. UK: Palgrave Macmillan; 1971

[22] Hartmann A. The role of organizational culture in motivating innovative behaviour in construction firms. Construction Innovation. 2006;6(3):159-172

[23] Miozzo M, Dewick P. Building competitive advantage: Innovation and corporate governance in European construction. Research Policy. 2002;31(6):989-1008

[24] Egbu CO. Managing knowledge and intellectual capital for improved organizational innovations in the construction industry: An examination of critical success factors. Engineering, Construction and Architectural Management. 2004;11(5):301-315

[25] Anderson F, Manseau A. A systemic approach to generation/transmission/ use of innovation in construction activities. In: Proceedings of the Third International Conference on Technology Policy and Innovation: Global Knowledge Partnership-Creating Value for the 21st Century; Austin, USA: LBJ School of Public Affairs. 1999

[26] Dubois A, Gadde L-E. The construction industry as a loosely coupled system: Implications for productivity and innovation.
Construction Management and

Economics. 2002;20(7):621-632

[27] TBMM (Grand National Assembly of Turkey). 10th Development Plan, 2014-2018; Ankara, Turkey. 2013 



\title{
Chapter 6
}

\section{Nonfinancial Reporting: Theoretical and Empirical Evidence}

\author{
Nidžara Osmanagić Bedenik and Petra Barišić
}

\begin{abstract}
Nonfinancial reporting (NFR) is a relatively new topic in the business practice; it evolved a couple of decades ago. Initially, NFR was mostly disclosed on a voluntary basis. Because of deeper awareness regarding climate change and environmental challenges, as well as pressure from investors, customers, and competition, nonfinancial reporting developed from a voluntary to a mandatory highly standardized practice. This research sought to address the following questions: How understanding of business value creation determines business reporting? How sustainability approach manifests on the company level? What is nonfinancial reporting and why should companies care about it? What are the motivations and benefits for companies and for whom do they publish sustainability reports? What about experiences in public sector? How contemporary concepts of green, circular, and zero-waste economy influence business reporting? Which open questions do organizations face on the path of sustainability reporting? This study contributes to the discussion on NFR and stimulates paradigm shift from profitability toward sustainability as adopting a holistic perspective, respecting people and the planet. This research stimulates business community to invest time and energy into sustainability reporting and encourages scholars to explore new ways of business reporting and therefore contributes to our knowledge and well-being.
\end{abstract}

Keywords: business value creation, shareholder, stakeholder, business reporting, green and sustainable business, contingency approach

\section{Introduction}

Since human activities have transformed the biosphere, leading to global climate change, biodiversity loss, and various types of pollution, green and sustainable business has been developed to support management in the face of new challenges. Decision-makers outside and inside the company need business reports because they provide information on the business activity of a company. The system of business reporting includes financial and nonfinancial reports that are interrelated and aim to provide an integrative and comprehensive overview of the business activities of a company, their results, and consequences for people and the environment.

Financial reporting on the business performance of companies was introduced several decades ago, after which it developed through diverse stages as voluntary reporting, mandatory reporting, and highly standardized reporting. Financial reporting reflects on the financial aspects of business activities. It includes a few 
basic financial statements: balance sheet, profit and loss account, cash flow statement, statement of changes in equity, and notes to the financial statements. The statements also complement each other, reflect monetary values, and refer to a specific time period, most often, annual or semiannual.

But the modern business economy, however, faces more comprehensive demands for nonfinancial reporting, which includes reporting on social and ecological aspects of business, i.e., sustainable business practice or sustainability. Business sustainability is often defined as the triple bottom line management, a process in which companies manage their financial, social, and ecological risks, threats, and opportunities. These three impacts are often called "Profit, People, and the Planet" or 3P-a syntagma introduced by Elkington in 1994. The concept of Corporate Social Responsibility (CSR) is being increasingly replaced by another concept, Holistic Corporate Responsibility (HCR). The trend of sustainability reporting is on the rise, but the tools are still being developed. Analyses of corporate responsibility reports in the world demonstrate a sharp increase: from 26 reports in 1992 to 5593 reports in 2010 to 9500 in 2015 [1]. Sustainable business success is constructed gradually by achieving ecological standards above the usual norms, forming value creation chains in a sustainable manner, developing eco-friendly products and services, introducing new business models, and opening new markets.

Sustainability business reporting is known under different names such as sustainability reporting, integrated reporting, and nonfinancial reporting. Global reporting initiative and triple bottom line are principles and standards that encompass reporting on business, social, and ecological activities, which have recently gained more importance and are applied increasingly. In general, sustainability information has to be perceived as credible and reliable to be meaningful and reduce information asymmetries. As a costly signal, assurance helps increase transparency and trust in the assured information [2].

Instruments of sustainability reporting include principles, guidelines, standards, and methods. Major organizations adopted the following guidelines: GRI sustainability reporting guidelines, United Nations Global Compact (UNGC), UN guidelines for business and human rights, OECD guidelines, ISO 26000 guidelines of the International Organization for Standardization, and the Tripartite Declaration of the International Labour Organization. Newer guidelines are presented through Integrated Reporting of the International Integrated Reporting Council (IIRC) that concise communication on how organizational strategy, management, success, and progress lead to value creation in the short, medium, and long term. GRI and IIRC cooperate as strategic partners.

The importance of nonfinancial reporting increases: more and more companies follow principles of sustainable development and sustainable business and provide NFR as well. In December 2014, the European Parliament adopted the Directive 2014/95/EU about nonfinancial reporting. Since January 1, 2017, companies of public interest with 500 or more employees have been including a nonfinancial statement in the management report. Nonfinancial reporting encompasses environmental and social aspects, the area of employee and human rights, anticorruption, and bribery measures, and it outlines its own business model, outcomes, and policy risks on the issues mentioned, as well as the variety of policies implemented by management and supervisory bodies [3].

This trend of making nonfinancial reporting a company's obligation raises the following questions: What is nonfinancial reporting and why should companies care about it? Why would companies invest an additional effort and report on social and ecological aspects of their business activity? What are the motivations and benefits for companies and for whom do they publish sustainability reports? How understanding of business value creation determines business reporting? How 
sustainability approach manifests on the company level? What about experiences in public sector? How contemporary concepts of green, circular, and zero-waste economy influence business reporting? Which open questions do organizations face on the path of sustainability reporting?

Regarding the abovementioned, the aim of this study is to provide a contribution to the discussion of NFR, since NFR is a relatively new topic in the business practice and is still insufficiently explored due to its tools that are still being developed. The study objectives are to stimulate paradigm shift from profitability toward sustainability as adopting a holistic perspective, respecting people and the planet. As well, this research stimulates business community to invest time and energy into sustainability reporting and encourages scholars to explore new ways of business reporting and therefore contributes to overall world knowledge and well-being.

This study may be of interest to all stakeholders: management, owners and employees as internal stakeholders, and investors, customers, supply chain, insurers, trade unions, media, and local community as external stakeholders. Besides business community, this study may be of interest to academic community stimulating new national and international research projects and acquiring/developing new perspectives.

This chapter is organized as follows: The first part presents a context and a need for NFR: The purpose of the company and business value creation is a wider frame for business reports. Changes in business context and in understanding business purpose through sustainability approach lead to changes in business reports as well. The following section examines nonfinancial reports from business practice, their motives, stimulus and benefits, and stakeholders who are interested in NFR. In this part, sustainability reporting in the public sector is also explored. The third part addresses challenges of nonfinancial reporting, followed by a discussion. Lastly, conclusion provides resume, contribution, research limitation, and suggestions for future research.

\section{Business value creation}

\subsection{Financial value creation and financial reporting}

Value creation is often emphasized as the most important business objective. There are two different concepts of value creation in business, depending on the perspective of parties involved in value allocation [4]. Creating shareholder value is a concept according to which a company should only satisfy the interests of its owners achieving attractive financial returns in the short and long run. According to that concept, the enterprise is most commonly understood as an investment project with a pronounced financial aspect of activity, and business performance in that concept is most commonly measured by profitability or latterly economic value added (EVA) as the main indicator of success. Value-based management is a concept of a company's value based on discounted future cash flow.

For decades, it was thought that the main goal of the company is to make profit and to increase its financial value. Profitability is the primary goal of all business ventures [5]. A strong influence on today's understanding of profitability was made by the American economist and Nobel Prize winner Milton Friedman (1970), who wrote that "The social responsibility of business is to increase its profits" [6]. This attitude has resulted in the focus on profit and profitability, neglecting the way profit is generated as well as neglecting the consequences of such perspective focus. Profit has been, and often still is, accepted as the main business goal that has to be maximized. 
Financial reporting on the business performance of companies was introduced a few more decades ago, after which it developed through several few stages as voluntary reporting, mandatory reporting, and highly standardized reporting. Financial reporting has a long history. In different parts of the world, the first financial statements were published as early as at the end of the nineteenth century. The intention to clearly outline and compare financial statements led to the passing of Generally Accepted Accounting Principles (GAAP, 1933), which provided a set of basic guidelines [7]. After World War II, as economic integration occurred and capital started to travel over national borders, it became necessary to harmonize financial statements internationally (IASC, 1973; IASB, 2001) and to devise International Financial Reporting Standards (IFRS, 2002). In order to improve cooperation in the international application of reporting standards, the Accounting Standards Advisory Forum was established (ASAF, 2013) [8]. The development of the economy and reporting standards as well as the development of international investments led to the development of financial auditing, certification, and testing of financial statements based on the international auditing standards (GAAS, IAASB, and ISAs). Financial statements reflect the financial position of the company and business performance, and they provide present accounting information. This arguably narrow view is powerfully reinforced by financial accounting systems that were well adapted to the industrial economy but were inadequate in the information economy [9].

Focus on financial value and financial goal is a predominantly short-time and a very narrow understanding of business fundamentals. It ignores the ways of achieving it and all the consequences for people and the planet: the search for profitability maximization justifies depletion of natural resources, water, air, soil, light, as well as noise, electromagnetic and other types of pollution, loss of biodiversity, and climate change and it ignores human rights and income inequality. It is necessary to change the current business paradigm and to employ a wider perspective that takes into account human rights and environmental issues.

\subsection{Business context changes: sustainability approach}

Our planet could be seen as our billion stars hotel; we are called to behave as properly and well-educated guests, and as responsible guests, we have to respect and care about our hotel and leave it in the best condition for future visitors. There is a well-known 7th Generation Principle based on an ancient Iroquois philosophy that says the following: "In our every deliberation, we must consider the impact of our decisions on the next seven generations." [10] Models and theories of business traditionally have been silent on the subject of the environment. Silence, however, is no longer an option in the face of society's recognition of the potential cost that environmental damage may have on corporate profits [11].

Business context changes and therefore it requires business to change. The contingency approach is a management theory based on the idea that there is no single best way to manage; the most appropriate style of management is dependent on the context of the situation. Effective organizations must tailor their planning, organizing, leading, and controlling to their particular circumstances. Contingency theory is beneficial to organizations because of the potential for learning from specific situations and using these lessons to influence future management of the same or similar situations. The ability to adapt to external pressures and changes is also an advantage. The leaders must then work to integrate all these facets into a solution that is most appropriate for a specific circumstance [12].

In fact, we are facing the change from economies of scale, over economies of scope to economies of soul [6]. Actually, a soul economy is not a very new perspective. Tracing a seismic shift in American social thought, Sklansky (2002) wrote 
the book "Soul's Economy: Market Society and Selfhood in American Thought, 1820-1920" offering a new synthesis of the intellectual transformation entailed in the rise of industrial capitalism. As early as in 1922, Rudolf Steiner wrote the book "Soul Economy, Body, Soul, and Spirit in Waldorf Education," trying to integrate material and immaterial perspectives.

Modern developments in the economy and society are marked by two phenomena: companies are becoming bigger and more powerful while social pressure for responsible business is becoming more pronounced. This unhealthy power in corporate hands results in ecological destruction, the loss of civil freedom, the erosion of democracy, and community disintegration [13]. According to the results of a research study [14], among 100 largest economies in the world, 51 are corporations and 49 are countries! Companies are more powerful than ever, and with power comes their responsibility for their own behavior toward people, the community, and the environment. A short-term focus on profit is detrimental for all [15], and it is necessary to establish balance between monetary and nonmonetary business objectives as well as between short-term, medium-term, and long-term goals. Sustainability reporting has its role here as it encompasses not only economic effects of the business activity of a company but also the effects on people, general community, nature, and the environment [16].

Even though it seems to us that sustainability is a modern concept and problem, the first requirements for sustainable business activity date back several centuries. Hans Carl von Carlowitz (1645-1714) is considered to be the founder of the sustainability principle. In his work Sylvicultura oeconomica from 1713, he demanded, due to the crisis in raw materials (wood), that one should only lumber so many trees as can be grown by reforestation and planting. This was the demand of 'sustainable' usage and sustainable forest management soon caught as a professional term. This principle from forestry gave rise to the motto 'to live off the interest, not the capital' [17]. The growing identification of sustainability as both a process and a goal ensures long-term human well-being [18]. Moreover, sustainability approach is important not only for human well-being, but for the well-being of other beings, and the planet itself.

The contemporary terms of sustainability and sustainable development were coined in the early 1970s. The foundation of the definition of sustainability is the Brundtland report according to which sustainable development is that development which "...meets the needs of the present without compromising the ability of future generations to meet their own needs" [19]. In other words, the goal is improved better quality of life for everyone now, and for the generations to come. That is why modern business conditions demand a change in the dominant paradigm-from a reductionist focus on profit, toward a holistic perspective and a balance between economic, social, and ecological aspects of company's business accountability [20].

The modern business economy, however, faces ever clearer demands for nonfinancial reporting, which includes reporting on social and ecological aspects of business, i.e., sustainable business practices or sustainability. Former separation of economic, social, and environmental development is no longer acceptable anymore.

\subsection{Nonfinancial value creation and nonfinancial reporting}

Creating value for stakeholders is a broad concept that harmonizes different interests of particular stakeholder groups simultaneously. The company is considered an element of the environment so that this concept represents the foundation of sustainable business. According to that concept, business performance is viewed as a function of balance between economic, social, and ecological aspects of business activity. There is no doubt that companies do their business activities in an environment where there are numerous interrelations and relationships. 
Therefore, a company should not be viewed solely as an instrument of the owner, but as an organizational unity with influence on several groups that should function in symbiosis with one another [21]. Business performance should therefore be assessed based on the company's economic performance, environmental quality, and social justice [22].

The stakeholder theory proposes that the company should aim to satisfy the interests and needs of its stakeholders, as opposed to merely focusing on maximizing profit for the owners. The stakeholder theory implies that companies have the obligation to individuals and groups within and outside of companies, including owners, employees, customers, suppliers, creditors, and the wider community. The stakeholder concept was first used in 1963 in the internal memorandum at the Stanford Research Institute. According to that concept, the stakeholders are those groups without whose support the organization would cease to exist. Freeman advocates the ethical principle according to which the concept of corporate responsibility implies responsibility to all stakeholders [23]. Freeman is considered the father of stakeholder theory, which explains that stakeholders are individuals and groups affected by, or affecting, directly or indirectly, policies, activities, and decisions of the company. In that context, a company needs to create value for its stakeholders balancing their demands in decision-making and defining priorities. The stakeholder theory has become a dominant paradigm of corporate social responsibility and sustainability [24]. Moreover, the quality of relationship with stakeholders and the capacity to create long-term value are two sides of the same coin [25].

There is a consensus nowadays that financial statements can no longer be sufficient when it comes to business reporting because they do not reflect the entire business activity of a company. The information in financial statements reflects only short-term monetary aspects of business, but does not provide insight into environmental, social, and managerial aspects of business, which are, in the long term, much more important. Nonfinancial reporting is a 'must' in the modern economy for different groups of the general public as it reflects the responsibility of a company to conduct business activities in a sustainable way. On the basis of a sample of 200 senior executive managers across the world, and according to the results of a study conducted by The Economist, $87 \%$ of respondents agree that sustainability will become more important over the next 3 years [26]. Fifty-seven percent of respondents say that their firms use sustainability reporting as a basis for new business strategies. The results show that $49 \%$ of respondents report progress in meeting their environmental sustainability goals and $53 \%$ report progress toward social sustainability. There is growing evidence that sustainability reporting increases in significance. According to the results of KPMG from 2008, almost 80\% of the world's largest 250 enterprises report on sustainability [26].

Sustainability report [27] is a report that provides information on economic, environmental, social, and managerial aspects of a company's performance. Sustainability reporting is a new task. Integrated report merges information on sustainability together with traditional financial information in a single report. It offers a comprehensive picture of value creation viewed across time [28]. The International Integrated Reporting Council (IIRC) defines an integrated report as one that 'brings together material information about an organization's strategy, governance, performance and prospects in a way that reflects the commercial, social and environmental context within which it operates' [29]. In the case of nonassured sustainability information, integrated reporting positively affected professional investors' evaluation of a firm's sustainability performance, resulted in a higher weighting of this information, and led to higher investment-related judgments [2].

It is important to notice that only the reports that include all three dimensions of sustainability simultaneously can truly be referred to as 'sustainability reports,' 
unlike one-dimensional reports that only cover isolated aspects of sustainability. In that sense, the so-called sustainability reports often exclude important aspects of business activity, especially the economic aspects that are usually presented in a separate annual report [30]. The nonfinancial report provides stakeholders with an important and comprehensive overview of the position and characteristics of a company's business activity. In a nutshell, the common core of all these reports is their focus on social and ecological aspect of a company's business activity. While sustainability reports and nonfinancial reports can be disclosed autonomously, an integrated report represents a single report that includes not only social and ecological but also economic aspects. In that sense, integrated reports are comprehensive, reflecting a holistic perspective on business activity.

From a microperspective, studies indicate that firm size, growth opportunities, profitability, gender diversity on the board, or the assurance of nonfinancial reports positively correlate with the adoption of integrated reporting. From a macroperspective, several country-level determinants, such the legal system, value system, and the intensity of market coordination, have been considered as potential determinants [2].

Recent research results indicate that the integration of sustainability and financial information did not lead to an improved acquisition of this type of information. However, the integration increased professional investors' potential access to sustainability information, because readers could not entirely opt out of encountering sustainability information during their information processing. This in itself remains an important objective of integrated reporting because, as our experiment indicated, a substantial number of professional investors showed no interest in the separate sustainability report.

In December 2014, the European Parliament adopted the 2014/95/EU Directive on nonfinancial reporting [3]. This Directive is part of a broader initiative of the European Union regarding corporate social responsibility, which includes a consistent approach to reporting and supporting smart, sustainable, and inclusive growth under Europe 2020 objectives. Since January 1, 2017, this Directive has made nonfinancial reporting in the entire European Union mandatory for public interest entities employing more than 500 people. According to the Directive, the disclosure of nonfinancial information is central for combining long-term profitability with social justice and environmental protection. Nonfinancial reporting includes ecological aspects, social and employee-related matters, respect for human rights, anticorruption measures, description of the business model, outcomes and risks of the policies on the above issues, and the diversity policy applied by the management and supervisory bodies.

\section{Experiences from business practice}

\subsection{Motives and stimulus}

There are different international and national initiatives for promoting sustainability reporting: Global Reporting Initiative's, European Commission and the European Parliament, and many other organizations. Firms disclose corporate social responsibility information for two main reasons: (1) to conform to societal expectations and thereby ensure continued access to resources, such as capital, customer support, and so on and (2) to provide additional information that allows capital market participants to more accurately assess firms' financial prospects and risk profiles, potentially leading to higher share prices and higher firm values [31]. These two broad reasons for disclosure can be further explored using, respectively, 
legitimacy theory and agency theory. Legitimacy theory encapsulates the idea that firms have to conform to societal norms in order to prosper [32], whereas agency theory focuses on explaining the motivations and actions of both agents (i.e., managers) and principals (i.e., investors) [33].

The question of motivation is a question of purpose and true meaning of sustainability reporting. Maybe it is legitimate to ask the following question: "Why would companies invest an additional effort and report on social and ecological aspects of their business activity?" [34]. Indeed, there are many reasons, arguments, and theories on corporate social responsibility, which go beyond companies' financial responsibility to shareholders. These reasons include a new level of consciousness, growing and visible pressure of the environment, lack of policies in the protection of the public good, and material risks, including the risk to reputation. Corporate social responsibility undoubtedly helps some companies to find new opportunities of value creation to ensure permanent business. These companies set their goals publicly and take into account serious global problems such as climate change to distinguish themselves from less responsible companies [35]. Other similar companies were simply set up by visionary entrepreneurs with social responsibility as their foundation [36].

Sustainability reporting has significant internal and external benefits. Internal benefits include the following [37]:

- Increased understanding of risks and opportunities

- Emphasizing the link between financial and nonfinancial performance

- Influencing long-term management strategy and policy, and business plans

- Streamlining processes, reducing costs and improving efficiency

- Benchmarking and assessing sustainability performance with respect to laws, norms, codes, performance standards, and voluntary initiatives

- Avoiding being implicated in publicized environmental, social, and governance failures

- Comparing performance internally, and between organizations and sectors

External benefits include the following [37]:

- Mitigating—or reversing—negative environmental, social, and governance impacts

- Improving reputation and brand loyalty

- Enabling external stakeholders to understand the organization's true value, and tangible and intangible assets

- Demonstrating how the organization influences and is influenced by expectations about sustainable development

According to the results of a survey conducted by The Economist among 1254 executive managers in the world in 2007 , the biggest benefits from adopting sustainable practices were reported in the following areas [38]: 
1. Ability to attract new customer base/retain existing one: $37 \%$

2. Improved shareholder value: $34 \%$

3. Increased profitability: $31 \%$

4. Ability to identify and manage reputational risks: $29 \%$

5. Better quality products and processes: $28 \%$

6. Ability to attract best-quality employees: $26 \%$

7.Improved relations with regulators/legislators: $19 \%$

\section{Greater attractiveness to investors as a whole: $17 \%$}

The results of this survey have shown that only $4 \%$ of respondents did not adopt sustainable practices, and only $6 \%$ of respondents expected no benefits in that relation. The same study asked the respondents to rank the importance of sustainability-related goals at their firms and $57 \%$ mentioned environmental footprint of products, 52\% mentioned improved energy efficiency, 51\% mentioned developing new products to help reduce social and environmental problems, and finally, $50 \%$ said improving the impact of operations on surrounding local communities and $50 \%$ said improving the impact of operations on surrounding environments. Communicating their organizations' performance on sustainability to investors and stakeholders was among top long-term benefits (61\%). It is considered that customers and the government have a key impact on the introduction and adoption of sustainability practices, while within the organization, the biggest responsibility is on the CEO (33\%) and company's board (26\%). Of course, it is also interesting to explore the most significant impediments to achieving more sustainability objectives. The following barriers are the most significant: the fear that sustainable business practice will increase business costs in relation to competition (40\%); difficulties devising useful targets, measures, and controls to entrench sustainability in the organization (36\%); and problems aligning social and environmental efforts with financial ones (31\%). The final conclusion is that today's leading companies align their business strategy with social and ecological needs. According to Mark Kramer, founder of FSG, "It used to be easy to say that you cannot do anything because of competitive pressures. You can no longer argue that it is impossible for business to do this because many have. [39]" Both the European Commission and the European Parliament have been actively promoting NFR, not only for the benefit of society but also as a means to improve the competitiveness and innovation of businesses in the European Union [40].

International comparison in sustainability reporting widens perspectives and provides new knowledge. Factors that influence sustainability reporting are corporate characteristics, general context factors, country-specific impact factors, and internal factors [41]. A comprehensive research study on sustainability reporting in 11 Central and Eastern Europe and 2 Western Europe countries provides significant contribution to theory and practice. According to this study, economic development, globalization level, civil society, cultural differences, and regional patterns are examined as the determinants of sustainability reporting [42].

The quality of NFR practices was investigated in Poland and Romania prior to the European Directive's adoption. The authors found that prior regulation, local institutional characteristics, ownership, industry, and auditors have an impact on the 
quality of disclosures. Poland experienced a higher extent of voluntary reporting, but Romania faced prior regulatory demands for nonfinancial reporting. The authors suggested that the overall disclosure score is higher for Romania, which provides support for the importance of regulations to strengthen the spread and quality of NFR [43].

A report from the European Sustainable Development Network characterizes Poland as a country that integrated CSR into national strategy documents [44]. There is a growing recognition in Poland of the notion that a business must be responsible like any other party and play an active and positive role in society [43]. Responsible Business Forum, operating since 2000, is the first nongovernmental organization in Poland that provides in-depth focus on the CSR issues [45]. On the other hand, the social reports issued in Romania were not considered credible. Also, the general information regarding the environmental impact included in the annual reports is coined as 'incomplete and irrelevant to users and mostly generic' [43].

Authors also identify proof of stakeholder pressure as an institutional factor of NFR, in the case of trade unions, and establish that pressures from the community or society at large are not yet a determinant institutional factor in Poland and Romania. For the Romanian subsample, authors notice a relationship between company size and quality of disclosures. The content of the Polish reports indicates that reporters' experience and the presence and use of voluntary reporting standards and guidance have a positive influence on the quality of reports [43].

The sustainability reporting practices of Turkish nonfinancial companies show that the main factors influencing sustainability reporting are listing on the Corporate Governance Index (CGI), having a sustainability committee, the type of industry, the size of the company, and profitability, whereas leverage is not [46].

The research study of 500 largest European firms found that firms are more predisposed to disclose more CSR information in countries with better investor protection, higher levels of democracy, more effective government services, higher quality regulations, more press freedom, and a lower commitment to environmental policies. Authors' analysis of the association of different levels of CSR disclosure with share prices indicates that a high level of CSR disclosure is associated with higher share prices, whereas a low level of CSR disclosure in sensitive industries is associated with lower share prices-compared to no disclosure [47].

Market participants find CSR disclosures more informative in countries where investors are in a better position to voice their concerns and where there is better regulation and more effective government implementation of regulations [47].

Firms in countries that show a greater commitment to an environmental agenda could be more likely to disclose more CSR information to reflect the local social concerns and to respond to higher levels of stakeholder pressure to provide information. However, in more environmentally committed countries, CSR-related issues are more likely to lead to negative financial consequences and managers may fear that additional CSR disclosure will play into the hands of potential litigants. For example, the 2010 Gulf of Mexico oil spill cost BP billions of dollars [47].

Firms are likely to disclose higher levels of CSR information if they are larger, are more profitable, have high book-to-market firms, are more leveraged, use older equipment, spend more on capital, and operate in environmentally sensitive industries [47]. If they belong to environmentally sensitive industries, they tend to provide more comprehensive social and environmental disclosure regarding the impact produced by their business to reduce the potential concern by the communities in which they are rooted and to gain respect on the market and thus legitimize their actions [48]. As it is shown, motives for sustainable NFR and CSR reporting vary; determinants and incentives differ as well.

Organizations have the freedom to choose the standards of reporting. They can develop their own standards of NFR as well. Since these standards are currently 
evolving, competing, and converging in some aspects [49], the analysis by Hales et al. provides useful insights and synthesis of developments in external reporting standards for corporate sustainability performance [50]. GRI estimates to have information on about half of all reports applying its guidelines [51]. The GRI's publicly accessible registry currently lists 13,528 organizations, 53,098 reports, and 31,991 GRI reports [52].

\subsection{For whom: investors, customers, employees, and other stakeholders}

In recent years, it has become increasingly common for companies to disclose information about their nonfinancial performance and to engage in sustainability reporting alongside traditional financial reporting [2]. Among such powerful stakeholders identified as influencing NFR are governments, nongovernmental organizations, multinational companies, regulatory agencies, the EU Global Reporting Initiative, auditors, shareholders, and the media [43]. Investors are the key addressees of such reporting, and there is initial evidence that they consider nonfinancial information value relevant [53].

According to the research, the interests of investors, customers, and employees are common subjects of studies [54]. As for investors, studies explored what investors are interested in when it comes to nonfinancial reporting. Findings suggest that $64.5 \%$ investors regularly assess ecological and social aspects of business, but only $35.5 \%$ conduct a modest analysis of these aspects or conduct no analysis at all [55]. The $2014 \mathrm{PwC}$ survey shows that $61 \%$ of US investors are not satisfied with the company's published information on sustainable development [56].

Customers also show great interest in sustainability, and recent data on customer trends are clear in that respect [57]:

- $72 \%$ of customers are interested in learning what companies are doing in terms of sustainability and "going green."

- $75 \%$ of customers would more likely purchase products and services from companies that are making a great effort to adopt environmentally conscious practices.

- $82 \%$ of consumers are more likely to purchase a product that demonstrates a company's corporate social responsibility initiatives than one that does not.

- $93 \%$ of Americans reported having done something to conserve energy in their household in the past year.

According to the same study, the younger generation shows an even stronger trend of green consumption.

Employees are also very important stakeholders. Many future employees use ecological policies to measure corporate values. In 2007, it was reported that $92 \%$ of students and entry-level workers were seeking an environment-friendly company for employment [58]. According to SHRM 2011 survey [3], 89\% of organizations assessed the importance of sustainable strategy as "important" or "very important" in creating a positive employer who attracts talents. Regarding future employees, there is an interesting survey result: $70 \%$ of millennial job seekers said that a firm's community image is an important determinate in job selection. It is obviously apparent that sustainability message and image have an impact on attracting the best talent [59]. When companies were asked to rank three most important stakeholders in their sustainability initiatives, employees ranked second with $22 \%$ of 
replies, after consumers who ranked first with $37 \%$ replies, while owners ranked third with $15 \%$ of replies [60].

It is worthy to note that sustainability reporting is no 'magic tool' simultaneously fulfilling communication and management functions; instead, attempts to reach all audiences with a single document are doomed to fail, ushering in 'jack-of-all-tradesmaster of none' [51]. Simply calling for integrated, high-frequency, high-complexity reporting is misguided as there are trade-offs between conciseness and completeness [61]. Nevertheless, there are positive effects of integrated reporting on the effectiveness of sustainability management, thus creating long-term firm value [62].

\subsection{Sustainability reports in the public sector}

In the private sector, both financial and sustainability reports are usually published annually, strengthening the case for their integration, although this is not mandatory. Many local governments in Germany issue sustainability reports at multiyear intervals [63]. Sustainability reporting is on the rise throughout the public sector. International frameworks such as the United Nations Sustainable Development Goals (specifically SDG target 12.6) call for increased reporting by all types of institutions [51].

France recently mandated all municipalities with more than 50,000 inhabitants to periodically produce sustainability reports [64]. A study about sustainability reporting by local governments investigated in Amsterdam, Basel, Dublin, Freiburg, Nuremberg, and Zurich suggests that sustainability reporting can benefit organizational change, management, and communication yet also lead to 'fatigue' and discontinuation [51]. Commitment to sustainability reporting is a vital step toward creating 'vibrant cities' [65]. The six analyzed 'early adopters' all initiated sustainability reporting voluntarily. Over the years, each deliberately made different major design choices. Zurich started with sustainability reporting in 2004, Basel and Amsterdam in 2005, Nuremberg in 2009, and Dublin in 2010 [51].

The analysis of content quality showed a mixed picture. Most reports addressed questions of context, public policies, organizational performance, and outlook to some degree. In Zurich, switching from multiyear to annual reports brought reduced coverage of context and outlook issues. Freiburg's report stands out since it pays detailed attention to (select) public policies and organizational performance, while lacking city-level outcome indicators - a context feature common to most sustainability reports. From one edition to another, reports usually discuss long-term trends through a set of indicators (ranging from 21 in Basel to over 100 in Nürnberg). In addition to such continuity in monitoring, Nürnberg's reports contain changing focus themes (e.g., 'education') [51].

For the dissemination of reports, all local governments recently used websites and social media. Usually, this involves making reports available for download (with Dublin's not existing in print); only Zurich visualizes its data on a dedicated dashboard [51].

The disclosures are required to be made in the form of a nonfinancial statement or of a nonfinancial report and to include a brief description of the entity's business model and its policies in relation to environmental, social, and employee matters, respect for human rights, procedures to counteract corruption and bribery and their outcomes, risks and risk management related to those matters, and nonfinancial key performance indicators [43].

\section{Challenges of nonfinancial reporting}

Nonfinancial reporting is a relatively new task for companies and is connected with few open questions. Some of them are general challenges caused by general framework change; some of them are more specific. 
Paradigm shift in our perceiving finds its reflection in economy and business. Green economy and green business, circular economy, and zero-waste economy are new perspectives on the path to sustainable business with new requirements toward companies. Green is more than just a color. It is a way of doing business and a way of life, which respects and maintains balance in the environment. Green strategies that respond to increased consumer interest are green products, recycled/refurbished products, and the green process - green strategies do matter to eco-consumers and industry reports indicate that this group is growing quickly [66].

Green economy is the way to reduce environmental risks and ecological scarcities; it is low carbon, resource efficient, and socially inclusive [67]. It is a system of economic activities related to the production, distribution, and consumption of goods and services that result in improved human well-being over the long term, while not exposing future generations to significant environmental risks or ecological scarcities [68]. Green economy is described as an economy in which economic growth and environmental responsibility work together in a mutually reinforcing fashion while supporting progress on social development [69]. It presents an attractive framework to deliver more recourse efficient, lower carbon, less environmentally damaging, more socially inclusive societies [70]. Moreover, it is suggested that proper measurement of the green economy needs to move beyond GDP as the central measure of progress and to better track the "transformational green economy' Bhutan's Gross National Happiness Index, developed from the 33 indicators in the next domains: psychological well-being, health, education, time use, cultural diversity and resilience, good governance, community vitality, ecological diversity and resilience, and living standards, is example of innovative and sustainable measurement of national progress. Introduced by Bhutan with support from 68 member states, UN adopted in 2011 a General Assembly Resolution, calling for a 'holistic approach to development' [71]. Green Economy from EU Commission Perspectives encompasses seven dimensions that ensure the path to sustainable business [72]. Thus, new paradigm is not only a talk; it is a walk as well.

Circular economy is the next general challenging perspective; it aims to redefine growth, focusing on positive society-wide benefits. It entails gradually decoupling economic activity from the consumption of finite resources, and designing waste out of the system. Underpinned by a transition to renewable energy sources, the circular model builds economic, natural, and social capital. It is based on three principles [73]:

- Design out waste and pollution

- Keep products and materials in use

- Regenerate natural systems

On March 4, 2019, the European Commission adopted a comprehensive report on the implementation of the Circular Economy Action Plan. The report presents the main achievements under the Action Plan and sketches out future challenges to shaping our economy and paving the way toward a climate-neutral, circular economy where pressure on natural and freshwater resources as well as ecosystems is minimized [74]. Zero-waste economy is also one dimension of paradigm shift. The objectives are to recycle more and create less waste and to recover materials rather than waste them. To minimize waste means to reuse it, to recycle it for further use, and to recover energy [75].

The next open question deals with research studies in this area. An increasing number of companies that decide to disclose nonfinancial reports allow research to be conducted in that area as well. Since there are different standards and 
guidelines for such reporting and companies are free to choose reporting standards, it is often difficult to collect and process data furthermore to compare different reports. There is a clear need to improve the comparability of the indicators disclosed in corporate sustainability reports, particularly among corporations in the same sector [76]. It should also be stressed that studies and findings obtained represent an encouragement to other companies in the process of disclosing nonfinancial reports.

The next question includes the type of data and information that are disclosed, the way the data are collected and processed, and the way they are presented-in a qualitative and/or quantitative form. IT support plays a very important role in that process because collecting data for NFR is often done manually, which makes the preparation of the documents harder and slower. The process of NFR is for every company the challenge to rethink and redesign business activities and to report about their effort in this area. Quantity of information is the challenge as well: 'the more information there is in a report about individual, social, environmental, and economic impacts, policies, and practices, the greater is the likelihood of information overload for readers' [77].

\section{Discussion}

Our environment changes: we are witnessing a climate change causing unexpected droughts and floods, glacial meltdowns, migrations of population, a drastic decrease in biodiversity, unlimited expansion, and growth of business, which contributes to the destruction of nature and animal habitats. The pollution of air, water, and soil, as well as light, noise, and electromagnetic pollution, is different forms of environmental pollution caused by human activity or, more precisely, caused by company activities. Therefore, companies today face great challenges because they can transform undesirable trends in the economy and society into socially and ecologically responsible creation of new activities and long-term jobs, inventions, and new methods of production and consumption. A growing number of companies publish their sustainability business reports. For some companies, this led to innovations, better risk management, new business opportunities, and an enhanced capacity to create value in the future. But the companies are not the only ones who publish the sustainability reports; sustainability business reports are on the rise throughout the public sector as well.

There are more and more stakeholders that influence on NFR like governments, nongovernmental organizations, multinational companies, regulatory agencies, the EU Global Reporting Initiative, auditors, shareholders, and the media. Specific questions with regard to NFR encompass standards of reporting, ways to measure the company's sustainability efforts, type of data, and IT support. Since there are several different standards of NFR, every company has to choose one to follow or to create their own reporting standards, which is a complex task. On those standards, different factors will have their influence, and those are corporate characteristics, general context factors, country-specific impact factors, and internal factors, and, further, economic development, globalization level, civil society, cultural differences, and regional patterns.

Companies and nonprofit organizations are called to publish NFR for their stakeholders, especially for investors, customers, employees, and wider community. Published NFR is an argument in favor of organization's sustainability orientation and responsibility for people and planet in creating long-term values. 


\section{Conclusions and suggestions}

The aim of this study is to provide a contribution to the discussion of NFR. The purpose of the study is to stimulate companies on the path of sustainable business and sustainable reports that reflects their efforts in social and ecological business dimensions. The aim is also to stimulate wider research that could contribute to a shift in perspective from mechanistic to a holistic paradigm.

In the past, economic growth often seemed to depend on using up natural resources as though supplies were unlimited. The result is a 'resource crisis,' with a threat of shortages and rising prices. Today, growing numbers of citizens and economists are looking to different economic models, where wealth can be created without harming the environment. According to the European Commission, the Europe 2020 strategy emphasizes smart, sustainable, and inclusive growth as a way to overcome the structural weaknesses in Europe's economy, improve its competitiveness and productivity, and underpin a sustainable social market economy. Not only Europe, but the whole planet needs smart, sustainable, and inclusive growth.

The foundation of business is value creation. Creating financial value for owners is a widely accepted business goal measured with profit and communicated in financial reports. Because of changes in environment, more and more companies choose to create sustainable values for stakeholders and communicate it by nonfinancial or sustainable reports.

Dominant understanding of business value creation determinates business reporting: financial reports reflect monetary and short-term aspects of business value creation, which is only one dimension of business activities, important for shareholders. Nonfinancial reports discover existing social and environmental aspects of business activities and reflect nonmonetary and long-term values important for all stakeholders. They manifest sustainability approach on the business level. Nonfinancial reporting is still done on a voluntary basis, but from 2017, it was an obligation for EU companies with more than 500 employees or for companies of special public interest. They include ecological aspects, social and employee-related matters, respect for human rights, anticorruption measures, description of the business model, outcomes and risks of the policies on the above issues, and the diversity policy applied by the management and supervisory bodies.

Contemporary concepts of green, circular, and zero-waste economy influence business reporting and led companies to innovations, better risk management, new business opportunities, and an enhanced capacity to create value in the future. Every organization on the path of sustainability reporting meets general and specific open questions regarding NFR: implementation of contemporary sustainability concepts into business strategy, ways to measure company's sustainability efforts, type of data, and IT support are some of them. NFR is still in development; business experience is still insufficient.

This study contributes to the discussion on dominant business value creation and ways to measure and communicate it. It stresses the need for paradigm shift from mechanistic, monetary short-term view to holistic long-term view, and it points out the business responsibility for people and planet and for future generations. This research stimulates profit and nonprofit organizations to publish NFR pointed at their benefits and incentives. Scholars from academic community are encouraged to conduct further research to help organize and implement sustainability reporting. 


\subsection{Limitations and suggestions for future research}

There are few limitations of this study. The first one is in the gap between growing number of research studies on NFR and their comparability, since the researcher observes different industries, sectors, countries, etc. and in this process uses different approaches. Another limitation is the obstacle to compare different reports since there are different standards and guidelines for such reporting and companies are free to choose their own reporting standards. The third limitation is the high level of generality regarding NFR, and it would be interesting to observe specific industries and their NFR habits. And the last one is the exclusive focus on the motives for NFR without analyzing whether they are financially oriented or they are the expression of a business model.

There are some suggestions and questions for future research on NFR: Does and how global and national culture influences sustainability reporting? Are there specific characteristics on NFR for branches, size of the organization, level of profitability, or gender diversity on the board? How can scholars encourage the implementation of NFR? Is there any connection with NFR in specific countries and their GDP? Do countries with higher level of GDP have a higher level of NFR?

\section{Author details}

Nidžara Osmanagić Bedenik* and Petra Barišić

Faculty of Economics and Business, University of Zagreb, Zagreb, Croatia

*Address all correspondence to: nosmanagic@efzg.hr

IntechOpen

(C) 2019 The Author(s). Licensee IntechOpen. This chapter is distributed under the terms of the Creative Commons Attribution License (http://creativecommons.org/licenses/ by/3.0), which permits unrestricted use, distribution, and reproduction in any medium, provided the original work is properly cited. (cc) BY 


\section{References}

[1] Szekely N, vom Brocke J. What can we learn from corporate sustainability reporting? Deriving propositions for research and practice from over 9,500 corporate sustainability reports published between 1999 and 2015 using topic modelling technique. PLoS One. 2017;12(4):e0174807. DOI: 10.1371/ journal.pone.0174807

[2] Reimsbach D, Hahn R, Gürtürk A. Integrated Reporting and Assurance of Sustainability Information:

An experimental study on professional investors' information processing. European Accounting Review. 2018;27(3):559-581. DOI: $10.1080 / 09638180.2016 .1273787$

[3] European Union. Directive 2014/95/ EU of the European Parliament and of the Council pf 22 October 2014. Official Journal of the European Union. 2014. Available from: https:// eur-lex.europa.eu/legal-content/EN/ TXT/?uri=CELEX\%3A32014L0095. [Accessed: 2017-06-06]

[4] Kochalsky C, editor. Green Controlling and Finance. CH-Beck; 2016. p. 76

[5] Hofstrand D. Understanding profitability [Internet]. Available from: https://www.extension.iastate.edu/ agdm/wholefarm/html/c3-24.html [Accessed: 2019-01-15]

[6] Osmanagic Bedenik N. Business between profitability and sustainability. In: Proceedings of the 25th International Business Information Management Association Conference - Innovation Vision 2020: From Regional Development Sustainability to Global Economic Growth, (IBIMA 2015); 7-8 May 2015; Amsterdam. IBIMA. 2015

[7] What is GAAP? [Internet]. Available from: http://www.accounting.com/ resources/gaap/ [Accessed: 2018-01-15]
[8] Comparability in International Accounting Standards-A Brief History [Internet]. Available from: http://www.fasb.org/jsp/FASB/Page/ SectionPage\&cid $=1176156304264$ [Accessed: 2018-10-15]

[9] O’Malley P. Value Creation and Business Success [Internet]. 1998. Available from: https://thesystemsthinker. com/value-creation-and-businesssuccess/ [Accessed: 2018-02-18]

[10] 7th Generation Principle [Internet]. Available from: http://7genfoundation. org/7th-generation/ [Accessed: 2018-08-12]

[11] Freeman RE, York JG, Stewart L. Environment, Ethics and Business. Bridge Papers; 2008. p. 3

[12] Contingency Approach to Management [Internet]. Available from: https://www.encyclopedia.com/ management/encyclopedias-almanacstranscripts-and-maps/contingencyapproach-management [Accessed: 2018-08-10]

[13] Korten DC. When Corporations Rule the World. 1st ed. Kumarin Press Inc./Berreth-Koehle; 1995. p. 99

[14] Anderson S, Cavanagh J. Report on the top 200 corporations. [Internet]. 2000. Available from: http://www. corporations.org/system/top100.html [Accessed: 2018-08-15]

[15] Bakan J. The Corporation: The Pathological Pursuit of Profit and Power. Free Press; 2005. p. 41

[16] Osmanagic Bedenik N et al. The Role of Controlling and IT Support in Non-financial Reporting. Zagreb: Veble; 2018. p. 8

[17] Colsman B. Nachhaltigkeitscontrolling, Strategien, Ziele, 
Umsetzung. Wiesbaden: Springer, Gabler; 2013. p. 11. DOI: 10.1007/978-3-8349-3599-1

[18] Jassim AK. Sustainable solid waste recycling. In: Ijagbemi CO, Campbell HM, editors. Skills Development for Sustainable Manufacturing. IntechOpen; 2017. DOI: 10.5772/intechopen.70046. Available from: https://www.intechopen. com/books/skills-developmentfor-sustainable-manufacturing/ sustainable-solid-waste-recycling [Accessed: 2019-04-15]

[19] Our Common Future. Brundtland Report [Internet]. 1987. Available from: https://www.are.admin.ch/are/ en/home/sustainable-development/ international-cooperation/2030agenda/ un-_-milestones-in-sustainabledevelopment/1987--brundtland-report. html [Accessed: 2019-02-25]

[20] Osmanagić Bedenik N et al. Kontroling između Profita i održivog Razvoja. Zagreb: M.E.P; 2010. p. 7

[21] Kochalsky C, editor. Green Controlling and Finance. CH-Beck; 2016. p. 77

[22] Svendsen et al. Measuring the business value of stakeholder relationships, 2001. p. 3; according to Kochalsky [21]

[23] Freeman RE. The politics of stakeholder theory: Some future directions. Business Ethics Quarterly. 1994;4(4):409-429

[24] Hopkins M. Planetary Bargain, Corporate Social Responsibility Matters. London: Earthscan Publications Ltd; 2003. p. 33

[25] Tsoulfas GT, Pappis CP. Corporate social responsibility and reporting. In: Kuei C-H, Madu CM, et al., editors. Handbook of Sustainability
Management. EBSCO Publishing; 2015. p. 42

[26] Managing for sustainability. Economist Intelligence Unit [Internet]. 2010. Available from: http://graphics. eiu.com/upload/eb/Enel_Managing_ for_sustainability_WEB.pdf [Accessed: 2018-07-15]

[27] Osmanagic Bedenik N et al.

Sustainability reporting in Croatia:

The challenges of sustainable business. In: Horváth P, Pütter J, editors. Sustainability Reporting in Central and Eastern European Companies. Springer; 2017. pp. 199-214. DOI: 10.1007/978-3-319-52578-5

[28] Integrated Reporting [Internet]. Available from: https://www.kpmg. com/PT/pt/IssuesAndInsights/

Documents/corporateresponsibility2011.pdf [Accessed: 2018-08-14]

[29] IIRC [Internet]. Available from: http://integratedreporting.org/theiirc-2/ [Accessed: 2018-10-14]

[30] Friedman M. The social responsibility of business is to increase its profits. The New York Times Magazine. 1970. Available from: http:// umich.edu/ thecore/doc/Friedman.pdf [Accessed: 2018-11-10]

[31] Moser DV, Martin PR. A broader perspective on corporate social responsibility research in accounting. Accounting Review. 2012;87(3):797-806

[32] De Villiers C, Van Staden C. Can less environmental disclosure have a legitimising effect? Evidence from Africa. Accounting, Organizations and Society. 2006;31(8):763-781

[33] Healy PM, Palepu KG. Information asymmetry, corporate disclosure, and the capital markets: A review of the empirical disclosure literature. 
Journal of Accounting and Economics. 2001;31:405-440

[34] Osmanagic N, Prebežac D, Strugar I, Barisic P. The challenges of controlling and IT support in nonfinancial reporting. International Journal of Industrial Engineering and Management. 2019;10(1):22. Available from: https://bib.irb.hr/ datoteka/994562.The_challenges_ of_controling_and_IT_support_in_ non-financial_reporting.pdf Accessed: 2019-03-25

[35] Kramer M, Kania J, Mcbreen M. Game changing CSR. In: Corporate Social Responsibility Initiative Working Paper No. 18. Cambridge, MA: John F. Kennedy School of Government, Harvard University; 2006. p. 13. Available from: https://www.hks. harvard.edu/sites/default/files/ centers/mrcbg/programs/cri/files/ workingpaper_18_krameretal.pdf Accessed: 2019-03-23

[36] Baron R. The evolution of corporate reporting for integrated performance. In: Background Paper for the 30th Round Table on Sustainable Development. Paris: OECD Headquarters; 25 June 2014. Available from: https://www. researchgate.net/publication/275038287_ The_Evolution_of_Corporate_Reporting for_an_Integrated_Performance [Accessed: 2019-03-20]

[37] Global Reporting Initiative. Benefits of reporting [Internet]. Available from: https://www.globalreporting. org/information/sustainabilityreporting/Pages/reporting-benefits. aspx\#sthash.9h6fx0hd.dpuf [Accessed: 2019-03-20]

[38] Doing good. Business and the sustainability challenge. Economist Intelligence Unit. p. 9 [Internet]. Available from: http://graphics.eiu.com/ upload/Sustainability_allsponsors.pdf [Accessed: 2019-03-21]
[39] Osmanagić Bedenik $\mathrm{N}$ et al. Nonfinancial reporting-The challenge of sustainable business. In: Empirical Research Results in Companies in Croatia. M.E.P; 2016. p. 15

[40] Federation of European Accountants. EU Directive on disclosure of non-financial and diversity information. Achieving good quality and consistent reporting. Position Paper, Corporate Reporting; March 2016. p. 1. Available from: https://www. accountancyeurope.eu/wp-content/ uploads/FEE_position_paper_EU_ NFI_Directive_final.pdf [Accessed: 2019-03-21]

[41] Pütter J. Impact factors on sustainability Reporting. In: Horváth P, Pütter J, editors. Sustainability Reporting in Central and Eastern European Companies. Springer; 2017. pp. 51-62. DOI: 10.1007/978-3-319-52578-5

[42] Horváth P et al. Status quo and future development of sustainability reporting in Central and Eastern Europe. Journal of East European Management Studies. 2017;22(2): 221-243. DOI: $10.5771 / 0949-6181$ $-2017-2-221$

[43] Dumitru M, Dyduch J, Gușe RG, Krasodomska J. Corporate reporting practices in Poland and Romania-An ex-ante study to the new non-financial reporting European directive. Accounting in Europe. 2017;14(3):279-304. DOI: 10.1080/17449480.2017.1378427

[44] European Sustainable Development Network. Sustainable development governance \& policies in the light of major EU policy strategies and international developments [Internet]. 2011. Available from: https://www. sd-network.eu/?k=quarterly $\% 20$ reports\&report_id=22 p. 38. [Accessed: 2019-03-21] 
[45] Responsible Business Forum [Internet]. 2016. Available from: http:// odpowiedzialnybiznes.pl/english/ [Accessed: 2019-03-19]

[46] Kilic M, Kuzey C. Factors influencing sustainability reporting: Evidence from Turkey. Recent Issues in Accounting Finance and Auditing. 2017:139-175. DOI: 10.2139/ ssrn.3098812

[47] De Villiers C, Marques A. Corporate social responsibility, country-level predispositions, and the consequences of choosing a level of disclosure. Accounting and Business Research. 2016;46(2):167-195. DOI: 10.1080/00014788.2015.1039476

[48] Manes-Rossi F, Tiron-Tudor A, Nicolò G, Zanellato G. Ensuring more sustainable Reporting in Europe using non-financial disclosure-De facto and De jure evidence. Sustainability. 2018;10:1162. DOI: 10.3390/su10041162

[49] Joshi S, Li Y. What is corporate sustainability and how do firms practice it? A management accounting research perspective. Journal of Management Accounting Research. 2016;28(2):1-11. DOI: $10.2308 /$ jmar-10496

[50] Hales J, Matsumura EM, Moser DV, Payne R. Becoming sustainable: A rational decision based on sound information and effective processes? Journal of Management Accounting Research. 2016;28(2):13-28. DOI: 10.2308/jmar-51394

[51] Niemann L, Hoppe T. Sustainability reporting by local governments: A magic tool? Lessons on use and usefulness from European pioneers. Public Management Review. 2018;20(1):201-223. DOI: 10.1080/14719037.2017.1293149

[52] Global Reporting Initiative. Sustainability disclosure database [Internet]. Available from: http:// database.globalreporting.org [Accessed: 2019-03-19]

[53] Berthelot S, Coulmont M, Serret V. Do investors value sustainability reports? A Canadian study.

Corporate Social Responsibility and Environmental Management. 2012;19(6):355-363

[54] Osmanagić Bedenik $\mathrm{N}$ et al. Nonfinancial reporting-The challenge of sustainable business. In: Empirical Research Results in Companies in Croatia. MEP; 2016. p. 26

[55] Nelson M. How nonfinancial reporting driving investment decisionmaking [Internet]. 2018. Available from: https://www.ey.com/en_gl/ financial-services/how-nonfinancialreporting-is-driving-investmentdecision-making [Accessed: 2019-03-18]

[56] Law 360. Emerging Trends in Corporate Sustainability Reporting. Expert Analysis [Internet]. New York; 2015. Available from: https:// www.law360.com/articles/624183/ emerging-trends-in-corporatesustainability-reporting [Accessed: 2019-04-10]

[57] Green generation: Millennials say sustainability is a shopping priority [Internet]. 2015. Available from: https://www.nielsen.com/eu/en/ insights/news/2015/green-generationmillennials-say-sustainability-is-ashopping-priority.html [Accessed: 2019-04-08]

[58] Institutional investor attitudes shifting as environmental and social risks impact investment decision. 2015. London [Internet]. Available from: https://www.ey.com/gl/en/newsroom/ news-releases/news-ey-institutionalinvestor-attitudes-shifting-asenvironmental-and-social-risksimpact-investment-decisions [Accessed: 2019-04-07] 
[59] Leddy Ch. Use sustainability to attract and retain millennial employees [Internet]. 2018. Available from: https:// www.forbes.com/sites/adp/2018/06/12/ use-sustainability-to-attract-and-retainmillennial-employees/\#4af0f9f06d00c [Accessed: 2017-06-06]

[60] Barić A. Corporate social responsibility and stakeholders: Review of the last decade (2006-2015). De Gruyter Open. Business Systems Research. 2017;8(1):133-146. p. 138. DOI: $10.1515 / \mathrm{bsrj}-2017-0011$

[61] Perego P, Kennedy S, Whiteman G. A lot of icing but little cake? Taking integrated Reporting forward. Journal of Cleaner Production. 2016;136(Feb.):53-64. DOI: 10.1016/j. jclepro.2016.01.106

[62] Churet C, Eccles RG. Integrated reporting, quality of management, and financial performance. Journal of Applied Corporate Finance. 2014;26(1):56-64

[63] Plawitzki JK. Welcher Voraussetzungen Bedarf Es in Deutschen Kommunen Für Die Erstellung Eines Nachhaltigkeitsberichtes? [What conditions are required in German local governments for the elaboration of a sustainability report?] [Bachelor thesis]. Lüneburg: Leuphana Universität; 2010. p. 17

[64] CGDD (Commissariat Général au Développement Durable). Premiers Éléments Méthodologiques Pour Lélaboration Du Rapport Sur La Situation En Matière de Développement Durable À L'usage des Collectivités Territoriales et EPCI À Fiscalité Propre de plus de 50000 Habitants. Paris: Service de l'Économie, de l'Évaluation et de l'Intégration du Développement Durable; 2012

[65] Ballantine J. The value of sustainability reporting by cities. Cities
Today. 2014. December 1. p. 4. Available from: http://cities-today.com/2014/12/ value-sustainability-reporting-cities/

[66] Borin N, Lindsey-Mullikin J, Krishnan R. An analysis of consumer reactions to green strategies. Journal of Product \& Brand Management. 2013;22(2):118-128. DOI: 10.1108/10610421311320997

[67] UNEP. Towards a Green Economy: Pathway to Sustainable Development and Poverty Eradication [Internet]. 2011. Available from: https:// sustainabledevelopment.un.org/index. php?page $=$ view \& type $=400 \& n r=7 \& m e$ $\mathrm{nu}=35$ [Accessed: 2019-03-21]

[68] Green Economy Initiative. Linkages to Sustainable Consumption and Production, Paris, 18-19 March 2010. Green Economy: Context and Definition [Internet]. Available from: http://www.unep.fr/scp/marrakech/ pdf/SCP-GE\%20Workshop\%20 presentation\%20Steven\%20Stone.pdf [Accessed: 2019-03-18]

[69] ICC comments on the UNEP draft Green Economy Report. International Chamber of Commerce [Internet]. Available from: https://iccwbo. org/publication/icc-comments-onthe-unep-draft-green-economyreport-2011/. p. 7. [Accessed: 2019-03-21]

[70] Georgeson L, Maslin M, Poessinouw $M$. The global green economy: A review of concepts, definitions, measurement methodologies and their interactions. Geography and Environment. 2017;4(1):e00036. p. 4 [Internet]. Available from: https://rgs-ibg. onlinelibrary.wiley.com/doi/ pdf/10.1002/geo2.36 [Accessed: 2019-03-22]

[71] Bhutan's Gross National Happiness Index. Oxford Poverty \& Human Development Initiative [Internet]. 
Available from: https://ophi.org. uk/policy/national-policy/grossnational-happiness-index/ [Accessed: 2019-04-08]

[72] Environment and Economics. European Commission [Internet]. Available from: http://ec.europa.eu/ environment/enveco/studies.htm [Accessed: 2019-04-28]

[73] Re-thinking Progress: The Circular Economy. Ellen Macarthur Foundation [Internet]. Available from: https:// www.ellenmacarthurfoundation.org/ circular-economy/concept [Accessed: 2019-04-09]

[74] Circular Economy: Implementation of the Circular Economy Action Plan [Internet]. European Commission; 2019. Available from: http://ec.europa. eu/environment/circular-economy/ index_en.htm [Accessed: 2019-04-09]

[75] Jassim AK. Sustainable Solid Waste Recycling [Internet]. Available from: https://www.intechopen.com/books/ skills-development-for-sustainablemanufacturing/sustainable-solidwaste-recycling [Accessed: 2019-0409]. DOI: 10.5772 intechopen.70046

[76] Roca LC, Searcy C. An analysis of indicators disclosed in corporate sustainability reports. Journal of Cleaner Production. 2012;20:103-118

[77] de Villiers C, Rinaldi L, Unerman J. Integrated reporting: Insights, gaps and an agenda for future research. Accounting, Auditing \& Accountability Journal. 2014;27(7):1042-1067. p. 1045. DOI: 10.1108/AAAJ-06-2014-1736 


\title{
Principles of Equality: Managing Equality and Diversity in a Steiner School
}

\author{
Robin Attfield and Kate Attfield
}

\begin{abstract}
Principles of equality are examined in the context of managing equality and diversity in practice. Our case study is the Cardiff Steiner School, an independent international school located in Wales, UK with educational values guided by the philosophers and educationalists Rudolf Steiner and Millicent Mackenzie. The sustainable management referred to and assessed in this chapter is the School's management structure and the related School pedagogical operation, with the founding Steiner value of human justice informing these. We argue that at this School the management of equality and diversity reflects theories of Diversity and Equality Management, with School managers aspiring to encourage respect for all. We appraise the philosophical and spiritual values of the founders in relation to equality and diversity, in order to demonstrate the visionary ideals of these philosophers and the extent to which their beliefs live on sustainably in contemporary society, and particularly in a Steiner education community.
\end{abstract}

Keywords: principles of equality, equality of consideration, Rudolf Steiner's philosophy of education, Millicent Mackenzie, Steiner school equality and diversity management practices

\section{Introduction}

When people talk about 'the principle of equality' in the abstract, what they really mean depends on which version or variety of equality they have in mind. Indeed there is a whole array of different principles (see $[1,2]$ ). Prominent principles include equality of opportunity and equality of consideration, while equality of treatment and equality of outcome will also receive mention. In this chapter, management examples are brought to bear, to illustrate pertinent issues about equality and diversity, examples that are drawn from the Welsh independent school, the Cardiff Steiner School. These issues are found to be raised by or around its equality and diversity policy (itself comprising part of our case study), as well as its core collaborative management and unique pedagogical system. The underlying established values of the School are discussed in the case study, examining examples of the management of: the School's daily practices, the School's qualification and the School mandate structure, all of which illustrate the fundamental grounding of these examples in equality and diversity. 
We suggest that the selected principles of equality are worthy of discussion against an underlying Steiner philosophical education backdrop that both values innovative thinking and expresses such thinking itself. While not flawless (because some of Steiner's approach to teaching is considered outdated and unsuitable in today's terms), Steiner propounded the core value of mutual reverence between children and teachers in connection with a teaching and learning operation, and this can be explored in today's terms in relation to equality and diversity. Issues arising within the School community as well as issues of the wider society relating to equality and diversity illustrate and challenge the principles of equality mentioned above, principles, that is, of equality of opportunity, treatment, outcome and consideration.

Our methodology is interdisciplinary, comprising a blend of methods. These include philosophical analysis, used to sift principles of equality and related understandings of diversity, specification of some contextually relevant legislation, and a sociological case study of the application of relevant principles of Rudolf Steiner and Millicent Mackenzie in the Cardiff Steiner School, conducted through a review of sample School management structures and practices, supported by interviews in the form of informal personal communications. There is a literature from Diversity and Equality Management; we draw on this, and on principles of equality, stemming from the work of Peter Singer in this field [2], as well as the earlier work of Michael Young [3]. Out of the extensive literature on Steiner, relevant works are limited to those with a bearing on education and related principles, as opposed to his works in several other fields, including those of business and medicine. Little has been written about Millicent Mackenzie, but, as we shall argue, her work and characteristic stance as a Professor of (what later became) Cardiff University helped generate not only the existence but also the ethos of the Cardiff Steiner School. What has not been done previously is to bring together some widely recognised principles of equality and diversity with the philosophy of education of Rudolf Steiner and of Millicent Mackenzie, and with their concrete application in a particular school and its sustainable management. The research question we are addressing is whether a defensible principle of equality which at the same time provides appropriately for diversity can be successfully integrated into the management of a school, with positive educational outcomes. On this interdisciplinary undertaking, a blend of philosophy, sociology, and theories of education and management, we now embark.

\section{The distinctive field and context of this research}

\subsection{The case study}

We have selected a case study for our research in order to assess the management of equality and diversity in a single setting, and to examine principles of equality, and the principle of equality of consideration as the prevalent interpretation of equality in this instance. The Cardiff Steiner School is an 'exemplifying case' where particular research questions can be posed, and social processes identified and analysed [4]. The case study embodies the philosophical and educational values of Steiner and of Mackenzie in their seeming visionary views of reverence and educational autonomy and a complex bridging of the modern-day values of equality and diversity. We scrutinise the School equality and diversity policy, selected daily School practices, the School's qualification, and the management and leadership structure of the School, in accordance with the human resources management system of Diversity and Equality Management. The case in question is opportune 
in both its complexity, its particular nature and its locality. We do not claim that the case study is representative, but rather that some aspects are transferable to other cases; what can be seen as useful is the theory that emerges from our findings $[5,6]$.

\subsection{Literature}

Strategic human resources management theory has supported the implementation of DEM (Diversity and Equality Management) practice since the (American) Civil Rights Act 1964 [7]. Recent research argues that DEM, and so widened diversity, to some degree facilitates improved performance. Three recent examples of sustainable management research studies, those of Richard et al. [7], Konrad et al. [8] and Ali and Konrad [9], each assess a different social group of women, minority ethnic and disabled people, and the potential outcomes of diversity advancement. The three given reasons for DEM are compliance with legality, the gaining of symbolic acceptance, and the accelerating of organisational performance.

In our case, the legality aspect is significant, with the (UK) Equality Act, as well as Welsh Government regulations, needing to be complied with. The second element is symbolic legitimacy, i.e., the organisation's perceived emphasis on diversity to justify its purpose, which derives from the prevalent cultural values and knowledge of the relevant community. The third component is about exhibiting a diverse employee cohort, as representative of the customer base (in our case the local and international community). Here, diverse representation and its assumed empathy with the customer base enable productivity and innovation at a strategic level; this is 'a business case for diversity' [7, 9].

Konrad et al. [8] examine how DEM is implemented, in accordance with one's own perceived organisational climate. They find a disconnection between theory and practice, where diversity strategies do not link to business aims. An example of the introduction of diversity into the workplace is gender mainstreaming. Lombardo and Meier [10] explain that where organisations are new, and where senior management is favourably disposed, gender mainstreaming is easier to initiate. De Boise [11] argues that gender mainstreaming has sometimes failed across Europe, when women are not appointed to decision-making positions where they can make a real impact; their (token) presence is not sufficient in generating such value. Richard et al. [7] similarly discuss the short-sightedness of a 'one size fits all' approach, and the lack of meaning in its implementation if token diversity is the extent of the programme. The management literature is considered as a point of reference throughout this chapter.

\subsection{The philosophy of education of Rudolf Steiner and of Millicent Mackenzie}

The School's world-view is based on the far-sighted teachings of Rudolf Steiner, the Austrian philosopher and educator (1861-1925). The first Steiner School (otherwise known as Waldorf School) was established in Germany in 1919. Steiner's ideas for education were founded on recognising the development of humankind (human individuals) according to his ideals of 'Liberty', one part of the 'Threefold Social Order' reinterpreted by Steiner in 1919. 'Liberty' meant the promotion of free-thinking culture, religion and education, 'Equality' would guide the equitable legal system, and 'Fraternity' would inform reciprocal economic life [12]. The three concepts diverge noticeably from one another, and more importantly from more modern conceptions of equality, and so it is his ideas for liberty in education that we focus on here. Steiner advocated the natural play and natural conceptual development of children, notions that remain different from those of mainstream State education. According to Steiner's philosophy, children develop within three distinct seven-year periods, hence the three stages of education, kindergarten 
(willing through imitation), lower school (feeling through imagination) and upper school (thinking through authority) [13]. For Steiner, learning was fundamentally linked to dignity and respect; it involved inviting children to learn as individuals, and encouraging their maturing emotional and intellectual development through creativity [14]. The high regard and value given by teachers to learners (as well as to their colleagues) can be seen in modern terms as an interpretation of a type of just treatment. This will be explored in depth below.

In 1904, Millicent Mackenzie (1863-1942) became the first woman to be appointed Professor in England and Wales, at Cardiff University. She was another philosopher and educator, and in addition established the regional Suffragettes of Cardiff, and the University Settlement of Cardiff. Mackenzie asserted values of the meaningful equal worth of human beings, particularly in relation to women, and to children. She can be seen as another visionary thinker of her time [15]. It was because Mackenzie directly responded to Steiner's entreaty for the chance to trial his educational philosophy, that Steiner education became established first in the UK, and thereafter worldwide. She invited him to an education conference in 1922 in Oxford, and consequently the second Steiner school anywhere was founded in 1925 [16]. Again, her values and campaigns are explored later in the chapter.

Mackenzie was neither messenger nor administrative facilitator; she was a visionary educationalist with independent values which complemented those of Steiner. She believed in freedom in education for children; in creativity and in recognising their developing autonomy, based on their wider sense of spiritual awareness. Her underlying value was of meaningful equality and deference towards children [17]. We discuss Mackenzie's significance partly because in parallel to other academic disciplines, women have sometimes been 'omitted' from history, which has to some degree been the case here; only through searching through records has Mackenzie's input now come to light. This is arguably illustrative of the prevalent systemic sexism of which we are a part [18]. Mackenzie asserted her influential support for Steiner's educative ideals, and wished to help him in his determined request for establishing Steiner education, externally to the then single existing school of its kind [16].

\subsection{Welsh statutory education policies}

While Steiner principles of reverence are core to Steiner education, both Welsh and British legislation and values underlying statutory education policies also inform the management and operation of Steiner Schools in these countries. This is also in accordance with the first reason for DEM systems; the school in question is seen to consider legal duties and guidance carefully [30]. The Independent Schools Standards (Wales) Regulations (2003) lays out clear statutory obligations, and the Independent Schools Registration and Operation Guidance (2014) and the Special Educational Needs Code of Practice for Wales (2004) provide guidance which the School elects to follow. The ESTYN Inspectorate is the Welsh schools' inspecting body that scrutinises 'standards, wellbeing and attitudes to learning, teaching and learning experiences, care, support and guidance, and leadership and management' against the obligations of quality and standards of an independent Welsh school [19].

\section{Principles of equality and diversity}

\subsection{The principle of equality of opportunity}

The equality and diversity policy refers to the conceptually limited and older principle that is widely being superseded, that of equality of opportunity. 
This principle rejects discrimination between applicants for jobs or for entrance to schools and universities, except on relevant grounds such as merit. The principle of equality of opportunity might be seen as exemplified in procedures such as the selective 11 plus examination system, which used to be regarded (and is still often regarded) as providing equal access to Grammar School education to all who undergo this test. This test was believed to offer equal opportunities to all applicants, regardless of gender, class or religion, but in fact at least one of its components, the IQ test, has turned out to favour candidates from middle-class families because it is to some degree a test of middle-class knowledge. In his Theory of Justice Rawls [1] talks about 'fair equality of opportunity', and may be interpreted as supporting theoretically egalitarian procedures of this kind. However, this principle was much earlier rejected by Michael Young [3] as liable to generate a radically divided society, which he called 'the meritocracy', a society divided between people whose advancement was due to their socially recognised 'merit' on the basis of employment of the Principle of Equality of Opportunity, and the rest of society, left with no basis to complain about their powerlessness.

UK employment law nevertheless requires recognition of this value in public organisations, allowing, for example, any applicant to apply for a post in a public authority. But, as we would argue, the successful applicant would often have a class advantage involving 'cultural capital'; they may have an advantaged understanding of the value of education, appropriate command of language, easier access to the education system, private funding opportunities, and/or established social networks [20]. In order to demonstrate compliance, organisations have, since the 1980s, adopted 'equal opportunity policies' (and many still have such policies), with, for example, the development of anti-discriminatory awareness and the appearance of morally approved values, current at that time.

'Equal opportunities' policies in public organisations have remained in place; this has shielded these organisations in law in terms of their demonstrating their prevention of unlawful discrimination. But arguably no more ambitious interpretation of 'equality' was generally propounded, introduced or achieved either in this legislation or in the resulting practices. Despite welcoming its rejection of overt discrimination, following Young [3] and Singer [2] we regard the Principle of Equality of Opportunity as inadequate, for the reasons given in this section, and also as failing to facilitate the kinds of equality favoured by Steiner and Mackenzie (see above).

\subsection{The principle of equality of outcome}

In absolute contrast, the Principle of Equality of Outcome aims at a levelling up or down of any population to which it is applied, such that those affected end up with equal achievements. But this Principle pays insufficient account to differences of inheritance, environment, culture and need, and thus to diversity. (When it is claimed that principles of equality and diversity are liable to conflict, this is the kind of principle of equality that lends this claim credibility.) In the context of the Cardiff Steiner School, this Principle might, for example, involve the adoption of a goal that all higher aged pupils achieve the same end qualification; but this would not be a useful or meaningful principle to be applied within the School, and would in fact diminish the strength and value of the end qualification, for which there is no desire. It would also counter the need for differentiation within class teaching and learner understanding at all levels, and could instead mean students being given the solutions to problems, rather than letting them learn at their own pace. This principle is therefore inappropriate in this context as it does not allow for the value of individual achievement, and also could not be applied in practice. 


\subsection{The principle of equality of treatment}

A lesser-rated rung on the equality ladder according to Singer [2], but perhaps more applicable principle of equality here, is the Principle of Equality of Treatment. This Principle requires for example pupils to be treated equally, receiving, for example, the same teaching and the same provisions, despite their differences of ability, aptitude and need. (This is another principle of equality which conflicts with respect for diversity.) There have sometimes been salutary motivations for adherence to this principle, such as a wish to avoid deference to some people because of the status into which they have been born, and relative contempt for others because of their lowlier status. But differential treatment grounded in irrelevant differences can be avoided without all differences being ignored; and respect for all, far from implying becoming blind to differences, frequently involves taking differences into account, and responding accordingly. Steiner's advocacy of equal 'reverence' for all implies just such sensitivity to different abilities, aptitudes and needs, and thus a principle of respecting diversity of ability, aptitude and need, rather than one of equality of treatment.

The UK Government's Equality Act 2010 became law, with the introduction of 'protected characteristics', that is, nine types of social groups eligible for legal protection in practice. The School Policy accordingly includes these categories. There is no mention of the principle or practice of equality of treatment in this legislation or other related legal guidance, and maybe this is why numerous public organisations continue to use the language of 'equal opportunities', even though they now have to incorporate the protected characteristics in their operation in a proactive sense. It may be that there remains a limited conceptual understanding of affording disadvantaged groups particular attention in terms of prohibiting discriminatory conduct, and their being offered equal access accordingly.

\subsection{The principle of equality of consideration}

Steiner's stance was later well articulated by the more recent philosopher, Peter Singer. As mentioned earlier, Singer [2] divided principles of equality into distinct and precise varieties. The principle that largely supersedes that of equality of opportunity, and also of equality of treatment, according to what may be regarded as a broader interpretation of fairness, is the Principle of Equality of Consideration. In philosophical terms, this principle involves 'giving equal weight in our moral deliberations to the like interests of those affected by our actions' ([2], p. 21). Since greater weight attaches to unsatisfied basic needs, such needs are prioritised over, for example, desires not corresponding to needs of this kind [21]. This principle, like the Principle of Equality of Opportunity, rejects discrimination on the basis of race, class or gender, but goes importantly beyond it in seeking to give equal consideration to those who, even if they theoretically enjoy equal opportunities, have very different needs, which are often unsatisfied. The Principle of Equality of Consideration well reflects the stances of Steiner and Mackenzie, embodies provision for respecting diversity, and incorporates the features that give their attractiveness to principles of equality, without preventing appropriate respect for otherness. This Principle overcomes the defects of the Principles of Equality of Opportunity, Treatment and Outcome, objections to which (as presented above) thus count as arguments in its favour. At the same time it captures the widespread intuitive endorsement of fairness, honoured across most if not all societies, without being tainted with arbitrary forms of discrimination such as those based on status, class, wealth, caste or gender. As such it should, we suggest, itself be endorsed. 
Examples of the application of this principle include the establishment of the Paralympic Games. Games reflecting merely equality of opportunity would almost inevitably see disabled athletes unable to benefit from the theoretical ability to compete on an equal basis with able-bodied athletes [22]. But consideration of the needs of disabled athletes has led to Games in which people with disabilities can compete on an equal footing with others who have comparable disabilities. The institution of Paralympic Games has vindicated the stated values of the Games of 'Determination, Inspiration, Courage and Equality'; and the kind of equality in question can reasonably be interpreted as Equality of Consideration.

This example also bears out how proper provision can be made for diversity without adoption of relativism. To adopt a relativism of perspectives in a would-be attempt to uphold recognition of diversity would in fact simultaneously imply the lack of a basis for recognition of diversity from all other perspectives (i.e., other than those which distinctively honour relevant kinds of diversity), and thus the complete absence of any universal basis for respecting diversity. But the kind of respect for diversity displayed in the Paralympic Games is based on acceptance of the principle of equality of consideration, which itself implies respect for diversity, and can be regarded as a universalistic principle, acceptable both to the able-bodied and the disabled, and to majorities and minorities alike, irrespective of divergences of perspective.

\subsection{Welsh government requirements and the principle of equality of consideration}

The Welsh Government may have intended the values of the Principle of Equality of Consideration in its advisory Special Educational Needs Code of Practice for Wales (2004). This arguably goes further than the Equality Act in addressing individuals and allowing them to perform according to a platform of policies to attain equal learning achievements based on students' own merit. This addresses four pre-identified pupil categories: 'More Able and Talented', 'Additional Learning Needs', 'English as an Additional Language', and 'Looked After Children'. Relatedly the School policy states 'The philosophical principle of equality of consideration is adopted by the School. This takes into account all people's types of need. People are encouraged and supported to fulfil the capacities and potential that they have. The Policy, in line with the School Access Plan, reminds the School of its obligation positively to consider the requirements of any child with a disability to access all areas of the School that children without a disability can access. This section of the Policy, required by the Independent Schools Registration and Operation Guidance (2014), allows independent schools the chance to gradually improve upon ease of access to physical entrances and the accessibility of the curriculum. The School has in fact attempted to counter an individualised model of disability, and rather, recognise disability as a socio-political issue, where the provider is responsible for implementing plans of modern designs for wide and easy access for all, such as building ramps for all access points [23]). The UK Equality Act's protection of the protected characteristics could be seen to be somewhat selective and exclusionary, in that there remain certain groups with social characteristics that are neither mentioned nor protected. This could be seen to allow such groups to be discriminated against (for example, larger people). Hence the Act may not fully take into account the Principle of Equality of Consideration, despite making considerable progress towards honouring it. Because of its encouragement of tolerance, and fostering of independently held positive values, the Policy goes further than the Equality Act in aiming to achieve equality of consideration, and in observing some groups who remain legally unprotected, where it states: 'In addition, the School will seek to 
prevent prejudice and discrimination on the grounds of the socio-economic class, size and appearance of School members'. The aim is to ensure that no negative discrimination will be tolerated by anyone in the School in any capacity; this concern also reflects a parallel, if localised, aim to address and challenge the hierarchical, negative assumptions one may make, however inadvertently, when occupying a position of advantage.

A pertinent example is the socio-economic class position that people who attend a Steiner school normally have. The presence of working-class members is moderately unusual, partly because as an independent charitable organisation, the School remains inaccessible to many, despite the existence of School bursaries. If such working-class members have different apparent material values and general use of language, then they could be visibly conspicuous in their difference. For members of a Steiner community, who may assume equal valuation of and respect towards others, this could serve as a useful test, to challenge their implicit assumptions about what is 'admissible', and whether in fact they fall into a hierarchical trap of assuming a sense of superiority in some aspects of social life.

In terms of 'the School (seeking) to prevent prejudice and discrimination on the grounds of ... size and appearance of School members,' another envisageable example within the community could be that of heterosexual couples where the woman is taller than the man. This situation challenges Westernised established stereotypes of the 'romantic ideal', where men are the physically, mentally and perhaps even intellectually strong 'masculine' partner, where they hold responsibility and ownership on behalf of women, that is, they follow the normative part of hegemonic masculinity [24]. Accordingly, women should, in contrasting parity be slim, pretty, emotional, vulnerable and 'feminine', and follow the normative role of subservient femininity.

These concepts can be seen to have justified centuries of division of labour between women and men, at least since Aristotle in ancient Athens onwards and more recently on the part of founder sociologist Harriet Martineau 1802-1876, for example, where she wrote about the 'political non-existence of women' [25], and educationalist and philosopher Millicent Mackenzie. Thomas [15] summarises Mackenzie's clear observation of institutional sexism justified by patriarchal society of the early 1900s. We may assume we have moved away from these antiquated notions, and yet the lingering norm is perhaps that males 'ought to be' taller or at least the same height as their female spouses in order to uphold 'normality'. Here we may be forced to reflect on our own prejudices that we apply to ourselves and others who surround us [26].

Another example of the importance of the equality of consideration is where people are respected as equally valid and 'normal' in a changing society, and recognised according to their own reality. As an example, Halberstam [27, 28] writes about the 'normal behaviour' of masculinity, and that rather than some lesbian women impersonating this, a trait of 'female maleness' is a valid and established identity. Cultural normative values behind the established understanding of fixed trait identities are perceived by some minority groups to be 'identity fictions', that is, at odds with user groups' own interpretations of fluctuating, and more complex, modernised identities. The School community is familiar with same gender parents; they are to an extent an understandable norm, and also have legal protection. This is possibly less judged as it is increasingly understood, as pioneers pave the way for establishing normalities.

\subsection{The principle of equality of treatment and 'colour blindness'}

A further undesirable example in relation to the principle of equality of treatment could be found in the form of a 'colour-blind approach' where for example 
black recipients used to be treated as if they were white recipients in normalising a community existence according to the white majority, and in treating people all the same. Ignoring racial difference may have prohibited directly racist conduct, but failed to recognise individual identities, or to value minority ethnic difference [29]. Richard et al. [7] argue that organisations implementing DEM practices should not make the mistake of ensuring that 'one size fits all'; organisations ought to differentiate between minority social characteristics, rather than assuming that having one type of minority representation allows an organisational claim of 'diversity'. The opposite to a 'colour-blind' approach is multiculturalism [30]: the proactive recognition and addressing of the diverse nature of society, together with an expectation of meaningful access and citizenship for all. This means that in this sense, one could propose that the opposite of equality of treatment here is the meaningful recognition and addressing of diversity, where rather than not being treated unfavourably, one receives positive recognition for being different. The Policy states ... 'Difference and diversity are valued .... Where a child has diverse 'protected characteristics', as well as aspects outside of the Equality Act, such as certain food requirements, these will be accepted, and children and students will be individually respected accordingly'.

\subsection{Diversity}

A current interpretation of Diversity questions 'objectivised' established knowledge, and recognises that many assumptions are subjectively formed according to established and changing cultural values. An example of some of society's failure to recognise the subjectivity of societal 'facts' is that, before 1968, being gay in the UK was criminal, according to law. In 1968 when the DSM-II (the American classification of mental disorders) defined being gay as a mental illness, it ceased to be criminal behaviour in the West, and became a mental disorder for 19 years. Then in 1987, homosexuality was removed from the DSM-II, although in 1988 the Thatcher Conservative Government introduced Section 28 of the Local Government Act stating that a local authority 'shall not ... promote the teaching in any state school of the acceptability of homosexuality as a pretended family relationship'. In direct response to this, also in 1988, Stonewall was established in the UK, a prominent gay rights campaigning body.

Significantly in 1988, while the UK was seen to have taken a step backwards, Denmark became the first country in the world to give legal recognition to samegender partnerships. The UK eventually followed from 1997, first with same-gender partners being recognised in relation to immigration. These examples illustrate the extent of normative values changing according to prominent tolerances, and not necessarily progressively or supportively towards the minority in question. However in accordance with the UK Equality Act 2010, diversity is recognised and protected, and society has partially followed suit and in particular within the School community in question.

In parallel, in 2002, the UK Government recognised that 'transsexuality' was not a mental disorder, whereas prior to this it had been assumed to be. In the same way, issues such as those surrounding transgender people challenge society's thinking further. Hines [31] found that many general practitioners still believe that being transgender is to have mental ill-health. The protected characteristic 'gender reassignment' has brought this group of people into the mainstream, by the legalising of their protection; yet 'gender fluidity' is not a protected status. Lobby group and UK campaign charity 'Gendered Intelligence' established in 2008 went some way towards the societal understanding of the notion of gender diversity. Arguably however, we have to think very differently nowadays, if we are to accept that gender can fluctuate. Respecting difference meaningfully means not being unnerved when 
we cannot tell if someone is female or male, or if we believe them to be a different gender from the one they are portraying, and that it no longer matters.

Accordingly the School encourages the use of 'they' and 'them' as gender neutral terms across written and verbal communication, and pupils are referred to as 'child', or 'student' upon entering class six [23]. And the Policy states 'The protected characteristic of 'gender reassignment' is understood and respected. This policy extends its protection and respect to members of the community with a fluctuating or fluid gender, where one's gender identity shifts, and is not fixed'. This is a pertinent example of a newly known minority group in the focus of public attention, that until recently may have been the topic of derision. Society may be slowly realising that this minority group has an equally valid and rational identity to others, and therefore one requiring acceptance and respect; the School community is no exception.

An ironic parallel example to the above is the fact that during Mackenzie's working life, women were the 'minority' group, and similarly treated with derision when they attempted to become visible and hold positions within society. Mackenzie fought against the institutionalised status quo with her individual belief in egalitarianism and liberty for women. In being appointed to Cardiff University Senate following her professorship of 1904, it was here that Mackenzie could prompt the strongly contested, yet laboriously slow progressive opportunities of women students and colleagues. Mackenzie also established work projects for women and girls of the lower classes in the Cardiff University Settlement project, a programme managed UK wide (normally for men of the lower classes) by philanthropists with an aim to reduce the socio-economic divide between classes. But in 1908 Mackenzie co-established the Cardiff and Vale Suffragists; this action perhaps illustrates her disputing women's discrimination and related prejudice the most clearly. She began with 70 members, and by 1914 she had 1200 members [32].

Mackenzie seems to have continued to defend values of respecting diversity as being central to a type of education that enabled individuals to become aware of and explore all parts of society: 'The tyranny of ... fixed ideas and prejudices disturb the balance of life, and render impossible that state of freedom which can only result when a unified will animates the whole being' ([17], p. 28). Mackenzie asserted that it was the role of education to challenge and enable a balanced perspective, and hence in the longer term to rid society of its discrimination and intolerance.

Mackenzie wrote of Steiner that his ideas on 'freeing the pupil' ([17], p. xi) were in accord with her own views of promoting a moral education. She stated 'we are all more conscious of the demand for freedom as coming from the young, and more ready to consider the validity of this demand than ever before' ([17], p. 24). Mackenzie wrote that the ultimate goal of 'freedom' for citizens is to be understood in spiritual terms, because this is where balance, consideration and creativity can be facilitated. This, as the crucial element for the basis of education, means that the young people of society will understand this intellectual and spiritual path, and become wiser than the current generation, "and those once started on the road that leads thitherward will not easily be induced to relinquish the quest” ([17], p. 27).

\section{Steiner's education and the Cardiff Steiner school}

\subsection{Steiner's education}

Steiner explained at the time of the first established school "that the characteristic feature of the (Waldorf-Astoria Cigarette Factory) School lies in its educational principles, based on the knowledge of $\operatorname{man}($ sic $)$.... (which) are closely connected 
with the most fundamental human impulses" ([33], p. 11). That is, the nature and the potential of humanity are taught to children, through person-centred, chronological, creative, and experiential methods of head, heart and hands; a foundational spiritual connection underlies this educative system. Steiner's understanding of the spiritual core of humanity reflects the education offered, which in turn becomes the spiritual core of the school [34]. Experiential learning involves the slow and controlled introduction of risk, enabling children to learn from doing, and to further natural development. Steiner recognised the capacity of humankind, and therefore the requirement, to treat children with reverence. This can enable their subsequent full engagement with increasing joy and wonder at the world that surrounds them. "When ... the emotional and volitional aspects of human experience combine with thinking, children are able to form an inner connection with what they study" ([34], p. 125).

Values diverse from the norm are thereby present in this education. Through the presentation of authentic stories of global mythologies for example, and the teacher offering an implicit balance, children can find their own answers to the ambiguities of life. Reverence for children by the teacher is partly an instrument enabling individual understanding, as is reverence for teachers by the children. Reverence is also explicitly present, in the underlying respect afforded for all racial and cultural identities [34]. In discussing the globally multi-cultural curriculum, Masters [35] states that for example in the study of a spiritual geography, countries' ethnic backgrounds are recognised and valued, and religious faiths of indigenous communities explored and respected. International Steiner teacher work visits reinforce this recognition of diversity, where the aims are to learn from international educational initiatives according to, for example, individual cultures' portrayals of their own streams of history, thus avoiding ethnocentrism [35].

\subsection{The Cardiff Steiner school ethos}

The Cardiff Steiner School claim that their ethos, guided by Steiner, and in line with the values of Mackenzie, is of an informed, progressive, and inclusive urban school, working to a city timetable $[23,36]$. In terms of being informed, staff and some of the wider community study academic theories and application of anthroposophy for their personal development, where teachers base their work on spiritual knowledge, and some study philosophy. While anthroposophy is not taught to children, Steiner explained how its aims are not just theoretical, but "that these (are) meant to enter social life quite directly and practically," in the form of teachers understanding child development and in their approach to education ([33], p. 3). Also, the School recognises and celebrates its origins in the form of mothers wishing to start a Steiner kindergarten in one parent's living room, 21 years ago, and from that, of women establishing a social business and managing the beginnings of a Steiner school; the community has grown in persistence and collaborative strength. The School could be seen as progressive where the Certificate of Steiner Education has been adopted and implemented in order to maintain meaningful Steiner education throughout children's school life, and where young people can progress to university as independent, balanced and critical thinkers. Also, a collaborative management system invites decisions and decision making to be respected and welcomed, and trust is afforded amongst core mandating groups, thus avoiding any sense of difficulty or inadequacy.

The School claims to be inclusive in the implementation of its fees system. The School has one of the lowest fee levels in Steiner schools UK wide, and is significantly lower than other independent schools; they also fundraise for a bursary to enable accessibility. Parents are invited to talks on educative and child 
developmental aspects, and there is a parent body that meets with the School Management Team. Parents report a feeling of a 'palpable community': a unique experience to those new to the School [23]. The School is an urban city school; it recognises its parent community and works according to their working timetable. The ethos could be seen to be founded on recognitions of equality and diversity in that both role models (Steiner and Mackenzie) believed in respect, the fulfilling of opportunities, additional care and support, and the recognition and promotion of groups and peoples. In terms of the third virtue of DEM practices as mentioned above, the school also appears to represent the diverse local and international community it serves through its own staff diversity, with gender and national diversity well represented $[9,33,36]$.

\subsection{Structure of the school}

The School asserts that its ethos informs its structure, in that its community has purposefully sought an informed, progressive and inclusive leadership and management system. This is based on modernising Steiner principles of egalitarianism. It is neither a hierarchy, which is the ladder system of State sector Steiner schools in England and indeed some other English Steiner independent schools, nor a collective, where there is equality-based, unanimous community-wide decision making, such as the Quakers (the Religious Society of Friends) have [37].

Neither is it the traditional model of a British Steiner school which has something similar to a collective consensus decision making through the College of Teachers, the central body made up of staff of a Steiner school. Steiner schools have gradually realised that while egalitarian minded, such systems have produced slow decision making, or indeed non-decisions. The Association of Waldorf Schools North America [38] has advocated a mandate structure for many years, where collaborative decision making is made by three constitutional mandating groups, of the Board of Trustees (voluntary overseeing governors), College of Teachers (staff body) and Administration (office managers). They logically delegate specific responsibilities to mandate groups made up of members of those three bodies [13]. An example of devolved decision making with accountability via the mandate structure is where College is responsible for pedagogical governance. That is, all governance level educational decision making is made by College; subsequently, College is accountable to Trustees, who are in turn accountable to the wider membership, according to British Company law.

In the Cardiff Steiner School, tying these three bodies together is the collaborative and devolved leadership body, the School Management Team. This is made up of two administrative managers, alongside three Educational Co-ordinators, for the three School faculties, Upper School, Lower School and Early Years. Educational Co-ordinators are not line managers; rather, staff working within faculties are expected to trust in and respect the advice of educational co-ordinators based on their experience and thorough knowledge of Steiner pedagogy, planning, monitoring systems and professional working. After some improvements, the system appears to generally work productively and positively, bearing trust and accountability in mind, with a clear division and clarity of roles; again principles of equality and diversity are held to be at the core of the mandate structure of School management, not least with respect to such egalitarian practices as delegation, co-operation and accountability [36].

\subsection{Examples of daily educational work practices}

Steiner wrote: "Reverence awakens a power of sympathy in the soul through which we draw towards us qualities in the beings around us, qualities which would 
otherwise remain concealed" ([14], p. 28). Daily educational work practices serve to exemplify the principles of equality and diversity, and we interpret these practices as fulfilling Steiner's intended meaning of a 100 years ago. Four examples are here highlighted. Children of Steiner schools recite a Steiner saying as a daily morning verse. The Lower School verse is centred on developing their personalities and knowledge assisted by 'humankind', and growing through the welcome exchange of ideas and development of equanimity. Similarly, staff of Steiner schools also have a daily morning verse that they recite together, and this focusses on their recognition of the wonder of the world, and of their personal strength in relaying this to their learners through awe, fervour, patience, responsiveness, and commitment to facilitating child lived experience. Equality and diversity are at the heart of both of these customs, which have been recited daily by Steiner children and teachers, all around the world, for almost a 100 years.

A third example of a daily School practice instilled by values of diversity and equality of consideration is the application of additional learning support for some pupils. The Additional Learning Needs teacher (a recurrent presence) advises other teachers about particular differentiation, that is, a flexibility in wider teaching to endorse the reverence given to the child. The Steiner approach to children with an additional learning need is that the label does not determine who the child is. Rather, the approach is person-centred and recognises diversity; there is an expectation that any child can progress and learn, and can develop their humanity [33]. A fourth daily practice embodying equality of consideration is the interpretation and application of competition in the curriculum. Competitive games promote combined endeavour, as opposed to individual ego. The joy is in the game, where both sides become energised to exceed their own skills, and where all participants' efforts are individually acknowledged by the other players [34]. These practices play a central role in the management of Steiner schools, including the Cardiff Steiner School [36].

Another practice exemplifies how education for sustainability is delivered in the School. Children are taken daily on visits to nearby countryside, for there is no substitute for experience of the natural world as a key to learning to cherish it sustainably, and to preserve rather than subvert its cycles. Relatedly, the School seeks to embody sustainable approaches in its management practices [39].

\subsection{The school qualification}

Steiner education is different from the UK educational system, and is also different from the majority of British schools. The School has adopted a unique external formal assessment system at Further Education level, enabling students to access Higher Education, and so University. Cardiff became the fourth Steiner School in the UK to adopt the New Zealand Certificate of Steiner Education, NZCSE, with other British and German Steiner schools following suit, and is the single school in Wales offering this educative system. According to the 'Lisbon Recognition Convention' international Further Education qualifications are recognised by Universities where countries are members of this agreement. The UK is one of these, as are 56 other member and non-member countries of the Council of Europe, including New Zealand [40].

In contrast with Principles such as Equality of Outcome, the final School qualification is given deep consideration and moderated at three separate stages, allowing pupils to achieve their formally measured units differentially, and not always passing a required minimum level. The upper school system works according to the application of pre-university levels of level one, two and three, and for an occasional project at level four (for an advanced piece of work that is equivalent to a first-year university module). The educative core is based on the continuation of purely Steiner 
education where pupils learn about the development of human kind, in an experiential way that allows for a wide consciousness of interlocking subjects, rather than narrowly defined and disconnected learning areas which may be passively absorbed.

The Steiner education aim is to shape young adults into developing an independent mind, an ability to debate and to consider others' positions through non-judgmental exploration, a strong sense of community, a physical sense of movement and their own being, a deep sense of creativity, a broad and in-depth general knowledge, as well as an advanced understanding of their 'extension subjects', that is, subjects they specialise in at the upper end of their education. Pupils are given the chance to achieve their targets allowing for categories of disadvantage that could apply to them [41], yet are still dependent on their own individual commitment, scholarship and hard work. This system again follows the principle of equal consideration; a student whose attendance is extremely poor may not achieve the certificate, irrespective of their work level. Conversely, students could still achieve a level of excellence at each level, without passing all learning outcomes, where certain types of testing prove too problematic. The assessment criteria test individual pupils in an all-round way, which allows individuals to excel in some testing environments rather than others, such as in essays, reports, presentations, debates, film making, performance, illustrations and projects (not an exhaustive list) [42].

The Cardiff Steiner School maintains that the management of the Certificate is equality- and diversity-based, and involves multiple layers of delegation, cooperation and accountability, and Steiner educational values. The Upper School Educational Coordinator manages the teaching programme, and moderates upper school teachers' learning outcomes and assessments of work. An internal moderator checks samples of work further. Random samples of work are then continuously sent to the New Zealand accreditation body SEDT for further layers of accountability, with respect to student work quality and standardisation of assessment [36, 42].

\section{Conclusions}

\subsection{Conclusion}

The purpose of Steiner education is to inform and nurture children and young people to give them 'love for the world and for (their) fellows ... (to develop) gentleness and quiet inner patience, (and to aim) for selfless co-operation' ([14], p. 212). Children's development is understood to be centred around their 'head, heart and hands'; their intellectual capacity is directed by their powers of empathy, patience and consideration, and these in turn are influenced by their physical awareness (not least of the natural world around them) and their ability to express themselves creatively. This leads them to reflective clarity and knowledge, ready to enter the world as young adults.

The Cardiff Steiner School strives to follow DEM systems, arguably in a principled rather than superficial way; the DEM tenets (as advocated in the recent literature of sustainable management practices) of legal compliance, symbolic value and organisational productivity (in this case the tenet of ensuring the School's viability) are visibly followed, but strict adherence to this management theory may occasionally fall short of the basis of humanity on which Steiner's philosophy was founded $[9,33]$. Steiner's principle of reverence for everyone including children (a principle endorsed also by Mackenzie) has been shown to embody the Principle of Equality of Consideration, and equally that of Respect for Diversity; and these principles have been shown to be embedded and embodied in the operation and educational management of the Cardiff Steiner School in multiple contexts. Our case study and in particular the examples we have presented illustrate how these principles, which 
currently enjoy legislative support, at least in Wales, are realised and implemented throughout the School, both in its teaching and in its management processes.

We have used management theory as a basis from which to assess the philosophical notions of equality and diversity, and investigate the purpose these can have in a modern school. We have sought to inform an audience with interests in management and sustainability about Steiner's (and Mackenzie's) educational philosophies, illustrated by the modern sustainable management practice of the Cardiff Steiner School. As we have shown, there is an underlying pervasive message of equality and respect for diversity deriving from the founding values of both Mackenzie and Steiner, which have in some ways been adapted into modern terms, but in another sense are timeless and remain as originally expressed. The modern Steiner community upholds these in modern Wales, in line with the requirements of Welsh Government legislation, and contemporary interpretations of both equality and diversity. The philosophical principle of equality of consideration, which we have shown to be far superior to rival principles of equality, informs the practice of this School on a sustainable basis, in an ongoing pursuit of both diversity and equality.

\subsection{Limitations of this research}

It lay outside the scope of our research to establish that successful educational outcomes are invariably generated within the Cardiff Steiner School, let alone in other Steiner schools. For example, while our interviews point in this direction, they were indicative rather than conclusive. There again, a longitudinal study of the careers of Cardiff Steiner School ex-students would be needed before such success could be demonstrated beyond doubt, and other Steiner schools would need to be subjected to parallel studies. Further, with respect to the dimension of sustainability, the sustainability of individual Steiner schools requires a worldwide system of such schools and its attainment of a critical mass sufficient to withstand localised problems and upheavals; and while this requirement may be well on the way to being achieved, another paper would be required to investigate how close it is to complete fruition. Nonetheless significant progress has been made in the space available in showing how the pursuit of equality and diversity enhance the sustainable management of at least one Steiner School.

\section{Author details}

Robin Attfield ${ }^{1 *}$ and Kate Attfield ${ }^{2}$

1 Cardiff University, Cardiff, United Kingdom

2 Cardiff Metropolitan University, Cardiff, United Kingdom

*Address all correspondence to: attfieldr@cardiff.ac.uk

IntechOpen

(C) 2019 The Author(s). Licensee IntechOpen. This chapter is distributed under the terms of the Creative Commons Attribution License (http://creativecommons.org/licenses/ by/3.0), which permits unrestricted use, distribution, and reproduction in any medium, provided the original work is properly cited. (cc) BY 


\section{References}

[1] Rawls J. Theory of Justice. Cambridge, MA: Harvard University Press; 1971

[2] Singer P. Practical Ethics. 2nd ed. Cambridge: Cambridge University Press; 1993

[3] Young M. The Rise of the Meritocracy. London: Thames and Hudson; 1958

[4] Bryman A. Social Research Methods. Oxford: Oxford University Press; 2004

[5] Attfield K. Qualitative individual interviews with Deaf people. In: Delamont S, Atkinson P, Hardy M, Williams M, editors. Social Science Research Methods Foundations. New York: Sage; 2019

[6] Innes M. Exemplar: Investigating the investigators-Studying detective work. In: Gilbert N, editor. Researching Social Life. London: Sage; 2001. pp. 211-223

[7] Orlando R, Roh H, Pieper J. The link between diversity and equality management practice bundles and racial diversity in the management ranks: Does firm size matter? Human Resource Management. 2013;52(2)

[8] Konrad A, Yang Y, Maurer C. Antecedents and outcome of diversity and equality management systems: An integrated institutional agency and strategic human resources management approach. Human Resource Management. 2016;55(1):83-107

[9] Ali M, Konrad A. Antecedents and consequences of diversity and equality management systems: The importance of gender diversity in the TMT and lower to middle management. European Management Journal. 2017;35:440-453

[10] Lombardo E, Meier P. Gender mainstreaming in the EU: Incorporating a feminist reading? European Journal of Women's Studies. 2006;13(2):151-166

[11] De Boise S. Gender inequalities and higher music education: Comparing the UK and Sweden. British Journal of Music Education. 2018

[12] Briault S. Rudolf Steiner's threefold image of a healthy society. In: Large $M$, Briault S, editors. Free, equal and Mutual: Rebalancing Society for the Common Good. Gloucestershire: Hawthorn Press; 2018. pp. 23-33

[13] AWSNA. 2018. Available from: https://waldorfeducation.org/waldorf education/awsna_principles [Accessed: April, 2019]

[14] Steiner R. Knowledge of Higher Worlds: How Is It To Be Achieved? London: Rudolf Steiner Press [1919]; 2007

[15] Thomas JB. Mistresses of method: Women academics in the day training college 1890-1914. Journal of Educational Administration and History. 1997;29(2):93-107

[16] Paull J. Stratford-on-Avon: In the footsteps of Rudolf Steiner. Journal of Biodynamics Tasmania Issue. 2013;111:12-18

[17] Mackenzie HM. Freedom in Education. London: Hodder \& Stoughton Ltd.; 1924

[18] Smith D. The Everyday World as Problematic: A Feminist Sociology. 4th ed. Toronto: Toronto University Press; 1998

[19] ESTYN. 2018. Available from: https://www.estyn.gov.wales/ inspection/inspection-explained [Accessed: April, 2019]

[20] Bourdieu P. Cultural reproduction and social reproduction. In: Brown R, 
editor. Knowledge, Education and Social Change. London: Taylor \& Francis; 1974. pp. $71-84$

[21] Attfield R. Ethics: An Overview. London: Bloomsbury; 2012

[22] Macdonald S, Deacon L. Disability theory and social work practice. In: The Routledge Handbook of Social Work Theory. London: Routledge; 2019

[23] Personal Communication with School Management Team staff at the Cardiff Steiner School. 2018

[24] Hearn J. The sociological significance of domestic abuse. Current Sociology. 2013;61(1):152-170

[25] Martineau H. Society in America. New York: Routledge [1837]; 2017

[26] Hill Collins P. Black Feminist Thought: Knowledge Consciousness and the Politics of Empowerment. 10th ed. Abingdon, Oxon: Routledge; 2014

[27] Halberstam J. The making of female masculinity. In Price J, Shildrick M, editors. Feminist Theory and the Body. New York: Routledge; 1999. pp. 125-133

[28] Halberstam J et al. Female Masculinity. Durham, United States: Duke University Press; 2018

[29] Lall M, Gillborn D. Beyond a Colour Blind Approach: Addressing Black \& Minority Ethnic Inclusion in the Education Strand of New Deal for Communities. Sheffield: Sheffield Hallam University Press; 2004

[30] Harris A, Han A. Malaysia? Young people and everyday multiculturalism in multiracialized Malaysia. Ethnic and Racial Studies. Special Issue. 2019

[31] Hines S. Recognising diversity? The gender recognition act and transgender citizenship. In: Hines S, Sanger T, editors. Transgender Identities: Towards a Social Analysis of Gender Diversity. Routledge: Abingdon; 2010. pp. 87-105
[32] Jenkins B. Queen of the Bristol Channel Ports: The intersection of gender and civic identity in Cardiff, c. 1880-1914. Women's History Review. 2014;23(6):903-921

[33] Steiner R. Soul Economy and Waldorf Education. Spring Valley, New York: Anthroposophic Press [1921]; 1986

[34] Petrash J. Understanding Waldorf Education: Teaching from the Inside Out. Edinburgh: Floris Books; 2002

[35] Masters B. Steiner Education and Social Issues. East Sussex: Sophia Books; 2007

[36] Personal Communication with School Management Team Staff. 2019

[37] Britain Yearly Meeting. 2016.

Available from: https:/qandb.org/ resources/members-articles /395-thefriends-decision-making-process-ahidden-gem [Accessed: April, 2019]

[38] Association of Waldorf Schools North America (SWSF). 2018. Available from: https://www.steinerwaldorf.org/ [Accessed: April, 2019]

[39] Attfield R. Sustainability and management. Philosophy of Management. 2015;14:85-93

[40] Council of Europe. 2018. Available from: https://www.coe.int/t/dg4/ highereducation/Recognition/LRC _en.asp [Accessed: April, 2019]

[41] Barton L. Disability and Society: Emerging Issues and Insights. London: Routledge; 2018

[42] Steiner Education Development Trust. 2019. Available from: https://sedt. co.nz/ [Accessed: April, 2019] 


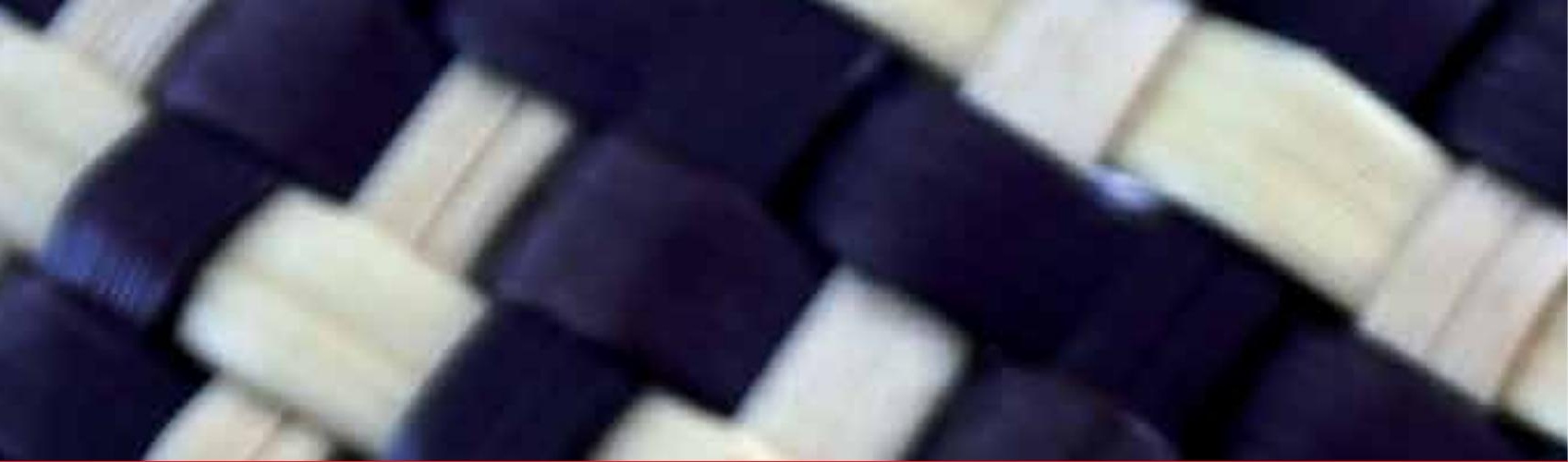

\section{Edited by Muddassar Sarfraz, Muhammad Ibrahim Adbullah, Abdul Rauf and Syed Ghulam Meran Shah}

This book encapsulates the advanced concept of sustainable management and will enlighten readers to understand this concept for practical applications. The book's salient features are as follows:

- Illustrates the basic concepts of human psychology causing risk factors such as burnout

- Differentiates adaptive sustainable measures and management practices

- Emphasizes sustainable agriculture management to confront the current dynamic environment and defines specific rules for enterprise development while coping with global climate change

- Assesses inertia with respect to economic development

- Constructs the linkage between technological strategies and innovation among construction companies

- Demonstrates non-financial reporting through theoretical and empirical evidence

- Elucidates the principles of equality, elaborating the managing of equality and diversity in a Steiner school

Published in London, UK 